SANDIA REPORT

SAND95-2529

Unlimited Release

Printed November 1995
$11 / 29 / 95$ RECENED

DEC 141995

OSTI

\title{
Fuel Dispersal Modeling for Aircraft-Runway Impact Scenarios
}

Sheldon R. Tieszen

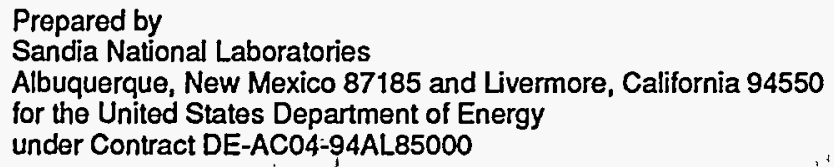

Approved for public release; distribution is unlimited.
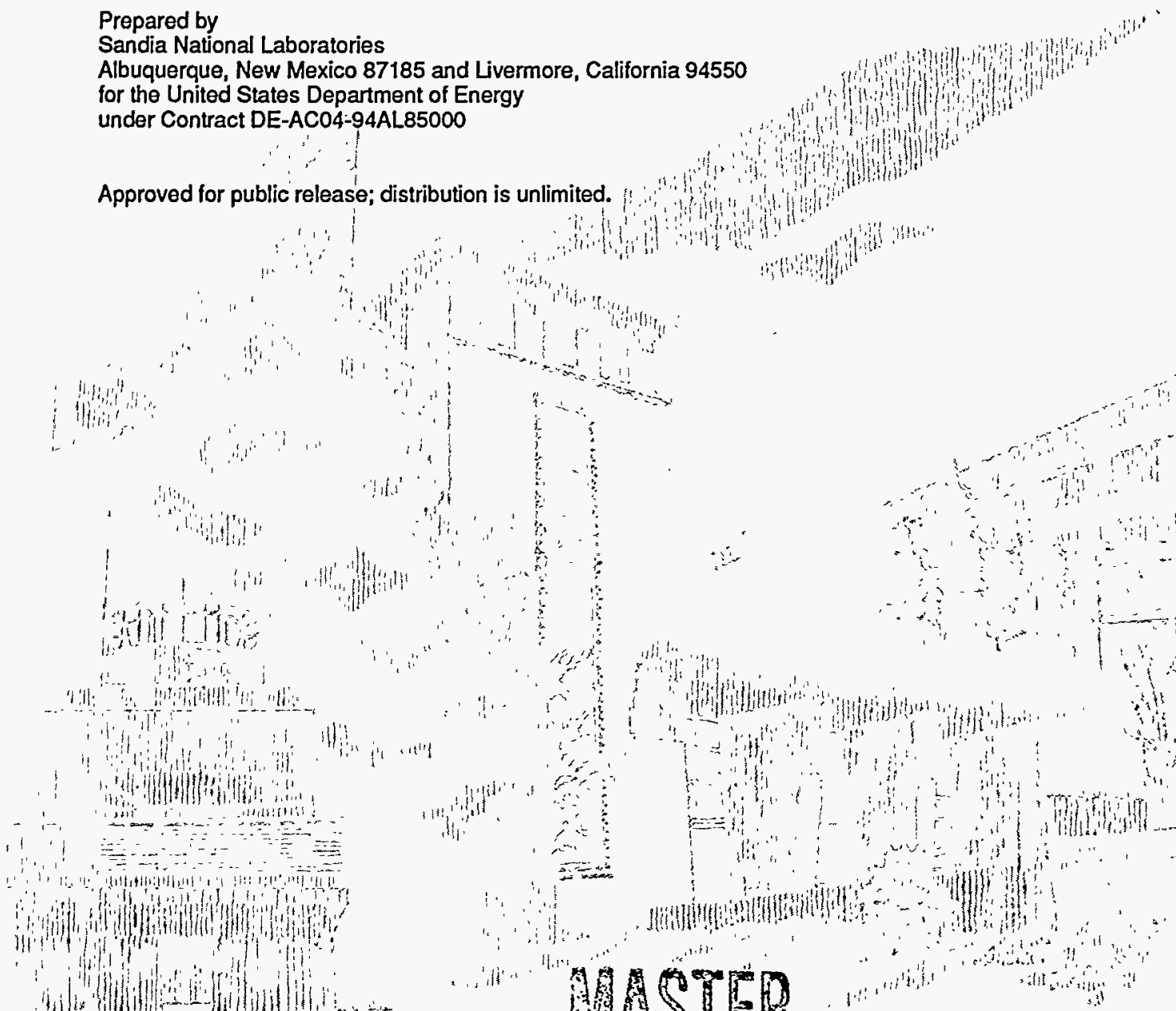
Issued by Sandia National Laboratories, operated for the United States Department of Energy by Sandia Corporation.

NOTICE: This report was prepared as an account of work sponsored by an agency of the United States Government. Neither the United States Government nor any agency thereof, nor any of their employees, nor any of their contractors, subcontractors, or their employees, makes any warranty, express or implied, or assumes any legal liability or responsibility for the accuracy, completeness, or usefulness of any information, apparatus, product, or process disclosed, or represents that its use would not infringe privately owned rights. Reference herein to any specific commercial product, process, or service by trade name, trademark, manufacturer, or otherwise, does not necessarily constitute or imply its endorsement, recommendation, or favoring by the United States Government, any agency thereof or any of their contractors or subcontractors. The views and opinions expressed herein do not necessarily state or reflect those of the United States Government, any agency thereof or any of their contractors.

Printed in the United States of America. This report has been reproduced directly from the best available copy.

Available to DOE and DOE contractors from Office of Scientific and Technical Information

PO Box 62

Oak Ridge, TN 37831

Prices available from (615) 576-8401, FTS 626-8401

Available to the public from

National Technical Information Service

US Department of Commerce

5285 Port Royal Rd

Springfield, VA 22161

NTIS price codes

Printed copy: A06

Microfiche copy: $\mathrm{A} 01$ 


\section{DISCLAMMER}

Portions of this document may be illegible in electronic image products. Images are produced from the best available original document. 
SAND95-2529

Unlimited Release

Printed November 1995

\title{
Fuel Dispersal Modeling for Aircraft-Runway Impact Scenarios
}

\author{
Sheldon R. Tieszen \\ Unsteady and Reactive Fluid Mechanics Department \\ Sandia National Laboratories \\ Albuquerque, NM 87185
}

\begin{abstract}
A fuel dispersal model for C-141 transport accidents was developed for the Defense Nuclear Agency's Fuel Fire Technology Base Program to support Weapon System Safety Assessments. The spectrum of accidents resulting from aircraft impact on a runway was divided into three fuel dispersal regimes: low, intermediate, and high-velocity impact. Sufficient data existed in the accident, crash test, and fuel-filled bomb literature to support development of a qualitative framework for dispersal models, but not quantitative models for all regimes. Therefore, a test series at intermediate scale was conducted to generate data on which to base the model for the high-velocity regime. Tests were conducted over an impact velocity range from $12 \mathrm{~m} / \mathrm{s}$ to $91 \mathrm{~m} / \mathrm{s}$ and angles of impact from $22.5^{\circ}$ to $67.5^{\circ}$. Dependent variables were area covered by dispersed fuel, amount of mass in that area, and location of the area relative to the impact line. Test results showed that no liquid pooling occurred for impact velocities greater than $61 \mathrm{~m} / \mathrm{s}$, independent of the angle of impact. Some pooling did occur at lower velocities, but in no test was the liquid-layer thickness greater than $5.25 \mathrm{~mm}$.
\end{abstract}




\section{Contents}

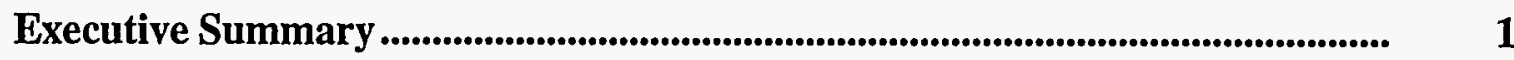

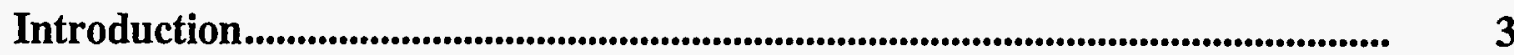

Programmatic Context of Fuel Dispersal Model ........................................................ 5

Evaluation of Existing Data on Fuel Dispersal ...................................................... 9

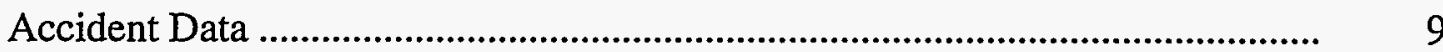

Crash Test Data............................................................................................ 12

Overview of crash test research ................................................................. 12

Relevant conclusions for dispersal modeling ................................................ 14

Crash dynamics ..................................................................................... 14

Structural response of fuel tanks .......................................................... $\quad 16$

Fuel dispersal characteristics ................................................................. 16

Fire dynamics ..................................................................................... 20

Fuel-Filled Bomb Data ................................................................................... 23

Analysis of Existing Data ............................................................................. 26

Framework for Fuel Dispersal Modeling ................................................................ 31

Development of Fluid Models for Dispersal Regimes................................................ 35

Fuel Leakage Model ......................................................................................... 35

Development of the analytical model ............................................................. 36

Applicability of existing numerical methods................................................. 40

Fuel Splash Model ................................................................................................ 41

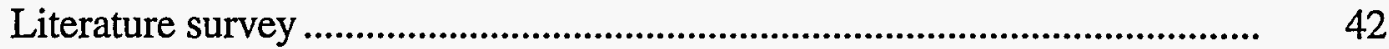

Transient jet impingement literature ...................................................... 43

Steady state jet impingement literature .................................................... 45

Applicability of existing numerical methods................................................... 49

Applicability of existing literature to model development .............................. 50

Phenomenological Testing to Provide Data for Model Development .................... 53

Experimental Test Plan ..................................................................................... 53

Test Apparatus ................................................................................................... 54

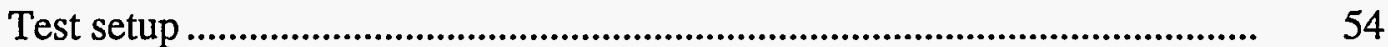

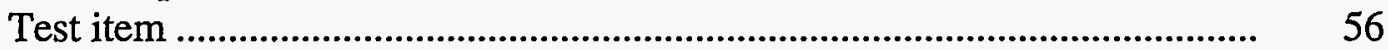

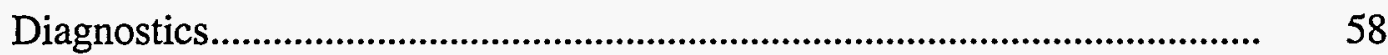

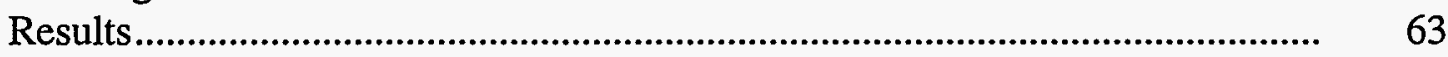

Photometric results ................................................................................... 64

Effect of impact velocity ........................................................................... 64

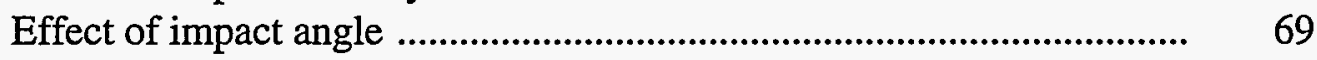

Measurements of mass................................................................................ $\quad 70$

Data reproducibility/uncertainty ............................................................ 
Effect of impact velocity ...................................................................

Effect of impact angle ...........................................................................

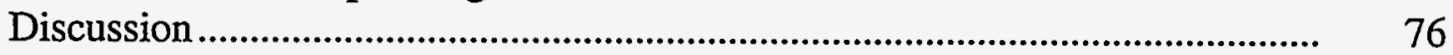

Splashing mechanism(s) ............................................................................. $\quad 76$

Applicability of test data to a WSSA program ................................................ $\quad 76$

Effect of geometric scale ....................................................................

Effect of fluid properties........................................................................... 79

Effect of wing structure .......................................................................... 80

Conclusions .................................................................................................................... 81

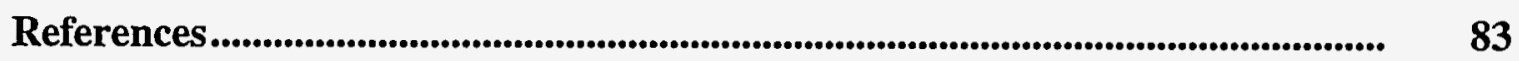

Appendix A. Rectangular Box Equivalent for Fuel Tanks ........................................ 91

Appendix B. Derivation of Stop Time ............................................................................ 95

Appendix C. Rationale for Orifice Diameter ….............................................................. 97

Appendix D. Mass Distribution Contour Plots ................................................................. 101 


\section{Figures}

Figure 1. Fuel dispersal model in the context of the WSSA. Statistics to support the WSSA are developed through repeated sampling of the deterministic models according to the probability distributions associated with the crash scenarios............... 6

Figure 2. Accident events that lead to a fire hazard for commercial aircraft (Wittlin, et al., 1982).

Figure 3. Typical velocity vs. distance plot available from the full-scale crash tests conducted for the FAA. This test, the second in a series, involves an A-3 (RB66) (Ahlers, 1977).

Figure 4. A typical example of fuel spillage behind an aircraft. The specific test is with a Constellation, 1.14 seconds after impact with main gear barriers. Numbers indicate fuel tank groups. (Reed, et al., 1965b)

Figure 5. Exceptional case in which fuel is splashed in front of the aircraft. This case occurred during a "high deceleration" late in the same test illustrated in Figure 4. Numbers indicate fuel tank groups. (Reed, et al., 1965b)

Figure 6. Perpendicular impact of an F-4 Phantom II into a concrete barrier at $215 \mathrm{~m} / \mathrm{s}$. Water is used as a fuel simulant. Note the circular splash that results from the impact. (von Riesemann et al., 1989)

Figure 7. FAA catapult test with an F-86 droppable fuel tank filled with 454 liters of JP-4. (a) Fireball resulting from a $35.7 \mathrm{~m} / \mathrm{s}$ impact at $40^{\circ}$. (b) Test rig for launching the fuel tank. (Russell, 1971). 22

Figure 8. Typical area covered by a thickened aviation fuel splashed from the $20^{\circ}$ impact of a 379 liter device dropped from $30 \mathrm{~m}$ at $157 \mathrm{~m} / \mathrm{s}$ indicated airspeed. (Gibson, 1956). 24

Figure 9. Typical dispersal patterns from the impact of 379 liters of Napalm B (a thickened hydrocarbon fuel). (a) Impact is at $18^{\circ}$ with a total velocity of $187 \mathrm{~m} / \mathrm{s}$. (b) Impact is at $7^{\circ}$ with a total velocity of $183 \mathrm{~m} / \mathrm{s}$. (c) Impact is at $15^{\circ}$ with a total velocity of $94 \mathrm{~m} / \mathrm{s}$. (Edwards, 1973).

Figure 10. The dispersal model. Three dispersal regimes have corresponding damage regimes. No or minor damage results in no or minor fuel leakage. Significant fuel tank damage results in fuel leaking behind the aircraft. Fuel tank failure results in fuel splashing.

Figure 11. Leakage from a damaged wing tank on a C-141.......................................... 35

Figure 12. Splash model parameters............................................................................... 41

Figure 13. Flow regimes associated with steady state jet impingement......................... 46

Figure 14. Hydraulic jumps. a) Typical jump found in jet impingement, with the highspeed flow separating and flowing over the top of the low-speed flow. b) Typical jump found in a civil engineering application, with the high-speed flow undershooting the low-speed flow................................................................. 48

Figure 15. Rocket Launch Facility in Technical Area III at Sandia National Laboratories, Albuquerque, New Mexico.

Figure 16. Honeycomb sections used to decelerate the rocket carriage for the $91 \mathrm{~m} / \mathrm{s} \mathrm{impact}$ tests.

Figure 17. Wing assembly. (a) Front view showing the aluminum foil face. (b) Rear view showing a Zuni rocket motor. Note that in both (a) and (b) the short cylinders 
are not rocket motors, but old casings that increased the structural rigidity of the carriage.

Figure 18. Wing at launch time. (a) Elevated on the I-beam just prior to launch. (b) Accelerating down the rail.

Figure 19. Preparation for measurements of liquid mass. (a) Mass-absorbing towels are laid over the concrete pad. (b) A waterproof vinyl cover with velcro strips is rolled over the towels. (c) The cover and towels are rolled away from the impact area.

Figure 20. Side view of liquid dispersal for an impact angle of $45^{\circ}$ and an impact velocity of $61 \mathrm{~m} / \mathrm{s}$. 65

Figure 21. Overhead view of liquid dispersal for an impact angle of $45^{\circ}$ and an impact velocity of $61 \mathrm{~m} / \mathrm{s}$. Sequence is given for times after impact of (a) $5 \mathrm{~ms}$, (b) 50 $\mathrm{ms}$, 66

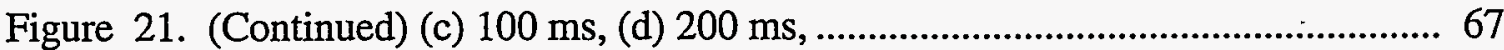

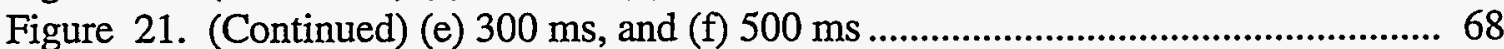

Figure 22. Mass distribution plots showing data reproducibility. ............................... 71

Figure 23. Mass fraction splashed vs. jet-free-flight-distance/jet-thickness. Impact angle is noted on the data.

Figure A. General arrangement diagram for the C-141, showing the location of the fuel tanks in the wings.

Figure B. Assumed crash scenario. (a) Prior to impact. (b) On slideout. ...................... 95

Figure C-1. Damage mechanism. (a) Time dependent impact load. (b) Response. Elastic deformation is $\mathbf{i}$, plastic deformation is ii, and failure is iii.

Figure C-2. Once failure occurs, further displacement results in an increase in the effective orifice diameter.

Figure D-1. Effect of impact velocity at an impact angle of $22.5^{\circ}$...............................102

Figure D-2. Effect of impact velocity at an impact angle of $45^{\circ} \ldots \ldots \ldots \ldots . . . . . . . . . . . . . . . . . . . . .103$

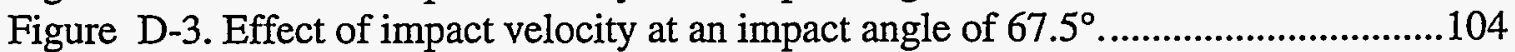

Figure D-4. Effect of impact angle at an impact velocity of nominally $12 \mathrm{~m} / \mathrm{s}$............105

Figure D-5. Effect of impact angle at an impact velocity of nominally $16 \mathrm{~m} / \mathrm{s}$. ...........106

Figure D-6. Effect of impact angle at an impact velocity of nominally $61 \mathrm{~m} / \mathrm{s}$............107

Figure D-7. Effect of impact angle at an impact velocity of nominally $91 \mathrm{~m} / \mathrm{s}$............108 


\section{Tables}

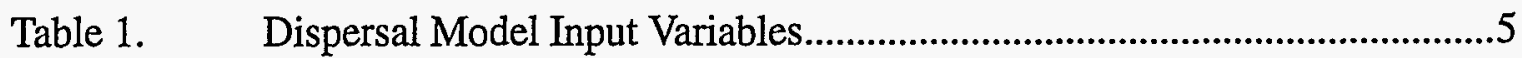

Table 2. Dispersal Model Output Variables..............................................................

Table 3. Accident Severity Categories......................................................................10

Table 4. Full-Scale Crash Tests Sponsored or Co-Sponsored by FAA That Have Resulted in Fuel Dispersal .......................................................................15

Table 5. Fuel Dispersal Model - Dispersal Regimes ..................................................31

Table 6. Test Matrix ................................................................................................64

Table 7. Summary Statistics for Areas with Average Liquid-Layer Thicknesses >

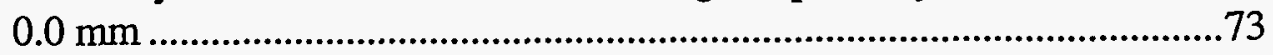

Table 8. Summary Statistics for Areas with Average Liquid-Layer Thicknesses >

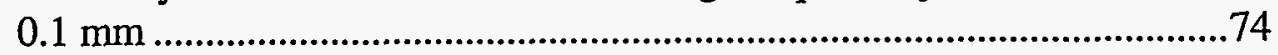

Table 9. Summary Statistics for Areas with Average Liquid-Layer Thicknesses >

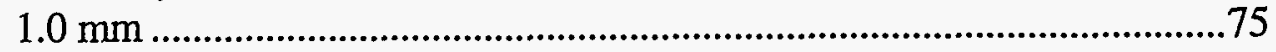

Table A. C-141 Information Relating to Fuel Tanks ..................................................91 


\section{Acknowledgments}

The author appreciates the support of Sandia reference librarians David Mays, who conducted the initial computer search of the fuel dispersal literature, and Ken Cutshall, who with Mays conducted the initial computer search of the jet and drop impingement literature. The author thanks the many individuals who contributed to the success of the experimental program: Bill Kampfe and his rocket operations team, who conducted the rocket tests (Bill also designed the wing section and advanced the crushable honeycomb technique for stopping rocket-borne carriages); Leroy Perea and members of his photometrics team, who produced the fine photometric results; and Rod Oliver, who designed and fabricated the test bed diagnostics, fabricated the wing section, and sweated in the August afternoon sun in New Mexico with the author during the 12- to 15-hour days required for each test. The author also thanks Nancy Benson, Technical Communication Services, Inc., for her writing, editing, and document production support. This work was funded by the Defense Nuclear Agency and conducted at Sandia National Laboratories, which is run by Lockheed Martin Corp. for the U. S. Department of Energy under Contract DE-AC0494AL85000. 


\section{Executive Summary}

This report describes development of a fuel dispersal model for the Defense Nuclear Agency's (DNA) Fuel Fire Technology Base Program that is being conducted to support both the current and future Weapon System Safety Assessment (WSSA) programs. The fuel dispersal model is one of several deterministic models being developed by various agencies to support DNA's WSSA program for C-141 transport accidents. The intent is to develop simple models that can be exercised thousands of times, by an event tree simulation, based on input variables sampled according to their uncertainty distributions.

Existing data in the accident, crash test, and fuel-filled bomb literature was reviewed and assessed. Sufficient data existed over nearly the entire parameter range for velocity and a significant subset of impact angle to develop a qualitative framework from which quantitative models could be developed. There were, however, insufficient data to support development of quantitative models for all the regimes. The developed framework consists of dividing the spectrum of accidents resulting from aircraft impact with the ground into three impact velocity regimes: low-, intermediate-, and high-velocity. The impact velocity regimes have corresponding damage and fuel dispersal regimes that are characterized by distinct physical processes.

The first damage regime, at low normal impact velocity, involves insignificant damage to the wing fuel tanks. In this regime, insignificant fuel leakage occurs, so no dispersal model is required. The second damage regime, at intermediate normal impact velocity, involves significant structural damage to the wing fuel tanks but insufficient damage to cause complete structural failure. In this regime, fuel will leak from the damaged tank at a rate proportional to the amount of damage. For this regime, sufficient data existed to build a model, and a leakage model was developed. The third damage regime, at high normal impact velocity, involves complete structural failure of the wing fuel tanks. In the highvelocity regime, fuel will splash on impact. For this regime, a splash model was developed.

In the splash model, the wing structural integrity is ignored and the fuel is treated as a transient, finite-length, two-dimensional jet that impinges on the ground. Fuel dispersal is characterized as a function of impact angle and impact velocity. A literature search was conducted for fuel-dispersal correlations and numerical methods applicable for the highvelocity regime.The literature review uncovered no correlations, data, or numerical studies on area coverage or splashing appropriate to model development for a WSSA. However, the literature did provide some insight into the mechanisms involved in transient jet impingement. From this insight, a test series at intermediate scale was conducted to generate data on which to base the model for the high-velocity regime.

Tests were conducted at Sandia National Laboratories Rocket Launch Facility with an approximately $1 / 9$ linear scale mass model of a $1 / 4$ span section of the C-141 wing. The 
independent variables were impact angle and impact velocity. The dependent variables were the area covered by dispersed fuel, the amount of mass in that area, and the location of the area relative to the impact line. The tests were conducted on a hard, flat, concrete surface to simulate impact on a runway. Twelve tests were conducted over an impact velocity range from $12 \mathrm{~m} / \mathrm{s}$ to $91 \mathrm{~m} / \mathrm{s}$ and angles of impact from $22.5^{\circ}$ to $67.5^{\circ}$. Diagnostics included high-speed cinematography and detailed mass distribution measurements.

The test results showed that no liquid pooling occurred for impact velocities greater than $61 \mathrm{~m} / \mathrm{s}$, independent of the angle of impact. At lower velocities, some pooling did occur; but in no test was the liquid-layer thickness greater than $5.25 \mathrm{~mm}$. Some atomization of the liquid was noted to occur at all velocities. However, at velocities less than $61 \mathrm{~m} / \mathrm{s}$ the splash products were not sufficiently atomized to prevent their reimpact with the concrete forward of the impact zone. The results showed that the angle of impact had only a secondary effect on the fuel distribution.

Although it was necessary to conduct the test program at an intermediate scale and without considering the effect of the wing structure, it is argued that the conclusions from the data are directly applicable to a WSSA full-scale aircraft impact scenario. This includes the conclusion that no pooling of fuel occurs for impacts over $61 \mathrm{~m} / \mathrm{s}$, provided that the wing completely disintegrates on impact and no cratering occurs. If cratering does occur, pooling is expected; this scenario is the subject of future investigations.

The developed framework and models represent a first attempt to describe the complexity of fuel dispersal from a spectrum of aircraft impact scenarios in a rational scientific manner. Both the leakage model and the splash model are at best first order approximations for use in safety assessments. Both models could be improved with further development and testing. Validation tests, particularly of the effect of wing confinement on splashing, would improve confidence in the models. 


\section{Introduction}

The objective of the work documented in this report was to develop a numerically fastrunning correlation that predicts fuel dispersal characteristics for C-141 transport accidents. Fuel dispersal is one event in a chain of events that require modeling to support both current and future Weapon System Safety Assessment (WSSA) programs. The fuel dispersal model to be developed is dependent upon input from the appropriate scenario variables and the model output variables from a crash dynamics model. Output requirements of the fuel dispersal model are dependent on the input needs of the pool fire model, which assumes instantaneous ignition of aircraft fuel on initial impact if any leakage or splashing of fuel occurs due to the impact.

The scope of work included evaluation of the existing fuel dispersal database, evaluation of existing correlations and computational approaches, intermediate-scale phenomenological testing, and model development. The spectrum of accidents resulting from aircraft impact on a runway was divided into three dispersal regimes: low-, intermediate-, and high-impact velocity. The latter two regimes required model development. Reviews of the literature indicated that sufficient data existed to build a model for the intermediate-velocity regime but not for the high-velocity regime. A test series at intermediate scale was initiated to generate data on which to base a model for the high-velocity regime.

This report presents an analysis of fuel dispersal data from the accident, crash test, and fuelfilled bomb literature; a description of the development of fluid models for the intermediate-velocity and high-velocity dispersal regimes; and details of the intermediatescale testing of a $1 / 4$ span section of a $\mathrm{C}-141$ wing, which provided data for model development. 


\section{Programmatic Context of Fuel Dispersal Model}

The objective of the fuel dispersal modeling task was to develop a numerically fast-running correlation that predicts fuel dispersal characteristics for C-141 transport accidents. As shown in Figure 1, the fuel dispersal event is second in a chain of events that require modeling in order to quantify the safety issues associated with air transport of weapon systems. Due to the complexity of the fuel dispersal phenomena and very limited existing knowledge base, the Defense Nuclear Agency's (DNA) Fuel Fire Technology Base Program funded the development of a framework and models to support both current and future Weapon System Safety Assessment (WSSA) programs.

In a WSSA process, the chain of deterministic models shown in Figure 1 is exercised in a probabilistic sense by running the models many thousands of times with different values of scenario variables. The scenario variables themselves are modeled in terms of probability distributions. This means that each model must accept as input the appropriate scenario variables and the model output variables from the previous model. The scenario variables and model output variables must be judiciously chosen so that all important parameters affecting weapon response are included.

The input requirements for the dispersal model come from the event-tree scenario descriptions and from the crash dynamics model. The input variables and ranges from WSSA scenarios that were considered for the current study are given in Table 1.

Table 1. Dispersal Model Input Variables

\begin{tabular}{|c|c|c|c|}
\hline Variable & Type & Value/Range & Reference \\
\hline \multirow[t]{2}{*}{ Velocity } & Total & $23-152 \mathrm{~m} / \mathrm{s}$ & \multirow[t]{2}{*}{ Woodford, 1992} \\
\hline & Normal & $0-145 \mathrm{~m} / \mathrm{s}$ & \\
\hline Fuel Type & JP-4 & & Martinez, 1992 \\
\hline \multirow[t]{5}{*}{ Fuel Load } & Pre-takeoff & $80 \%$ & \multirow[t]{5}{*}{ Woodford, 1992} \\
\hline & Takeoff/Climb & $80 \%$ & \\
\hline & Cruise & $50 \%$ & \\
\hline & Descent/Landing & $20 \%$ & \\
\hline & Post-landing & $20 \%$ & \\
\hline Fuel Weight & Max Flight & $68,698 \mathrm{~kg}$ & Martinez, 1992 \\
\hline
\end{tabular}

The output requirements of the dispersal model are dependent on the input needs of the pool fire model and the system response model. The needs of the fire and system response 


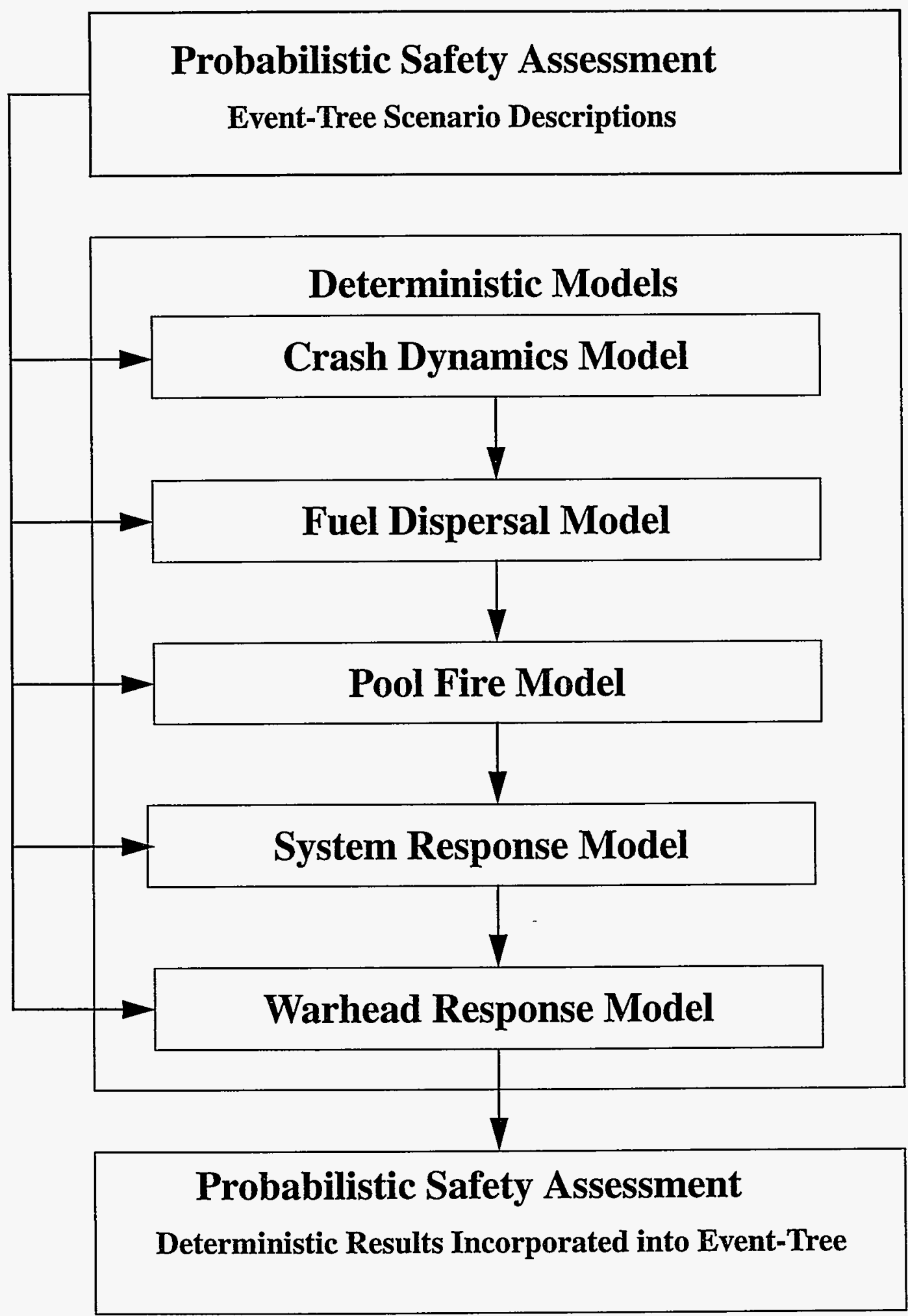

Figure 1. Fuel dispersal model in the context of a WSSA. Statistics to support a WSSA are developed through repeated sampling of the deterministic models according to the probability distributions associated with the crash scenarios. 
models that are relevant to the dispersal model are listed in Table 2. The fire model assumes that fuel ignition will occur on initial impact for all crashes. The fire model focuses on spill or pool fires. The effect of these fire model characteristics on dispersal model development warrants some discussion.

Table 2. Dispersal Model Output Variables

\begin{tabular}{|l|l|}
\hline \multicolumn{1}{|c|}{ Variable } & \multicolumn{1}{|c|}{ Reference } \\
\hline $\begin{array}{l}\text { Fuel Pool Location Relative to } \\
\text { the Aircraft \& Weapon System }\end{array}$ & \multirow{2}{*}{ Moya, 1992 } \\
\cline { 1 - 1 } Amount of Fuel in Pool & \\
\cline { 1 - 1 } Area Covered by the Pool & \\
\hline
\end{tabular}

The fire model assumes instantaneous ignition of aircraft fuel on initial impact if any leakage or splashing of the fuel occurs due to the impact. This assumption implies that there will be a fireball if fuel misting occurs. Further, it implies that a spill or pool fire will exist when the aircraft comes to rest. If significant damage has been done to the wing fuel tanks, then a spill fire will result. The size of the spill fire is coupled with the fuel consumption rate of the fire.

It is assumed that spill or pool fires will dominate the heat flux incident upon the weapon. It is assumed that even under engulfing pool fire conditions, if the weapon remains in the aircraft and shipping container, it will take several minutes to heat the high explosive beyond its thermal limit. A literature review indicated that the time scale for an aircraft to come to rest after impact is typically less than 10 seconds. A very complex set of non-linear transient/dynamic phenomena occur during the deceleration process. Because the time scales required to heat the weapon are a factor of 10 to 100 times greater than the crash deceleration time scales, the specifics of the transient process can be ignored, except where they affect the spill or pool fire characteristics.

The impact of this assumption is twofold: (1) all the complex phenomena leading to fireball formation can be ignored, and (2) the heat flux from the fireball itself can be ignored. The information of value for the fire model is the remaining fuel and its location relative to the weapon. Neglecting the thermal effects of the fireball is not expected to have significant bearing on the final thermal response of the warhead due to the warhead's thermal inertia and the fireball's short duration. This assumption simplifies the model development significantly, in that the many detailed phenomena involved in fireball development can be neglected.

It should be noted that deterministic modeling is one of three techniques for obtaining data for a WSSA program. The other two techniques are examination of historical data and elicitation of expert opinion. Each technique can be used in support of the others. For example, a model and/or historical data can support the insight of the experts. Similarly, historical data and expert opinion can support a model and its development. But each technique has inherent limitations. For example, if the deterministic model is based on 
overly simplified assumptions, its predicted outcome may not match real accident data because an important piece of physics is missing. If historical data is incomplete, or skewed due to some unknown variable, results may also be affected. As for expert opinion, the phenomenology may be counterintuitive-or the intuition of the expert may be wrong. 


\section{Evaluation of Existing Data on Fuel Dispersal}

In order to develop a fuel dispersal model for C-141 transport accidents, a two-stage literature search was conducted to assess the fuel dispersal database for completeness. The first stage was a computerized search of the national information databases. The second stage consisted of reviewing the reports from the computerized search and obtaining references that were not identified in the initial search.

Keywords used in the initial computer search were aircraft, accidents, fire, fuel, drop tanks, jettison, and napalm. The keywords were combined to reduce the set of hits to on the order of one hundred reports. The databases searched included Aerospace, Fluidex, Compendex Plus, Energy Science and Technology, and the National Technical Information Service, which includes unclassified Defense Technical Information Center (DTIC) reports. The search was conducted on the DIALOG information system. A reduced search was also conducted on the DTIC DROLS system in a classified mode, although all publications discussed in this report are unclassified. The publications reviewed can be divided into three types: accident data, crash test data, and fuel-filled bomb data.

\section{Accident Data}

A thorough review of the accident data is necessary for development of crash-scenario probability distributions. However, accident data was not of primary interest for the development of a dispersal model for two reasons. First, in accident reports, crash parameters are typically not documented in sufficient detail to develop deterministic, physics-based models. Secondly, crashes that happen to be well documented would fall under the category of integrated effects tests. It is much easier to develop models from separate effects data. For example, a well documented crash that results in significant fuel dispersal but no fire is far more useful to dispersal model development than one in which the evidence is burned away. Historical data are useful, however, for comparison with the integrated (i.e., crash-dynamics/fuel-dispersal/fire) model to determine if sufficient physics was included in the individual models to predict the outcomes.

The literature search did net several reports on accident data, but no attempt was made to ensure that the data acquired was complete. The most recent accident survey for civilian transport data is given by Widmayer and Brende, 1982, Cominsky, 1982, and Wittlin, et al., 1982. These three reports analyzed 176 out of 993 accidents between 1959 and 1979 that were deemed crash-survivable. Interestingly, the remainder of the accidents appear not to have been analyzed. 
There are several analyses of accident data in the literature. These include Wittlin, 1987, Thomson and Caiafa, 1983, Horeff, 1982, and Berens, 1971. The common conclusion from these studies is that fire is the dominant hazard to human survivability in crashes that are impact-survivable. Further, the primary cause of the fire is rupture of the fuel tanks resulting in significant fuel release. Wittlin, 1987, also notes that trauma-related fatalities generally increase with increasing aircraft sink rate (normal impact velocity).

The accident data lead to a qualitative understanding of the crash sequence leading to a fuel fire. Figure 2 shows an event tree developed from accident data (Wittlin, et al., 1982). As shown, the crash sequence leads to various structural failures resulting in fuel release. Accident data have also led to a classification of accidents into severity categories (Horeff, 1982), as shown in Table 3. From analysis of military crashes, Kuchta and Clodfelter, 1985 , note that the "angle of impact is most crucial in the damage sustained by aircraft in a crashtype situation." For shallow impacts, they find that a) aircraft breakup begins at the initial point of impact, b) aircraft parts will be scattered along the ground path, and c) fire is a probable outcome if the fuel tanks are ruptured. For steep impacts, they find that a) there will be a probable fireball of intense burning, but of short duration, and b) parts are scattered all around the impact crater.

Table 3. Accident Severity Categories (from Horeff, 1982)

\begin{tabular}{|l|l|}
\hline \multicolumn{1}{|c|}{ Classification } & \multicolumn{1}{|c|}{ Damage Description } \\
\hline 1. Minor Impact Damage & $\begin{array}{l}\text { Includes engine/pylon damage or separation, minor lower fuselage } \\
\text { damage, and minor fuel spillage }\end{array}$ \\
\hline $\begin{array}{l}\text { 2. Moderate Impact Dam- } \\
\text { age, Gear Separation or Col- } \\
\text { lapse }\end{array}$ & $\begin{array}{l}\text { Includes higher degrees of damage of classification type 1 and } \\
\text { includes gear separation or collapse }\end{array}$ \\
\hline 3. Severe Impact Damage & $\begin{array}{l}\text { Includes major fuel spillage due to wing lower surface tear and wing } \\
\text { box damage, but no fuselage break }\end{array}$ \\
\hline 4. Severe Impact Damage & $\begin{array}{l}\text { Includes severe lower fuselage crush and/or Class } 1^{*} \text { or Class 2 fuse- } \\
\text { lage breaks, may have gear collapse, but no tank rupture. }\end{array}$ \\
\hline 5. Extreme Impact Damage & $\begin{array}{l}\text { Includes Class 1 or Class 2 fuselage breaks with wing separation or } \\
\text { breaks, may have gear and/or engine separation. }\end{array}$ \\
\hline 6. Aircraft Destruction & $\begin{array}{l}\text { Includes Class 3 fuselage breaks or destruction with tank rupture, } \\
\text { gear and/or engine separation }\end{array}$ \\
\hline
\end{tabular}

*Fuselage breaks:Class 1 - sections break but remain together

Class 2 - sections break and open

Class 3 - sections break and move off 


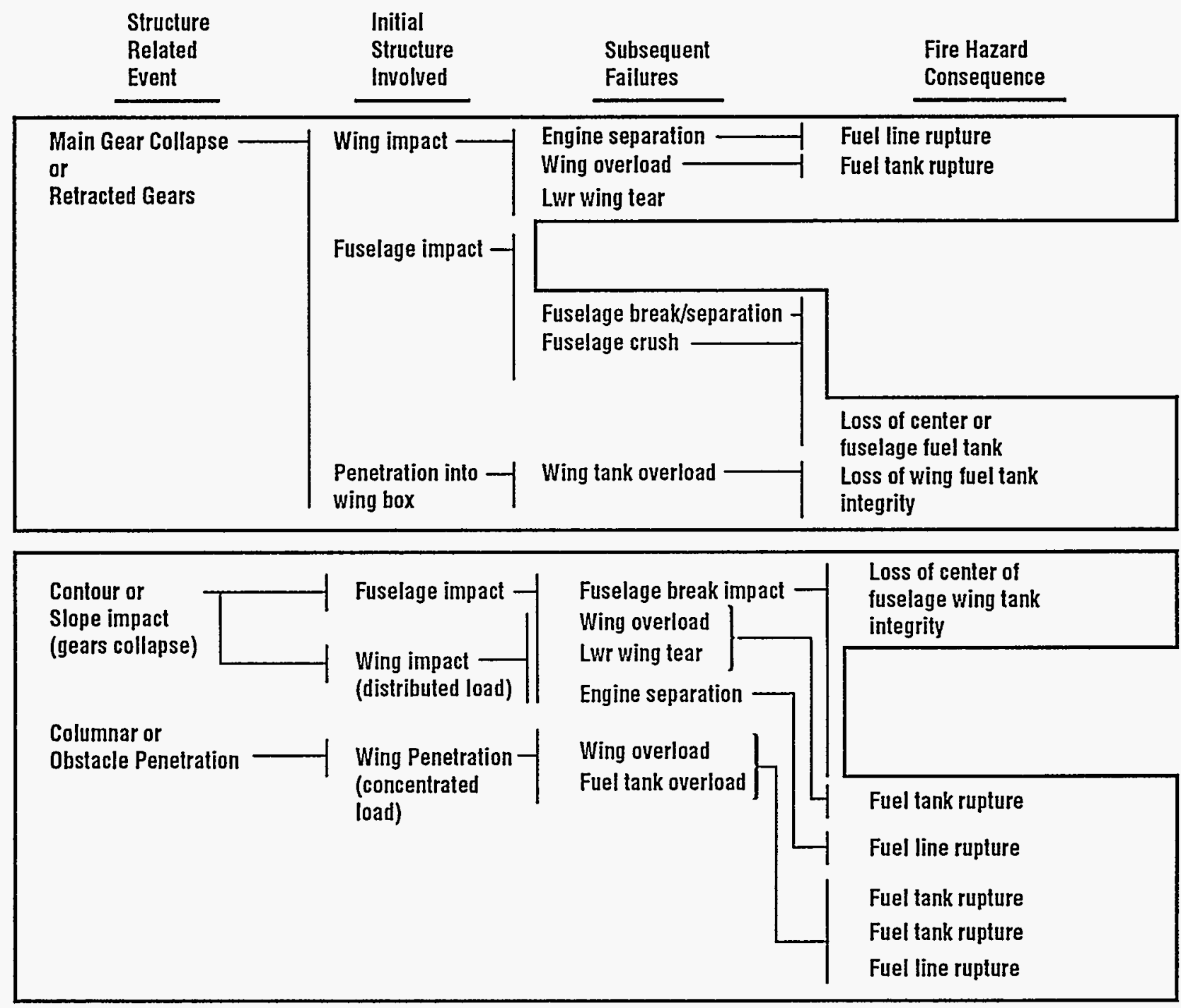

Figure 2. Accident events that lead to a fire hazard for commercial aircraft (Wittlin, et al., 1982). 


\section{Crash Test Data}

The crash test literature is fairly extensive. The discussion of this literature begins with a historical/programmatic overview, followed by specific technical conclusions relevant to fuel dispersal modeling

\section{Overview of crash test research}

A broad historical perspective on aircraft safety and survivability was presented by John $\mathrm{H}$. Enders to an FAA workshop on fuel safety. His published notes (Enders, 1985) are as follows:

"Contrary to what the critics would have us believe, aircraft fire has been a focus of research enquiry and engineering and regulatory improvements since the beginning of flight. Jerry Lederer informs me that the Wright Brothers incorporated a lanyard ignition cut-off on their early airplanes that could be activated in the event of a crash. A search of the aviation literature shows that in 1919, NACA published a two-volume translation of a French report 'On the Problem of Fire in Aircraft,' dealing mainly with in-flight fires. Other representative milestones:

1926 U. S. Air Corps conduct engine fire tests at McCook Field, Dayton, Ohio.

1930s Various fundamental studies of aircraft fuel \& fire by government, industry and academia.

1940-50s The NACA Lewis Full-Scale Aircraft Test Program that established a comprehensive engineering basis for the origin and mechanism of aircraft crash fires, and explored means of fire suppression.

1950s Establishment of the U. S. CAA Engine Fire Research Facility at Indianapolis; later moved to Atlantic City.

1960s Continuation of full-scale crash tests by Flight Safety Foundation's AvSER Division under contract to U.S. Army and FAA.

NASA/USAF/Industry research on lightning-induced fuel fires.

U. S. Army experiments with gelled and emulsified fuels.

FAA tests with anti-misting additives.

Industry IRAD fuel system design improvements.

FSF development (Army Contract) of helicopter crash-resistant fuel system with subsequent Army implementation in UH-1 helicopters.

1970s Sophistication...computer/pro-active chemistry at work by RAE, NASA, FAA, USAF, French and German government and industry.

U. K.'s CAA representative Laurie Edwards first coined the "AMK" term during a CAA-FAA-NASA anti-misting fuels meeting in Washington.

NASA's FIREMEN program established basis for improvements in materials flammability through contracts with industry and academia. 
FAA tests on cabin fires at NAFEC and complementary tests by industry established the environmental and materials flammability data base.

FAA's SAFER Committee, composed of an international group of representatives from government, industry, airlines, universities, and consumer groups, examined the state of aircraft crash fires and fuel containment knowledge at the end of the 1970s decade, producing a comprehensive status report of what was feasible for design and operation implementation, what regulations were feasible, and identified further work needed to continue the improvement of the aircraft fire safety record.

1980s FAA/NASA full-scale crash impact demonstration of instrumented B-720, gathering data on virtually all aspects of crash dynamics and fire that had been researched to date in smaller scale tests."

General overviews of the FAA fire programs can also be found in Wittlin, 1987, Yaffee, 1986, and Horeff, 1975. Based on the conclusion from accident data that fuel fires pose a significant risk, the FAA has explored two options to increase human survivability in crashes. One option is to increase the crashworthiness of the aircraft itself. Wittlin, 1987, summarizes the work in this area. He notes that a fuselage crash resistant fuel system (CRFS) has the highest potential for commercial aircraft.

A second option the FAA has explored in depth is to reduce the flammability of the aircraft fuel. As noted by Horeff, 1975, the early efforts in this area were emulsifiers and gells. Of pertinence to this study, Horeff notes that testing indicated that the various additives did not have as great an effect on reduction of the fire characteristics of JP-4 as compared to kerosene. The lower flash point and higher volatility of JP-4 had a greater influence on fire properties than the additive composition. At that point, the FAA programs dropped JP-4 and focused on reducing the flammability of kerosene fuels. As research continued, gells and emulsions were dropped in favor of a high molecular weight polymer additive, FM-9. Yaffee, 1987, notes that the addition of a small amount of FM-9 to kerosene created a nonnewtonian fluid with complex rheological characteristics. The additive did not alter the fuel chemistry, but significantly reduced its ability to mist under air-induced shear. Hence its generic term AMK for anti-misting kerosene.

The FAA, in conjunction with NASA and various DoD agencies, has conducted a number of large-scale aircraft crash tests since 1965. These tests are summarized in Reed, et al., 1965a, Reed, et al., 1965b, Ahlers, 1977, Zagrella, 1980, Schaible, 1982, Schaible, 1983, and Barber, 1986. These tests were conducted to examine the fuel-fire and structuralresponse characteristics under survivable impact conditions. Various targets, such as dirt mounds, or impact objects (telephone poles, etc.) were used to induce damage to the wing tanks. Initially, the tests involved water so that the fuel dispersal characteristics could be measured. When AMK FM-9 was developed, the tests focused on the ignitability/ combustion characteristics of the fuel. In these tests, the fuel was deliberately ignitedsometimes with extreme sources such as rear-mounted rocket packs. The objective of these tests was to determine the reduction in fireball size and the self-extinguishing characteristics of the fuel. 
In addition to full-scale tests, the FAA sponsored a number of wing-only tests. Two types of tests were conducted: structural and fuel flammability. The primary purpose of the structural tests was to determine the structural response and damage levels from concentrated and distributed impact loads. Structural test results are given in Nissley and Heid, 1964, Buckson, et al., 1965, Ahlers, 1970, Scheuerman, 1971, and Hackler, 1972. The results and implications of these tests are summarized by Wittlin, 1987. Fuel flammability tests were conducted to support AMK fuel development. Results from fire tests involving simulated wing punctures are given by San Miguel and Williams, 1978, and Salmon, 1981.

To support the full-scale and section tests, the FAA sponsored a number of small-scale tests. Among the most relevant are dispersal tests by Ahlers, 1970, and Russell, 1971, and flammability tests by Polymeropoulos,1975, and Parikh, et al., 1983.

Independent of the FAA programs, the U.S. Army investigated the possibility of increasing the crashworthiness of its helicopters by installing crashworthy fuel systems (CWFS). The program was begun in March 1968, and CWFS were in production by 1970 . Structural tests were conducted to support the CWFS development; see, for example, DiTaranto, et al., 1978 and Byerly, 1973. Shaw, 1971, reports on an extensive fuel dispersal/ignition test program involving nozzle shear, wind shear, impact dispersion/atomization, hot-source ignition, and simulated full-scale tests. The program led to development of an aircraft postcrash survival design guide (Johnson, et al., 1989).

\section{Relevant conclusions for dispersal modeling}

The crash test data, particularly the full-scale tests, cover the full range of crash physicsfrom crash dynamics through fuel-tank structural response and fuel dispersal to fire dynamics. Relevant technical conclusions from the crash test literature are now summarized, with emphasis on fuel dispersal.

\section{Crash dynamics}

Crash dynamics affects dispersal in two ways. It determines how the fuel tanks are damaged, and it determines the velocity and direction of the aircraft after the fuel tanks have been breached. This information can be used to determine the location of the fuel relative to the aircraft when it comes to rest. Crash dynamics data is derived primarily from the full-scale tests listed in Table 4 . The available data is in a fairly narrow velocity range, 48 to $76 \mathrm{~m} / \mathrm{s}$. In addition, the tests were conducted over a limited range of impact angle, generally between $3^{\circ}$ and $8^{\circ}$. Some tests had secondary impacts at $15^{\circ}$ and $20^{\circ}$.

Furthermore, the other tests, with the exception of the B-720 test in 1984, were conducted with no pitch, yaw, or roll at impact.

However, within the limited ranges, the number of full-scale tests is significant and the data acquired is substantial. All the reports listed in Table 4 give either deceleration, velocity, or arrival time as a function of distance from impact. The overall time to stop and 
Table 4. Full-Scale Crash Tests Sponsored or Co-Sponsored by FAA That Have Resulted in Fuel Dispersal

\begin{tabular}{|c|c|c|c|c|c|c|c|c|c|}
\hline Date & Aircraft & Test Agency & Fuel Type & $\begin{array}{l}\text { Impact } \\
\text { Speed } \\
(\mathrm{m} / \mathrm{s})\end{array}$ & $\begin{array}{l}\text { Angle of } \\
\text { Incidence } \\
\text { (Degrees) }\end{array}$ & $\begin{array}{c}\text { Fuel } \\
\text { Dispersal } \\
\text { Data }^{\mathrm{a}}\end{array}$ & $\begin{array}{l}\text { Remaining } \\
\text { Fuel Data }\end{array}$ & $\begin{array}{l}\text { Ignition } \\
\text { Source }\end{array}$ & Reference \\
\hline 1965 & DC-7 & $\begin{array}{l}\text { Flight Safety Foun- } \\
\text { dation }\end{array}$ & $\begin{array}{l}\text { Water, } \\
\text { Gelled Water }\end{array}$ & 72 & 8 then 20 & Yes & No & No & Reed, et al., 1965a \\
\hline 1965 & $\begin{array}{l}\text { Constellation } \\
\text { Model } 1649\end{array}$ & $\begin{array}{l}\text { Flight Safety Foun- } \\
\text { dation }\end{array}$ & $\begin{array}{l}\text { Water, } \\
\text { Gelled Water }\end{array}$ & 58 & 6 then 20 & Yes & Minimal & No & Reed, et al., $1965 \mathrm{~b}$ \\
\hline 1972 & $\begin{array}{l}\text { A-3 } \\
\text { (Navy RB-66) }\end{array}$ & $\begin{array}{l}\text { NAVAIRENGCEN } \\
\text { Lakehurst, NJ }\end{array}$ & Water & 62 & 6 & Yes & No & No & Ahlers, 1977 \\
\hline 1972 & $\begin{array}{l}\text { A-3 } \\
\text { (Navy RB-66) }\end{array}$ & $\begin{array}{l}\text { NAVAIRENGCEN } \\
\text { Lakehurst, NJ }\end{array}$ & $\begin{array}{l}\text { AM-1/Jet-A } \\
\text { FM-4/Jet-A }\end{array}$ & 59 & 3 then 15 & Yes & Yes & No & Ahlers, 1977 \\
\hline 1972 & $\mathrm{RB}-66$ & $\begin{array}{l}\text { NAVAIRENGCEN } \\
\text { Lakehurst, NJ }\end{array}$ & XD8132/Jet-A & 54 & 3 then 15 & Yes & Yes & Yes & Ahlers, 1977 \\
\hline 1973 & RB-66 & $\begin{array}{l}\text { NAVAIRENGCEN } \\
\text { Lakehurst, NJ }\end{array}$ & XD8132/Jet-A & 53 & 3 & No & No & Yes & Ahlers, 1977 \\
\hline 1979 & SP-2H & $\begin{array}{l}\text { NAVAIRENGCEN } \\
\text { Lakehurst, NJ }\end{array}$ & Jet-A & 60 & 3 & No & No & Yes & Zagrella, 1980 \\
\hline 1979 & SP-2H & $\begin{array}{l}\text { NAVAIRENGCEN } \\
\text { Lakehurst, NJ }\end{array}$ & AMK FM-9 & 48 & 3 & Yes & No & Yes & Zagrella, 1980 \\
\hline 1981 & SP-2H & $\begin{array}{l}\text { NAVAIRENGCEN } \\
\text { Lakehurst, NJ }\end{array}$ & AMK FM-9 & 61 & 3 & No & No & Yes & Schaible, 1982 \\
\hline 1981 & SP-2H & $\begin{array}{l}\text { NAVAIRENGCEN } \\
\text { Lakehurst, NJ }\end{array}$ & AMK FM-9 & 66 & 3 & No & No & Yes & Schaible, 1982 \\
\hline 1982 & $\mathrm{RB}-66$ & $\begin{array}{l}\text { NAVAIRENGCEN } \\
\text { Lakehurst, } \mathrm{NJ}\end{array}$ & AMK FM-9 & 72 & 4 & No & No & Yes & Schaible, 1983 \\
\hline 1984 & B-720 & NASA & AMK FM-9 & 76 & 3.5 & No & Yes & No & Barber, 1986 \\
\hline
\end{tabular}

a. A "No" means that the fuel ignited and was combusting during the crash transient. All tests had video/cinematography coverage so some dispersal data is available from all tests. 
decelerations experienced by the aircraft can be determined from this information.

Qualitatively, all the crashes are similar in the sense that the aircraft slide along the inclines and loft on the declines to impact further down the flight path. There are no major rolls, tumbles, etc. A typical example of the data is shown in Figure 3. The data is taken from Ahlers, 1977. Given an impact velocity of $59 \mathrm{~m} / \mathrm{s}$, the time required for the aircraft to come to rest for this test was determined to be a little over 4 seconds. This determination is consistent with Horeff, 1982, who notes that it has been estimated that the duration of the dynamic phase of an accident can be up to 10 seconds.

\section{Structural response of fuel tanks}

The structural response characteristics of the fuel tanks affect the dispersal characteristics primarily by the degree to which the tank fails. To the extent the tank cracks or is punctured, then fuel will leak from it. If the tank ruptures, fuel will flow freely from it. The fuel-tank structural-response data come from both the full-scale test data listed in Table 4 and from wing section tests. The references for the full-scale tests are listed in Table 4. As discussed previously, structural tests results are given in Nissley and Heid, 1964, Buckson, et al., 1965, Ahlers, 1970, Scheuerman, 1971, and Hackler, 1972. The results and implications of these tests are summarized by Wittlin, 1987. For example, in his review of concentrated and distributed load tests, Wittlin, 1987, concludes from the first two full-scale tests in Table 4, that a distributed-load wing impact (such as the wing striking a low hill or mound) at between 60 and $72 \mathrm{~m} / \mathrm{s}$ will devastate the wing fuel tanks. For concentrated-load impacts (such as the wing striking a telephone pole), the velocity at which the wing fuel tanks will be destroyed is significantly lower: 33 to $41 \mathrm{~m} / \mathrm{s}$, depending on the type of obstacle

To enhance human survivability in a crash, the FAA has been primarily interested in reducing the probability and significance of a crash-induced fireball. This focus has determined the types of tests conducted and the types of data taken in each test. The primary dispersal variable affecting fireball formation is misting. But the primary interest in a WSSA is the amount and location of the fuel available for a pool fire-not the details of aerodynamic drop fragmentation.

\section{Fuel dispersal characteristics}

Fuel dispersal tests include the full-scale crash tests in Table 4, dispersal tests by Ahlers, 1970 and Russell, 1971, and helicopter fuel system tests by Shaw, 1971. As noted in Table 4 , the first five full-scale tests have associated dispersal data. The data is qualitative in nature, coming from video or cinematography. A typical example of the data (from Reed, et al., 1965b) is shown in Figure 4. Fuel can be seen streaming from breaks induced in the wing tanks of a Constellation aircraft. Wind shear from the forward momentum of the aircraft causes the fuel to be fragmented into a mist behind the aircraft. All of the full-scale tests show similar data - with either fuel or fireballs being swept behind the leakage point on the wing tanks. Later in this same test, the aircraft experienced periods of high deceleration after leaving the $6^{\circ}$ slope (presumably from impacting the $20^{\circ}$ hill), and "fuel 


$$
17
$$



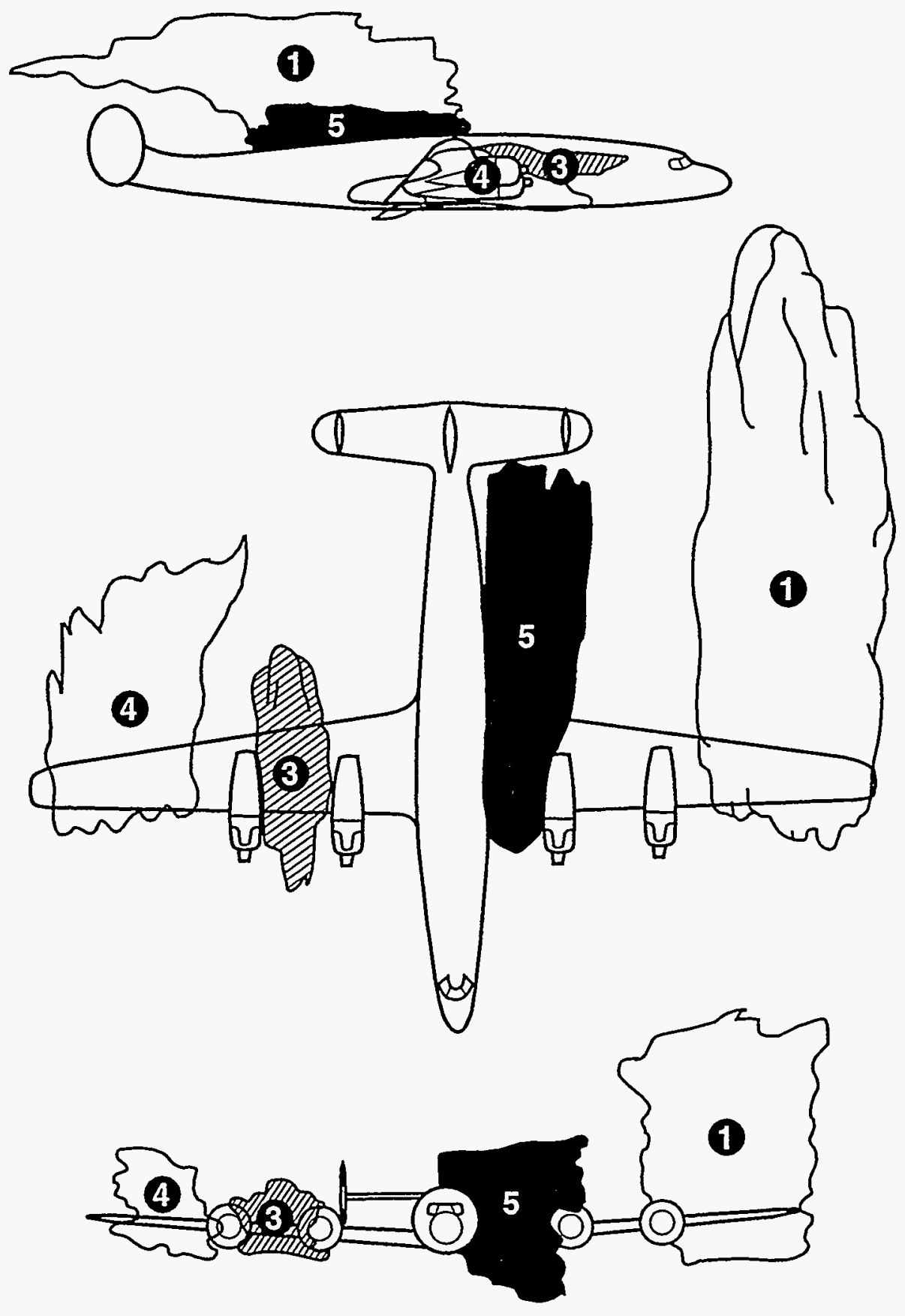

Figure 4. A typical example of fuel spillage behind an aircraft. The specific test is with a Constellation, 1.14 seconds after impact with main gear barriers. Numbers indicate fuel tank groups. (Reed, et al., 1965b) 
blossomed out ahead of the aircraft and spread 20 feet forward of the nose as it came to rest." This result, shown in Figure 5, is the sole exception to the typical dispersal pattern in which wind shear produced a mist behind the aircraft. In later full-scale tests, the fuel was deliberately ignited. These later tests also used AMK fuels, which significantly reduce the misting.

There is at least one full-scale aircraft test that contains qualitative dispersal data that was not conducted as part of a crashworthiness program. Von Riesemann, et al., 1989, report on a head-on $\left(90^{\circ}\right)$ impact of an F-4 Phantom II aircraft into a concrete block at $215 \mathrm{~m} / \mathrm{s}$. The purpose of this test was to measure the impulse load on the concrete target. Water was used as a fuel simulant. The aircraft failed catastrophically on impact, as shown in Figure 6. The aircraft fragments were so small that visually it appeared that the water and aircraft fragments formed a two-phase slurry. The water/fragment flow was perpendicular to the line of travel of the aircraft and formed a circular splash pattern around the aircraft.

Measurement of fuel dispersal characteristics other than misting is regrettably sparse. Only the second SP-2H test (Zagrella, 1980) reports quantitative measurements of the rate of fuel leakage from the wing tanks. Further, only the early RB-66 tests (Ahlers, 1977) report quantitative estimates of the fuel remaining in the tanks after the aircraft came to rest.

Ahlers, 1970, and Russell, 1971, report on drop and impact tests of droppable F-86 fuel tanks. Different techniques, such as the installation of foams and gelling, were used to reduce fuel misting during impact. The tests are noteworthy in that JP-4 was used as the reference fuel. Russell, 1971, reports on a test with a deliberately-weakened, droppable F86 fuel tank containing 454 liters of fuel. The tank was dropped from a height of 10.7 meters; the resulting fuel dispersal covered 44.2 square meters and created a plume 4.6 meters high. All subsequent gelled fuel tests were compared to the results of this test.

Russell, 1971, also conducted catapult tests. Figure 7 shows the catapult setup and a typical fireball resulting from the test. The test consisted of catapulting, at $35.7 \mathrm{~m} / \mathrm{s}$, the F-86 tanks into a steel plate at $40^{\circ}$ angle from the horizontal. Two 10 by $18 \mathrm{~cm}$ pans of burning JP4 were used as the ignition source. Two tests, one with JP-4 and the other with Jet-A, were used as references for the subsequent tests with gelled fuel. Figure 7 shows that a large fireball resulted from JP-4 fuel. The similarity between the gelled fuel tests and the napalm tests discussed in the next section was noted by the author.

\section{Fire dynamics}

Flammability tests conducted in support of crash tests were designed primarily to determine ignitability and combustion characteristics of fireballs. Typical studies include Shaw, 1971, Polymeropoulos, 1975, San Miguel and Williams, 1978, Salmon, 1981, Mahood and Talley, 1982, and Parikh, et al., 1983. The objective of these tests was to relate either ignitability or flammability to fuel-mist drop size. All the tests clearly show that flammability decreases with increasing drop size. Hence the desire to develop antimisting fuels, i.e., fuels resistant to breakup due to air-induced shear. 


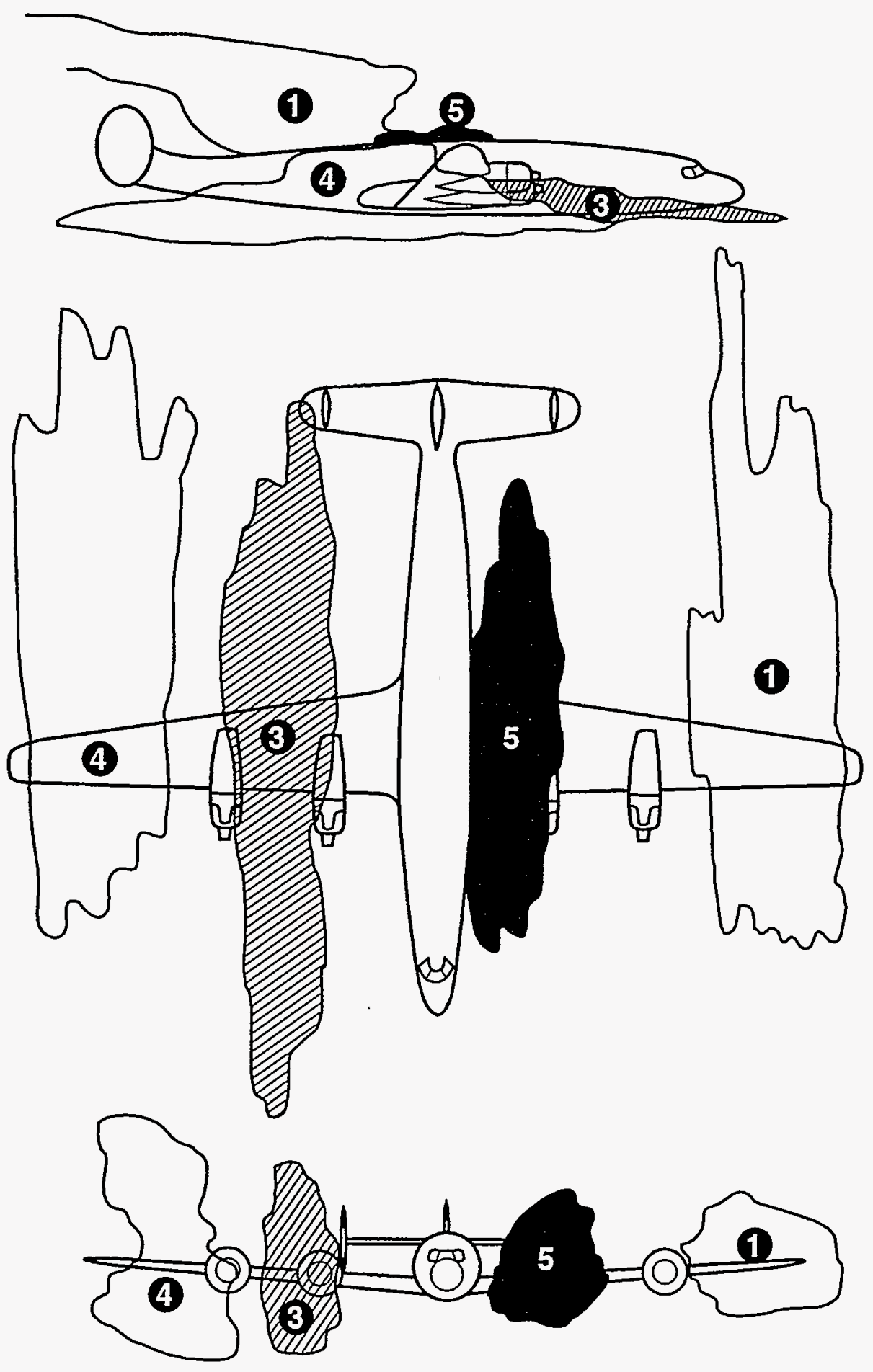

Figure 5. Exceptional case in which fuel is splashed in front of the aircraft. This case occurred during a "high deceleration" late in the same test illustrated in Figure 4. Numbers indicate fuel tank groups. (Reed, et al., 1965b) 

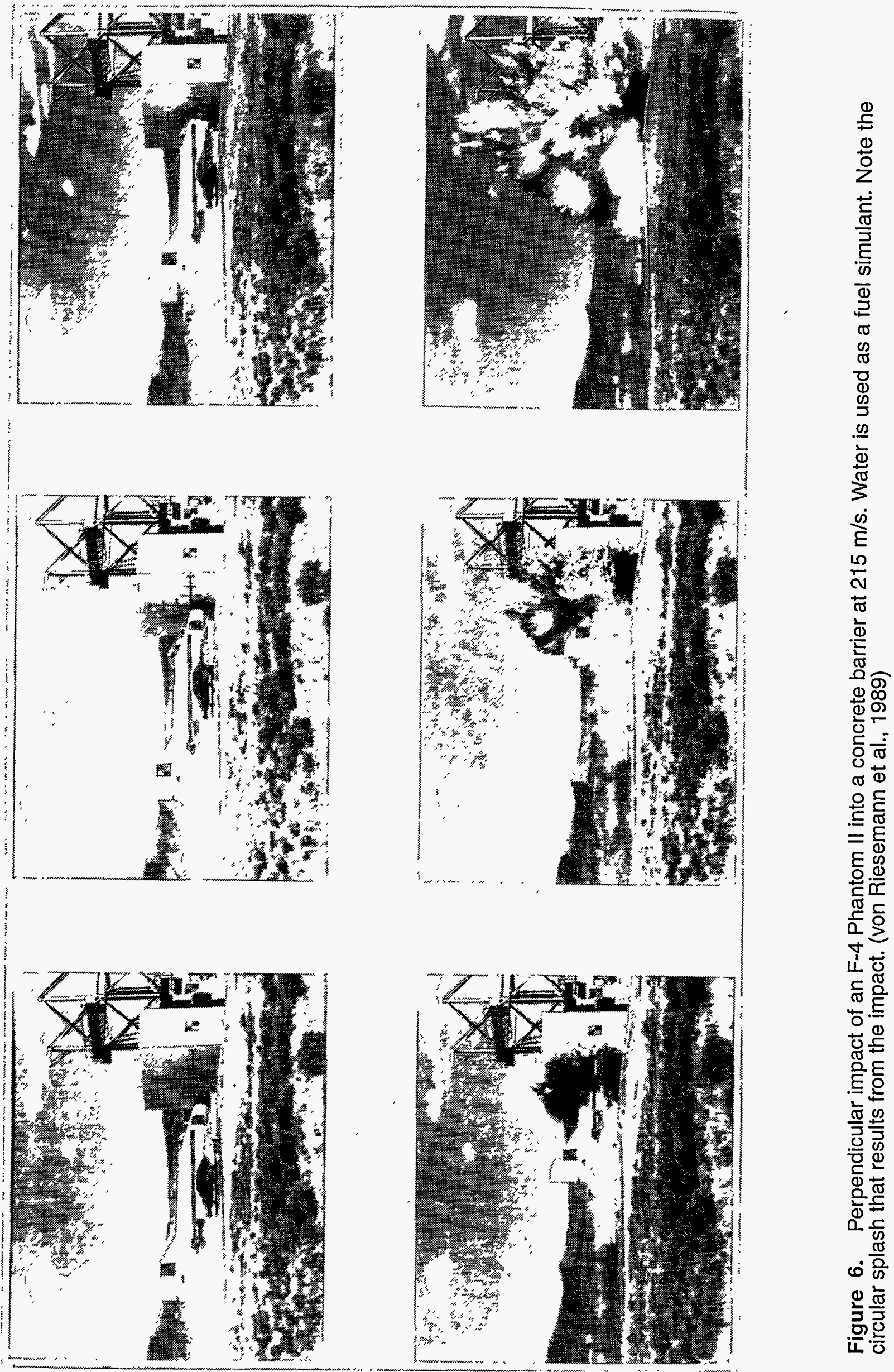


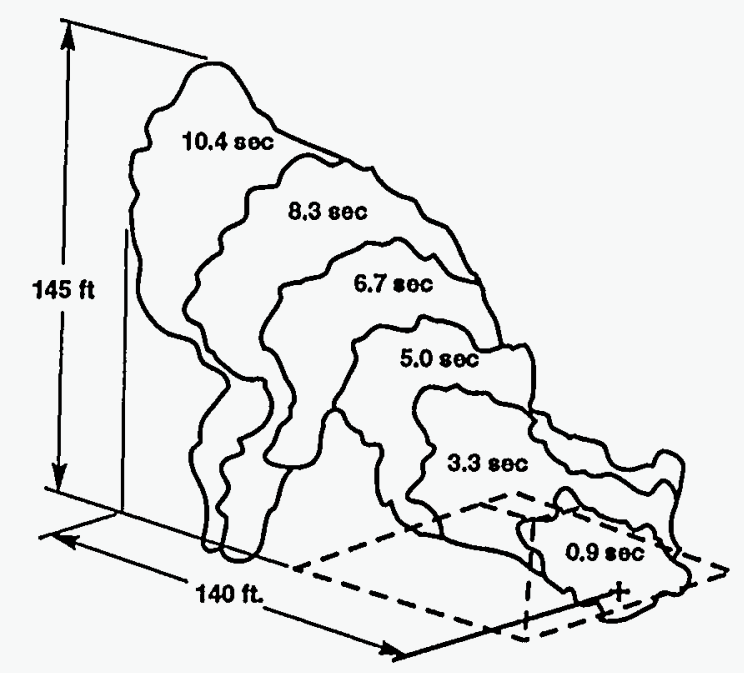

(a)

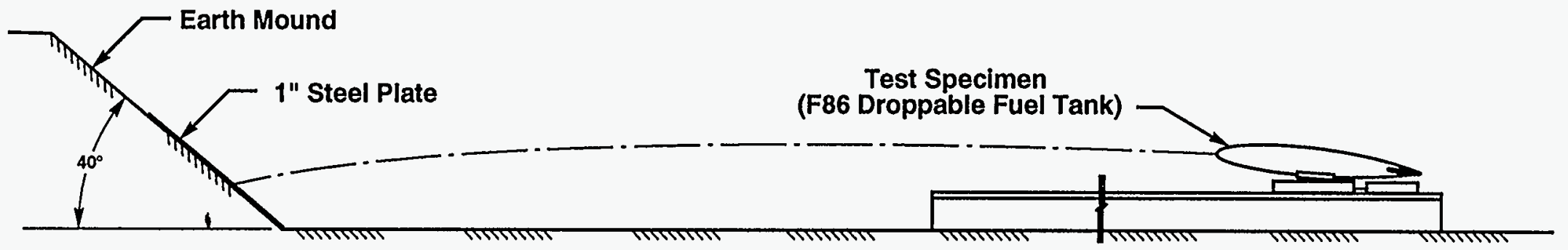

(b)

Figure 7. FAA catapult test with an F-86 droppable fuel tank filled with 454 liters of JP-4. (a) Fireball resulting from a $35.7 \mathrm{~m} / \mathrm{s}$ impact at $40^{\circ}$. (b) Test rig for launching the fuel tank. (Russell, 1971) 
The FAA and Army programs were designed to reduce the fireball resulting from the initial impact because there is a short time scale for human lethality in a fire environment. Human lethality from fire comes from both heat and toxic smoke inhalation. Horsfall, 1983, notes: "In a worst case of a massive fuel spillage where the fuselage is broken open, the cabin interior is likely to be involved almost immediately. However, when impact damage is less severe and fuel loss less extensive, it can take as long as five minutes for the conditions in the cabin to become lethal." Aluminum alloy fuselage skin is destroyed by a fuel fire in about one minute (Knapp and Knox, 1982).

In addition to being lethal in its own right, the fireball is an exceptionally effective ignition source for the remaining fuel and other adjacent combustible materials. Tilston, 1989 gives an overview of ignition and other combustion characteristics as applied to aircraft safety.

\section{Fuel-Filled Bomb Data}

Fuel-filled bombs evolved from droppable fuel tanks added to increase fighter range during World War II. The relationship between fuel-filled bombs (such as napalm) and aircraft crashes may not be readily apparent. But a fuel-filled bomb and a fuel-filled wing, although structurally somewhat different, can be expected to have similar impact characteristics: if the bomb or the wing tank fails, the fuel will come splashing out forward from the point of impact. Area coverage for various weapon sizes is given by Whitaker, 1945, King, 1952, Gibson, 1956, and Edwards, 1973. Figure 8 shows the area covered by the forwardsplashed fuel for nominally 379 liters of fuel dropped from 30 meters at nominally 157 meters per second indicated airspeed (Gibson, 1956). The impact angle is noted as $20^{\circ}$.

Naturally, bomb development involves many details that are not of interest to this study. The variables of interest are listed in Table 1 as total velocity, normal velocity, and amount of fuel. No systematic study of these variables has been conducted (at least in the literature that was obtained for this report). The total and normal impact velocities were studied as a function of deployment tactics. Ballistics determine the impact velocity and impact angle. Some of the studies contain impact information and others do not. Some of the more quantified results are given by Edwards, 1973, and are shown in Figure 9. In the Edwards report, the total amount of fuel used depends on the device being studied. Volumes include 76,220 , and 379 liters.

The quantitative use of the data in Figure 9 for a WSSA is difficult due to the use of gelled fuels. Unfortunately, early in the development of fuel-filled bombs it was noted that it was necessary to suppress the fireball to increase effectiveness. Edwards, 1973, notes that when Standard Napalm disintegrated into small particles with relatively large surface-to-mass ratios, the heat released generated powerful convective currents that swiftly carried aloft the cloud of particles. This created a "spectacular fireball, which receded rapidly from targets at ground level." Rigdon, 1973, cites a NWC, China Lake study that reports "when a flame agent breaks up into ultra-small particles (e.g., popcorn size or smaller) they tend not to travel very far and burn time is not long enough to ignite target materials. When a 


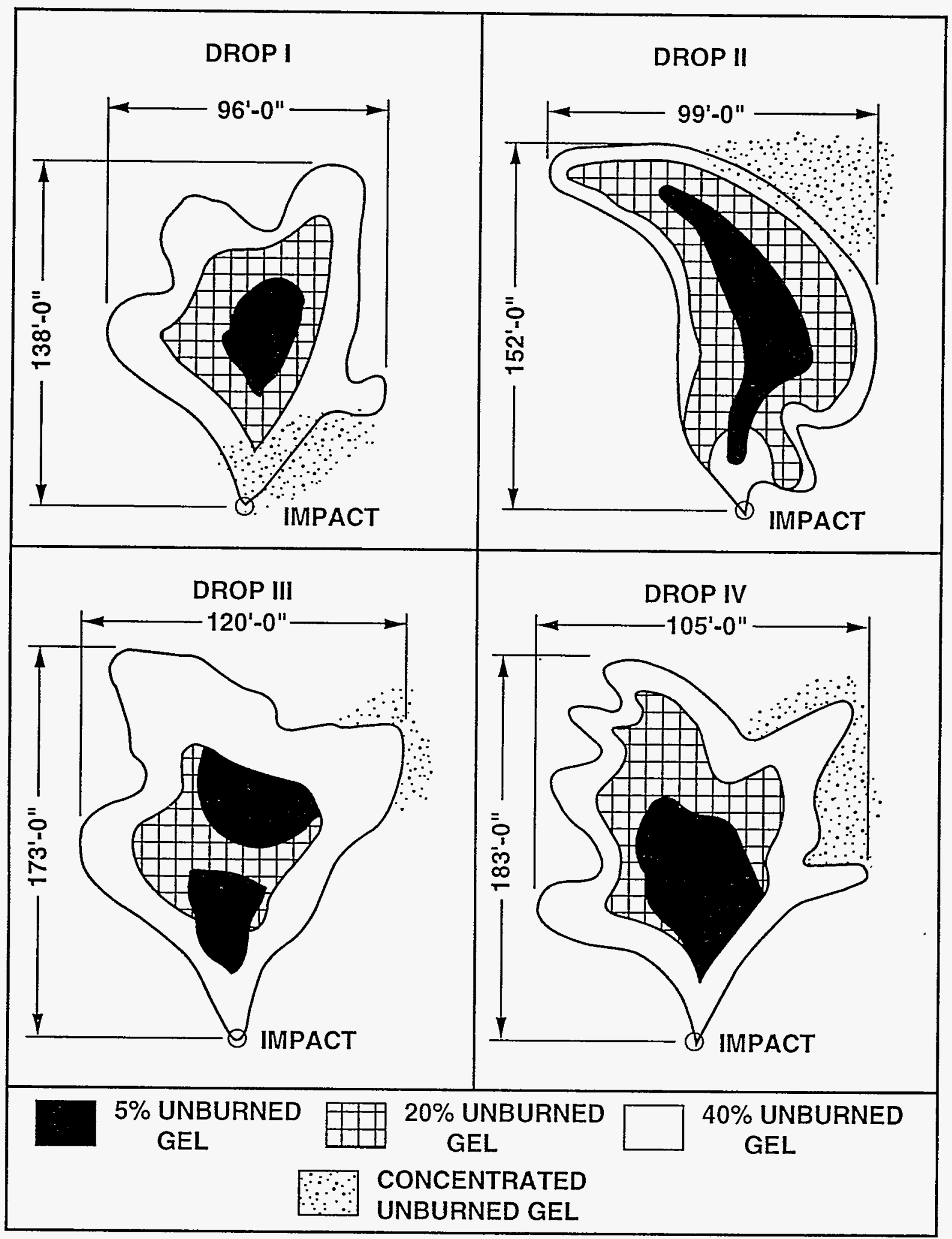

Figure 8. Typical area covered by a thickened aviation fuel splashed from the $20^{\circ}$ impact of a 379 liter device dropped from $30 \mathrm{~m}$ at $157 \mathrm{~m} / \mathrm{s}$ indicated airspeed. (Gibson, 1956) 

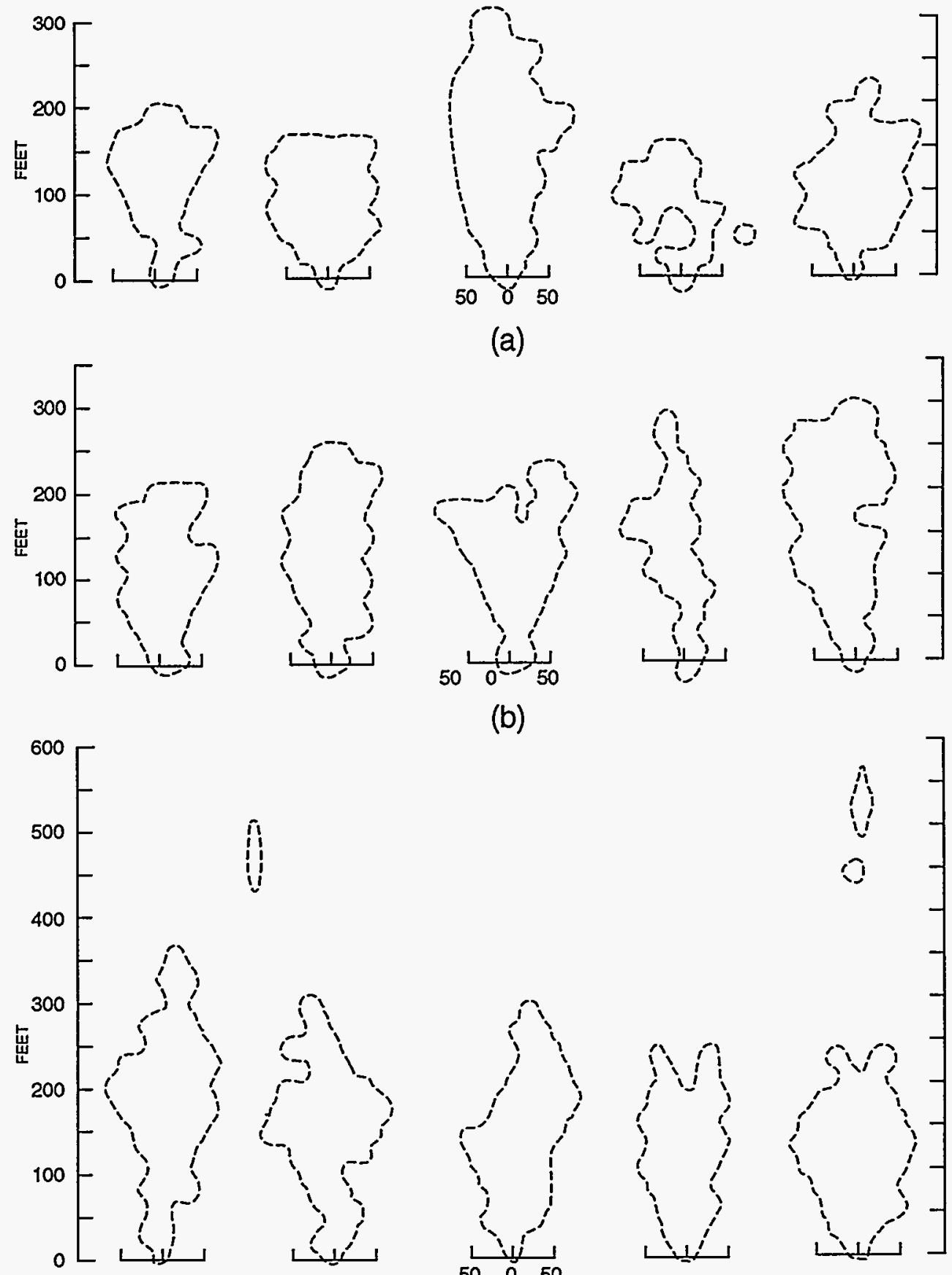

i

(b)

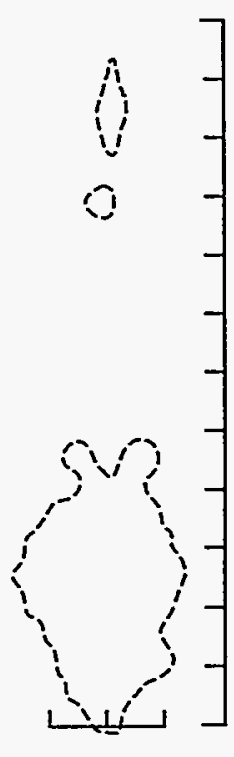

(c)

Figure 9. Typical dispersal patterns from the impact of 379 liters of Napalm B (a thickened hydrocarbon fuel). (a) Impact is at $18^{\circ}$ with a total velocity of $187 \mathrm{~m} / \mathrm{s}$. (b) Impact is at $7^{\circ}$ with a total velocity of $183 \mathrm{~m} / \mathrm{s}$. (c) Impact is at $15^{\circ}$ with a total velocity of $94 \mathrm{~m} / \mathrm{s}$.

(Edwards, 1973) 
flame agent breaks up into relatively few and ultra-large particles (e.g., football size or larger) they tend to travel far leaving many large void areas."

Qualitative dispersal observations are recorded by Edwards, 1973: "When fire bombs are released in the skip bomb mode, e.g., at 200 knots from 100 feet in straight and level flight, little if any unburned incendigel is likely to adhere to the sand at the point of impact. Evidently, practically all of the 100 gallons of incendigel in the canister is thrown out immediately on impact."..."There is a high degree of correlation between the vertical component of velocity at impact and the depth and volume of the crater gouged out at impact." Further, "The walls and the lip of the crater may interfere with the escape of spray at low trajectories and occasionally direct jets of spray at bearings completely unrelated to the direction of travel of the original fire bomb." Finally, "As fire bombs are released at higher speeds, from higher altitudes, and in steeper dives, the distribution of incendigel takes on changing geometrical patterns, approaching a circular distribution." Edwards further notes that no direct measurements of the velocity of the flying spray were made. However, he states that there is evidence from the number of datum poles knocked down in his tests that the initial velocity of the spray is directly related to the horizontal component of the bomb velocity.

In addition to napalm or fire bombs, another class of fuel-filled bombs has been developed: fuel air explosives (FAE). Serious development of FAE began in the 1960s. The objective of FAE weapons is to rapidly disperse the fuel in such a manner that a detonable cloud forms. Because of the fast time scales involved in detonations, the fuel cloud must be composed of a very fine mist. Early FAE weapons used one of two classes of fuel: pressureliquefied vapor or a moderate vapor-pressure liquid. The pressure-liquefied-vapor tanks were cut on impact, allowing the pressurized liquid to vaporize rapidly. In order to form a cloud with the moderate vapor-pressure liquids, the liquid was dispersed explosively using centrally located high explosive. In either case, minimal liquid was left on the ground and that dispersed in the air was finely atomized. The processes required to obtain these conditions are not of interest in this study, however.

\section{Analysis of Existing Data}

The purpose of this section is to discuss attributes of the data garnered from the literature search that apply to construction of a dispersal model: range of data, internal consistency of data, and applicability of data to model development.

The required ranges of data are given in Table 1 . The total velocity range is 23 to $152 \mathrm{~m} / \mathrm{s}$. The normal velocity range is 0 to $145 \mathrm{~m} / \mathrm{s}$. Using these two ranges, the range for impact angle is $0^{\circ}$ to $72^{\circ}$. The velocity range of the FAA-sponsored full-scale data is 48 to $72 \mathrm{~m} /$ $\mathrm{s}$, with an impact-angle range of $3^{\circ}$ to $8^{\circ}$ (with secondary data at $15^{\circ}$ and $20^{\circ}$ ). The bomb data, on the other hand, was taken at velocities in the range of 91 to $152 \mathrm{~m} / \mathrm{s}$. Further, the impact angles are typically higher, in the range of $7^{\circ}$ to $20^{\circ}$. Overall, the velocity range is adequately covered. Unfortunately, the impact-angle range is not covered at the high end, except for the F-4 impact test. 
The data was then analyzed for internal consistency. There are widely differing dispersal characteristics between the crash data and the fuel-filled bomb data. In all the full-scale crash tests listed in Table 4, the fuel leakage from damaged wing tanks is sheared into a rearward-directed mist and either falls behind the aircraft or is burned in a fireball. In all the bomb tests, the fuel splashes forward of the bomb impact point. Three tests overlap the range and indicate the data is consistent. Two of the FAA-sponsored tests show forward splashing, as does the Sandia National Laboratories F-4 test. The two FAA tests are shown in Figure 5 and Figure 7. The F-4 test is shown in Figure 6.

The key to relating the crash data to the bomb data is the normal impact velocity, i.e., the component of the impact velocity that is perpendicular to the ground, which is defined as the aircraft speed at impact times the sine of the impact angle. At impact, the normal velocity will be forced to zero. Because the ground is hard, the velocity change will occur quickly, resulting in high decelerations, and hence, high forces. The square of the normal impact velocity is proportional to the normal kinetic energy. At impact, this normal kinetic energy is going to be dissipated. If the normal kinetic energy is low, then the landing struts will dissipate it. If the normal velocity is higher, then the dissipation will be manifest in material deformation. At even higher normal velocities, the dissipation will be manifest in material failure and fragmentation. This view is consistent with the military crash investigations of Kuchta and Clodfelter, 1985, who note that the "angle of impact is most crucial in the damage sustained by aircraft in a crash-type situation." For a given flight speed at impact, the higher the angle of impact, the higher the normal impact velocity.

The full-scale crash data in Table 4 have normal impact velocities in the range of 2.4 to 10 $\mathrm{m} / \mathrm{s}$ (ignoring, for the moment, the $15^{\circ}$ and $20^{\circ}$ data). The bomb data have normal velocities in the range of 18 to $52 \mathrm{~m} / \mathrm{s}$. The three tests that show forward splashing have high normal impact velocities. The test in Figure 7 has a normal impact velocity of $23 \mathrm{~m} / \mathrm{s}$. The actual velocity at time given in Figure 5 is not given in the report, but the deceleration is noted as "high" (presumably because it has impacted the $20^{\circ}$ slope). The normal impact velocity for the F-4 test is $215 \mathrm{~m} / \mathrm{s}$. Clearly, at this normal impact velocity the aircraft was totally consumed.

The relation between the fuel trailing behind the aircraft as a mist or splashing ahead of (or around) the aircraft is dependent on: (1) the amount of structural damage sustained by the wing tanks, and (2) the distance the aircraft continues to slide along the ground after its initial impact. The FAA data show that if the wing tanks are damaged and the aircraft continues to move forward, then the fuel spills behind the aircraft. The specific case in Figure 5 shows that if the wings are damaged and the aircraft suddenly decelerates (i.e., stops moving forward), then the fuel splashes forward. At impact velocities high enough to cause the wings (or tanks) to fail, the bomb data, FAA data in Figure 7, and F-4 crash in Figure 6, clearly show that the fuel will splash. The splashing is forward in Figure 7, Figure 8, and Figure 9, which have impact angles in the 7 to $40^{\circ}$ range. As noted earlier, Edwards, 1973, observes "As fire bombs are released at higher speeds, from higher altitudes, and in steeper dives, the distribution of incendigel takes on changing geometrical 
patterns, approaching a circular distribution." The $90^{\circ}$ impact angle in the F-4 test clearly results in a circular distribution, as shown in Figure 6 . The conclusion from these comparisons is that the data is consistent between the crash data and the bomb data. The major differences in dispersal characteristics are due to differences in velocity and impact angle.

In addition to covering the required ranges and being consistent, the data had to be applicable to dispersal model development. The relevant fuel for the current study is JP-4, as noted in Table 1. Early on in their development studies, both the civilian and military stopped using unaltered JP-4 and began adding antimisting compounds*. The question arises as to what parameters are affected and to what degree they are affected by the use of an antimisting fuel rather than JP-4.

Clearly, the misting characteristics of JP-4 and the antimisting fuels are dramatically different. This parameter is extremely important in determining fireball characteristics. As noted in the section on Programmatic Context of Fuel Dispersal Model, the fireball will be ignored in the model because the fireball time scale is short compared to the time required to heat a weapon to a level of significant consequence.

The important parameters for a WSSA are how much fuel is available for pooling and where that fuel is located relative to the weapon. In the simplest sense, the results from antimisting fuel studies are conservative. The less fuel in the mist, the more fuel available for the pooling. The data, therefore, may be conservatively applied to fuel leakage behind a damaged wing tank. However, the effect of fuel type on the fuel splashing characteristics in the event of wing failure is more complex. As noted in the discussion of the bomb data, the effect of drop size is nonlinear. In the case of splashing, the data has to be taken as only qualitative when applied to JP-4.

Although there is a significant amount of data on dispersal in both the civilian and military literature, the purposes for which the data was developed are not the same as those of the current study. This is clearly true for the bomb development data. Unfortunately, it is also true for the crash data. The heat loads to cause weapon failure and human lethality drive differing goals in thermal modeling, and hence, dispersion modeling. And unlike human beings, weapons do not fail due to toxic smoke inhalation. For these reasons, the quantitative data that is directly applicable to a WSSA is less than would reasonably have been expected.

On the other hand, qualitatively, the data clearly identifies the characteristics needed in the dispersion model. The range of the velocity data covers nearly the entire range required for a WSSA. There are data for impact angles of up to about $45^{\circ}$. Beyond this, the F-4 test and

*It is interesting to note that the civilian programs added antimisting compounds in order to enhance survivability, whereas the military added them to enhance lethality. The logic of both is sound; the difference is the parameter ranges over which each is expected to operate. It has been the author's experience that such apparent contradictions are common in dealing with combustion (a highly nonlinear process) in complex systems. 
qualitative descriptions from fuel-filled bomb tests are internally consistent. Therefore, it is unlikely that any important qualitative feature was missing in the data available. In addition, the few data points that give fuel leakage or the amount of fuel remaining in damaged fuel tanks may apply quantitatively, in a conservative way, in the fuel leakage regime.

Some comments are offered on the completeness of the literature search to conclude the analysis of data garnered from that search. Computerized searches are a useful way to scan a broad area. However, reports can be overlooked in two ways: 1) the range of key words is not sufficiently broad to pick up the relevant technologies, and 2) the databases are not complete. Databases are only as good as the respective agencies are diligent about logging their reports. For example, all unclassified reports that are placed in the DTIC are supposed to be placed in the NTIS. But some reports that were developed as classified and later declassified are not transferred to the NTIS database.

By reviewing the reports from the computerized search and cross-referencing the citations in those reports, it was possible to develop a more complete set of literature. For the topics examined in this study, it is unlikely that significant civilian literature was overlooked. The same cannot be said of the fuel-filled bomb literature, however. 


\section{Framework for Fuel Dispersal Modeling}

Based on the review of data from the literature search, a three-regime dispersal model was defined. The three dispersal regimes are listed in Table 5. These three regimes are a condensation of the six levels of accident severity given in Table 3. The Low Normal Impact Velocity (low-NIV) regime corresponds to accident severity classification 1 . The Intermediate Normal Impact Velocity (intermediate-NIV) regime corresponds to accident severity classifications 2, 3, and 4. The High Normal Impact Velocity (high-NIV) regime corresponds to accident severity classifications 5 and 6 .

Table 5. Fuel Dispersal Model - Dispersal Regimes

\begin{tabular}{|l|l|}
\hline Regime & Description \\
\hline Low Normal Impact Velocity & No significant fuel leakage \\
\hline Intermediate Normal Impact Velocity & Fuel tanks are damaged and fuel is leaking behind the aircraft \\
\hline High Normal Impact Velocity & $\begin{array}{l}\text { Fuel tanks are ruptured and fuel splashes from the impact } \\
\text { around and in front of the aircraft }\end{array}$ \\
\hline
\end{tabular}

Figure 10 shows the three dispersal regimes on a tangential and normal impact velocity plot. These two parameters are consistent with the scenario input parameters listed in Table 1. The three dispersal regimes are defined by three corresponding damage regimes. The first damage regime, at low normal impact velocity, involves insignificant damage to the wing fuel tanks. In this regime, insignificant fuel leakage occurs. The second damage regime, at intermediate normal impact velocity, involves significant structural damage to the wing fuel tanks but insufficient damage to cause complete structural failure. In this regime, fuel will leak from the damaged tank at a rate proportional to the amount of damage. The third damage regime, at high normal impact velocities, involves complete structural failure of the wing fuel tanks. In this regime, fuel will splash on impact.

All damage levels are expected to be within the range of interest for a WSSA. For example, as noted in the literature review, Wittlin, 1987, concludes that a distributed-load wing impact (such as the wing striking a low hill or mound) of between 60 and $72 \mathrm{~m} / \mathrm{s}$ will devastate the wing fuel tanks. For concentrated loads (such as the wing striking a telephone pole), the velocity at which the wing tanks will be destroyed is even lower: 33 to $41 \mathrm{~m} / \mathrm{s}$, depending on the type of obstacle.

Specific fluid models will be developed for the intermediate- and high-NIV regimes. For the intermediate-NIV regime, a leakage model will be developed. The basic format for the leakage model is as follows: The remaining fuel available for pooling is equal to the amount of fuel at impact minus that which has leaked out. The amount that leaks out prior to the aircraft coming to rest will be modeled as drainage through an orifice. The size of the orifice 
(i.e., the amount of damage done to the fuel tank) will be developed from a crash dynamics model. The total amount of fuel that drains out is a function of the time that it takes for the aircraft to come to rest. This time can be estimated from the full-scale crash data or crash dynamic models. Once the aircraft comes to rest, the fuel remaining in the damaged tanks will continue to spill from the wing. The resultant size of the spill fire depends on the fuel spill rate and the combustion rate (i.e., fuel burn rate) of the fire. Because of this, the output of the fuel dispersal model (the input to the fire model) in the intermediate-NIV regime is the leakage rate from the wing tanks and the volume of the fuel remaining, as a function of time.

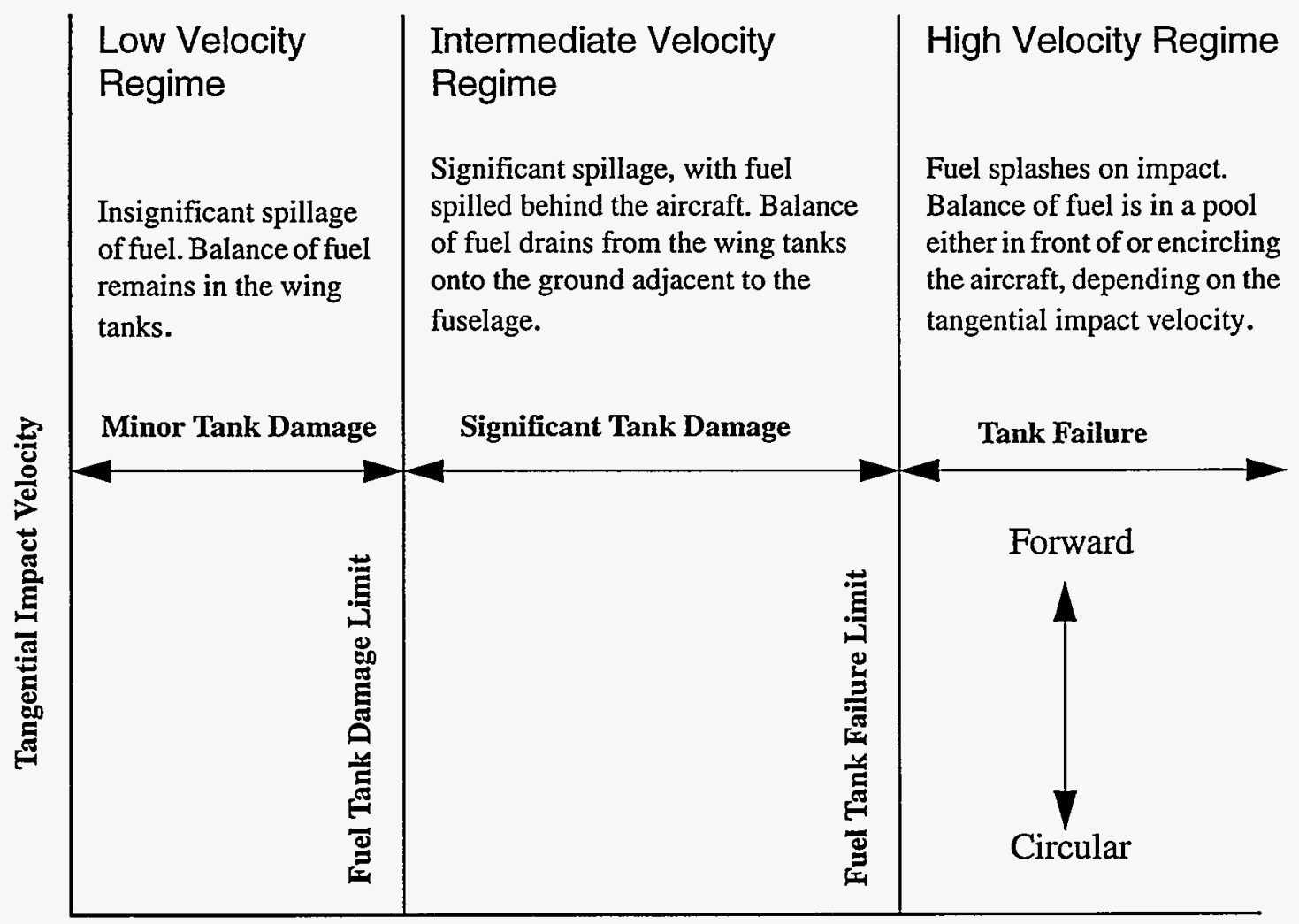

Normal Impact Velocity

Figure 10. The dispersal model. Three dispersal regimes have corresponding damage regimes. No or minor damage results in no or minor fuel leakage. Significant fuel tank damage results in fuel leaking behind the aircraft. Fuel tank failure results in fuel splashing.

For the high-NIV regime, a splash model would be developed. The basic format for the splash model would be as follows: The remaining fuel available for pooling is that which forms a contiguous, definable wet spot either in front of or encircling the aircraft, depending on the impact angle. The part of the splash that separates from the main flow will be assumed to burn up as a fireball and not be available for pooling. Unlike the leakage model, 
the splash model is not a classical model, and the available data is only qualitatively accurate. Some small-scale testing would be required in order to develop this model fully. The output of the fuel dispersal model (the input to the fire model) in the high-NIVregime is the wet spot area, its location relative to the aircraft, and the amount of fuel in the wet spot.

The proposed models will need to incorporate the input variables from the scenario input given in Table 1 and the important elements identified in the literature review, as well as from the crash dynamics model. The model needs include the wing fuel tank damage levels as a function of normal velocity, including the damage thresholds that separate the three dispersal regimes. The proposed framework does not take elements of terrain into account. Terrain is a complex subject, and parameters like obstacle impact or cratering can have an impact on the dispersal model. It is assumed for this study that impact will occur on a smooth rigid surface such as a runway. 


\section{Development of Fluid Models for Dispersal Regimes}

Specific fluid models were developed for the intermediate- and high-NIV regimes. For the intermediate-NIV regime, the model is referred to as the fuel leakage model. For the highNIV regime, the model is referred to as the splash model. This section discusses the development of both fluid models.

\section{Fuel Leakage Model}

A fuel leakage model was developed for the intermediate-NIV regime. The basic format for this model is shown in Figure 11, in which the fuel leaks from a damaged wing tank on the $\mathrm{C}-141$ and is dispersed as the aircraft decelerates. The amount of fuel remaining after the aircraft comes to rest is equal to the amount of fuel at impact minus that which has leaked out. The total amount of fuel that leaks out is a function of the extent of damage to the fuel tank and the time that it takes for the aircraft to come to rest. The model deals only with mass loss from the aircraft as it decelerates. However, once the aircraft comes to rest, the fuel remaining in the damaged tanks continues to spill from the wing. Given that ignition occurs, the resultant size of the spill fire depends on the fuel spill rate and the combustion rate of the fire. Fuel pool models for this scenario were developed by Cline and Koenig, 1983, Alvares, et al., 1992, and Magnoli, 1992. The leakage model for the deceleration phase is consistent with these combustion-controlled pool models.

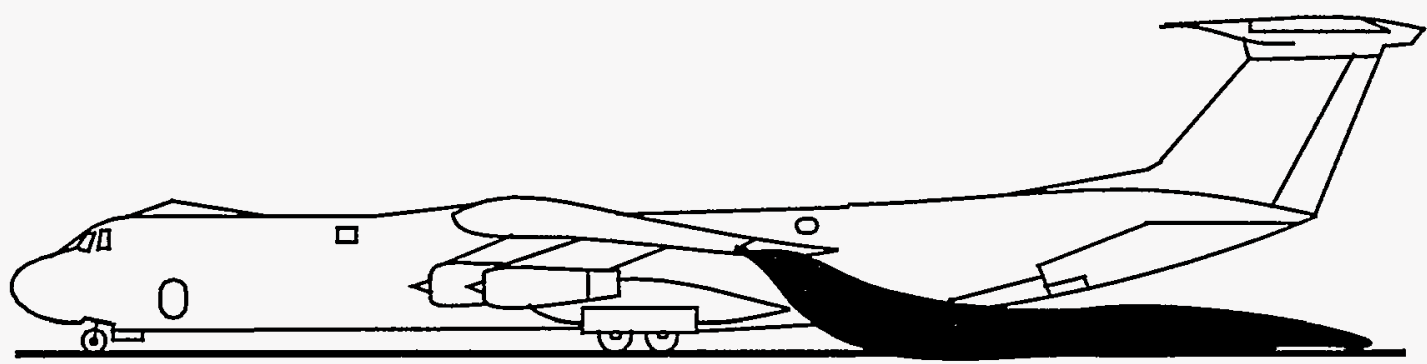

Figure 11. Leakage from a damaged wing tank on a C-141.

There are a number of complexities in the fuel leakage problem during deceleration. Some of these complexities are the same as those present after the aircraft comes to rest. These 
include complex fuel tank and damage geometry. Damage geometry can range from cracks to the complete loss of entire sections of the fuel tank. Two complexities are unique to the deceleration problem. The first complexity is that the aircraft deceleration, due to impact and slideout, causes the fuel to experience a time-varying body force. Since gravity also creates a body force, the resultant sum of the two body forces changes in magnitude and direction over the deceleration phase. This time-varying body force will result in sloshing of the fuel within the tanks. Further, the hydrostatic driving force for fuel leakage depends on both the height of the free surface above the location of the damage and the magnitude of the body force, both of which are time-varying quantities.

The second complexity unique to a decelerating aircraft is that the total pressure (static plus dynamic) on the wing surface is a function of the aircraft velocity, which is itself a function of time. The total pressure also varies across the surface of the wing, with a maximum at the leading edge of the wing stagnation point. Depending on the direction of the pressure gradient between the internal fuel-tank pressure and the free-stream pressure, leaking fuel will either experience a driving or retarding force. It is not intuitively obvious what the relative magnitude is between the driving force for fuel leakage induced by the pressure difference and by the hydrostatic head.

In any model development there is a trade-off between fidelity and complexity. The higher the fidelity of the model, the lower the uncertainty associated with its predictions. However, there is a cost in both time and money to develop high-fidelity models. In the spirit of program goals to achieve fast running models, the approach for this study was to use simplifying assumptions based on engineering judgement to achieve an analytical solution. Higher-fidelity solutions require numerical techniques. The required assumptions and resultant analytical model are discussed in the next section, which is followed by a discussion of the applicability of existing numerical techniques.

\section{Development of the analytical model}

Geometrical simplifications for both the fuel tank geometry and the geometry of the damage are necessary to obtain an analytical solution. All the fuel tanks in the C-141 are in the wings. For the model, it will be assumed that the fuel tanks are rectangular boxes of an average thickness, chord, and span. In addition, it will be assumed that each wing tank can be considered separately. The rectangular box equivalent of the whole wing is given in Appendix A.

In general, the damage to the fuel tank can range from a crack to a hole of arbitrary shape and size, up to the characteristic length of the tank. Further, multiple damage sites may occur on a single tank. For the model, it will be assumed that whatever the shape, size, or number of damage sites, the damage to the fuel tanks can be reduced to an equivalent round-orifice diameter.

The driving forces for fuel leakage include body forces and pressure differences. Due to the deceleration of the aircraft, the body forces are time and location dependent. Furthermore, due to the acceleration of air over the aircraft wings, the pressure external to the wings is 
also time and location dependent. In order to develop an analytical solution, it is necessary to simplify both the time and spatial dependencies. The location of the damage is important since the driving forces on the fuel are spatially dependent for the decelerating aircraft. For example, a given size hole in the bottom of the tank near the trailing edge may not leak if all the fuel has sloshed to the front of the wing. The same size hole in the leading edge of the wing will have significant leakage. Further, later in time when the deceleration has decreased and gravity dominates, the total leakage through the hole in the leading edge is limited by the level of the hole relative to the fuel level. At the same time, the leakage rate from a hole in the bottom of the tank near the trailing edge will increase after the fuel has shifted from the front of the wing to a more horizontal position.

It follows that in order to determine leakage rates in a decelerating aircraft, not only the size of the equivalent round orifice needs to be specified, but also its location on the wing surface. It is not possible to establish, a priori, where the damage is located on the surface of the wing without specifying a damage mechanism. In a WSSA study, it is unlikely that sufficiently detailed information will be available to determine the likelihood of wing damage being located at any one location versus any other location. Further, most damage will be spatially distributed, such as a long crack. The reduction of this crack to an equivalent round orifice can only occur if the leakage driving forces are taken into account in the equivalencing process.

In addition to not having the basis for selecting the location of an equivalent orifice diameter, further complication arises in the derivation of the model. The classical derivation of leakage from a vessel involves a technique that requires separation of variables. This technique cannot be applied if the free-surface fuel height above the orifice varies with time as a result of the deceleration of the aircraft.

As a first approximation, the effect of the deceleration on the fluid in the tank will be neglected. The liquid level will be taken as parallel to the ground, and the orifice will be assumed to be located in the bottom of the rectangular fuel tank.

Using the assumptions outlined above, conservation of mass gives,

$$
m_{\text {final }}=m_{\text {initial }}-\int_{0}^{\text {'stop }_{\text {leakage }}} d t
$$

where,

$$
\dot{m}_{\text {leakage }}=\rho_{\text {fuel }} A_{\text {orifice }} C_{c} V_{\text {flow }}
$$

where, $\rho_{\text {fuel }}$ is the density of the fuel, $A_{\text {orifice }}$ is the area of the orifice, $C_{c}$ is the discharge coefficient that relates the orifice area to the vena contracta area, $V_{\text {flow }}$ is the flowrate 
through the orifice, $t_{\text {stop }}$ is the time from impact until the aircraft comes to rest, $m_{\text {initial }}$ is the fuel mass at impact, and $m_{\text {final }}$ is the fuel mass when the aircraft comes to rest.

The flowrate through an orifice, $V_{\text {flow }}$, can be found in virtually any textbook on fluid mechanics; for example, see Sabersky, et al., 1971. In terms of the variables of interest, the result is,

$$
V_{\text {flow }}=C_{\nu}\left(\left(\frac{2}{\rho_{\text {fuel }}}\right)\left(\frac{g m_{\text {fuel }}}{A_{\text {tank }}}+P_{\text {tank }}-P_{\text {ambient }}\right)\right)^{1 / 2}
$$

where, $\rho_{\text {fuel }}$ is the density of the fuel, $A_{\text {tank }}$ is the area of the bottom of the tank with the drainage, $m_{f u e l}$ is the mass of fuel at a given instant in time, $C_{v}$ is the velocity correction coefficient, and $P_{\text {tank }}$ and $P_{\text {ambient }}$ are the tank and ambient pressures, respectively. It must be noted that some transient terms in the momentum equation were ignored in the development of Equation 3. These terms become increasingly important as the area of the orifice approaches the area of the tank. For orifice diameters less than $50 \%$ of the characteristic diameter, the error is less than 10\%. See Sabersky, et al., 1971, for details. In Equation 3, $m_{\text {fuel }}$ is a function of time. At impact, the initial flow velocity, $V_{0 \text { flow }}$, is given by Equation 3 with $m_{\text {fuel }}$ equal to $m_{\text {initial }}$.

Using conservation of mass between the free-surface of the fuel in the tank and the flow at the orifice, the fuel mass as a function of time can be found. A separation of variable technique is used to integrate the mass balance, which requires $P_{t a n k}$ and $P_{a m b i e n t}$ be constants. The resultant fuel mass as a function of time is,

$$
m_{\text {fuel }}=\frac{\rho_{\text {fuel }} A_{\text {tank }}}{2 g}\left(V_{0 f l o w}-\frac{A_{\text {orifice }} g C_{v} t}{A_{\text {tank }}}\right)^{2}-\frac{A_{\text {tank }}\left(P_{\text {tank }}-P_{\text {ambient }}\right)}{g}
$$

where, $t$ is time and the other symbols have been previously defined.

Substituting Equations 3 and 4 into Equation 2 gives the leakage flow rate as,

$$
\dot{m}_{\text {leakage }}=\rho_{\text {fuel }} A_{\text {orifice }} C_{c}\left(C_{\nu} V_{\text {oflow }}-\frac{A_{\text {orifice }} g C_{\nu}^{2} t}{A_{\text {tank }}}\right)
$$

Substituting Equation 5 into Equation 1 and integrating gives, 


$$
m_{\text {final }}=m_{\text {initial }}-\rho_{\text {fuel }} A_{\text {orifice }} C_{c}\left(C_{v} V_{0 \text { flow }} t_{\text {stop }}-\frac{A_{\text {orifice }} g C_{v}^{2} t_{\text {stop }}^{2}}{A_{\text {tank }}}\right)
$$

The stop time, $t_{\text {stop }}$, can be determined by balancing the initial momentum at impact with the frictional force generated by the ground. The derivation of $t_{\text {stop }}$ is given in Appendix B. The result is,

$$
t_{\text {stop }}=V\left(\frac{\cos (\alpha)-\mu \sin (\alpha)}{\mu g}\right)
$$

where, $\mu$ is the coefficient of friction between the aircraft and the ground, $\alpha$ is the impact angle, and $V$ is the impact velocity.

To estimate the area of the orifice, it is necessary to postulate a damage mechanism. In general, this will depend on the crash scenario. In the case in which no obstacles are present, it can be assumed that the damage is solely a function of the impact energy. Following this logic, an equation for orifice area is developed in Appendix C. The result is given by,

$$
\frac{d}{d_{\max }}=\frac{V_{n}^{2}-V_{n \min }^{2}}{V_{n \max }^{2}-V_{n \min }^{2}}
$$

where, $V_{n}$ is the normal impact velocity and is equal to $V \sin (\alpha), V_{n \min }$ is the minimum normal impact velocity necessary to damage the fuel tank sufficiently to cause leakage, $V_{n \max }$ is the maximum normal impact velocity in which leakage occurs, and $d_{\max }$ is the maximum value of the equivalent orifice diameter. Above $V_{n \max }$, the tank will fracture and the fuel will splash. At $V_{n \max }$, the equivalent orifice diameter equals $d_{\max }$ which can be taken as the characteristic length of the fuel tank under consideration.

The area of the orifice is,

$$
A_{\text {orifice }}=\frac{\pi d^{2}}{4}
$$

Solution of Equations 4 through 9 constitutes the splash model. Constants such as $C_{v}, C_{c}$, $\mu, V_{\text {nin }}, V_{n \max }$, and $d_{\max }$ need to be defined from experimental data. 
Figure 11 shows the fuel leaking behind the aircraft, which happens because the flow leaving the wing is subjected to aerodynamic drag. The drag force induces rearward motion of the fuel. It also subjects the fuel to shear forces, which result in the breakup of the draining liquid column. For this study, it is assumed that the draining column breaks up completely under the drag load and that the resulting spray is consumed in a fireball. This assumption is consistent with observations from the FAA large-scale crash tests. An alternate assumption can be made that the liquid column reaches the ground without breakup. This assumption would result in a pool fire extending rearward from the final resting point of the aircraft to the impact point. As long as the weapon remains in the aircraft, or is thrown forward of the aircraft, it is expected that either assumption will result in negligible heat flux on the weapon for long slideout distances. If the damage to the fuel tanks is high and the slideout is short, then the resulting pool fire may have a greater effect and, therefore, will need to be taken into account. It is beyond the current state of the art to determine the conditions for which a liquid jet in crossflow will break up.

\section{Applicability of existing numerical methods for leakage modeling}

Many of the assumptions made in the development of the analytical model can be quantified by employing numerical methods. However, as noted earlier, one of the principal reasons for making the simplifying assumptions is that the location of the tank damage must be specified in order to determine the driving force for leakage. In a WSSA study, it is unlikely that sufficiently detailed information will be available to determine the location of the damage on the wing tanks.

-If the location of the damage can be specified, numerical methods can be employed to predict the amount of fuel leakage with a higher degree of fidelity. The first increase in fidelity can be obtained by assuming that the deceleration is a constant. This results in a constant vector for the body force and eliminates time-dependent sloshing in the tank. The variation in pressure both inside and outside the fuel tank can be specified by time-varying functions. The integration leading to Equation 4 can be carried out numerically using any available ordinary differential equation solver. Solution times are expected to be fast, and the model could be incorporated directly into a WSSA process if desired.

If the deceleration is not constant but can be specified as a function of time, numerical solution is still possible. However, to determine the location of the free surface, partial differential equations will have to be solved. Numerical methods have been developed

specifically for this problem. One example of a commercially available code is Flow-3D*, which was developed to examine liquid propellant sloshing in spacecraft and missiles. The code allows for non-inertial accelerations so that any type of complicated fuel tank motion can be represented. Further, actual damage geometries can be represented-eliminating the need for reducing the damage to an equivalent orifice diameter. However, detailed numerical models of this type do not have solution times consistent with direct substitution

*Available from Flow Sciences Inc., 1325 Trinity Drive, Los Alamos, NM 87544 
into a WSSA process. They would have to be run over a limited number of cases and the results correlated for implementation in a WSSA.

\section{Fuel Splash Model}

A splash model was developed for the high-NIV regime. In this regime, the C-141 wing fragments upon impact with the ground and the fuel inside the wing disperses. Fragmentation is a complex process that cannot be modeled in a simple way. For simplicity, it is assumed that the wing has no structural integrity at impact. In other words, the breakup of the wing does not influence the dispersal of the fuel. In reality, some of the impact energy would be absorbed in the fragmentation process, so the energy available for fuel dispersal would be less than that considered here.

As shown in Figure 12, fuel is dispersed by its own momentum at the instant of impact. The fuel remaining in a contiguous, definable wet spot is the fuel available to support a pool fire. The part of the splash that separates from the main flow is assumed to burn up as a fireball and therefore does not contribute to the subsequent pool fire.

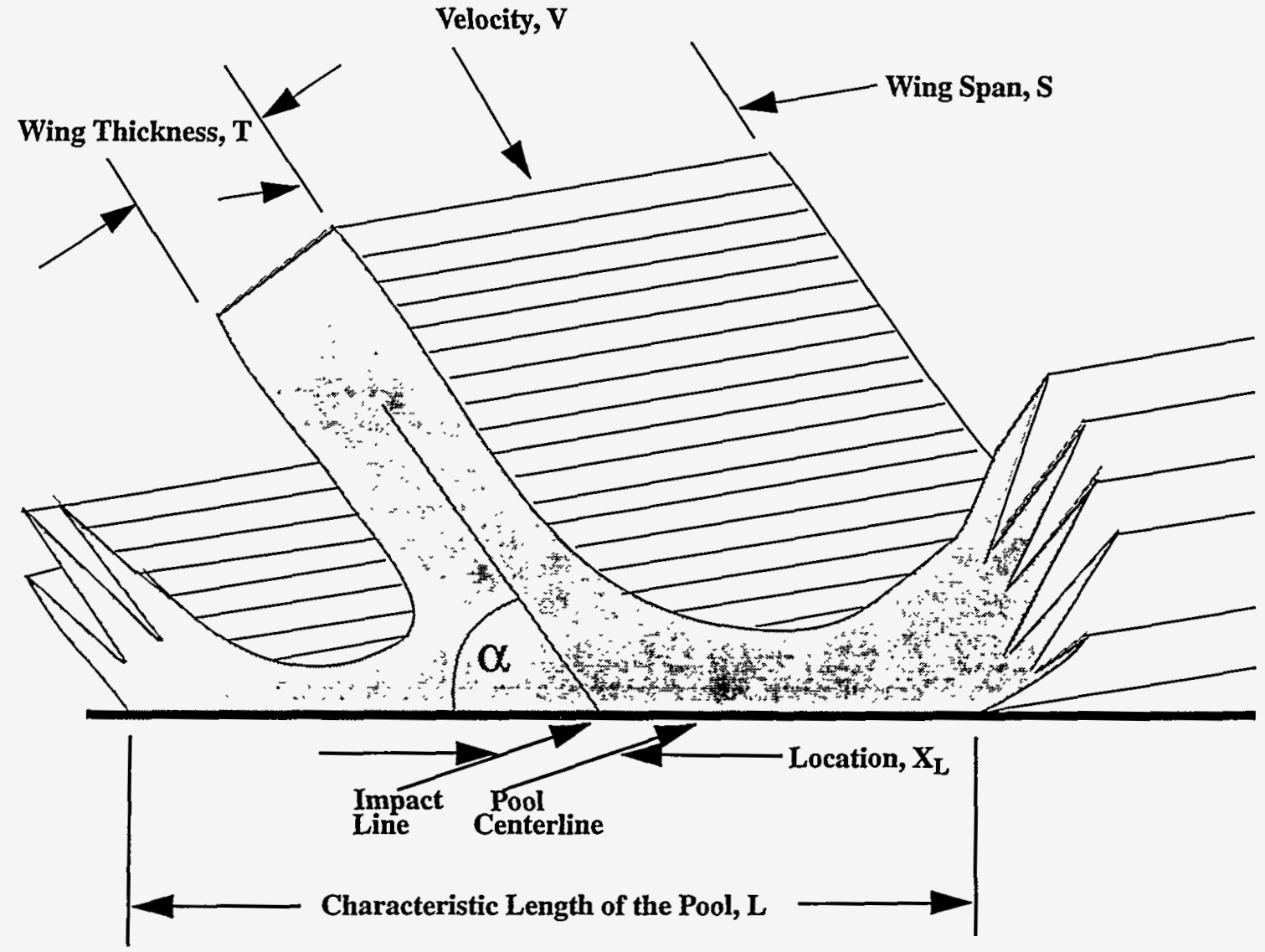

Figure 12. Splash model parameters. 
The dispersion of the fuel from the wing tanks of a C-141 is approximated as a transient, finite-length, two-dimensional slot jet that impacts the ground at an arbitrary angle and velocity. For simplicity, the $\mathrm{C}-141$ fuel tanks are approximated as a single rectangular fuel tank (see Appendix A). The thickness of the rectangular tank, $T$, is assumed to be proportional to the thickness of the wing. The length of the tank, $C$, is assumed to be proportional to the chord of the wing, and the span of the tank, $S$, is assumed to be proportional to the span of the wing. Therefore, the idealized jet will have a thickness, $\mathrm{T}, \mathrm{a}$ length, $\mathrm{C}$, and a width, $\mathrm{S}$.

\section{Literature survey}

Unlike the fuel leakage model, the splash model is not a classical model. Therefore, a literature search was undertaken to determine what correlations and/or numerical techniques were available for solving the transient, finite-length, two-dimensional slot jet impact problem. The solution is required in order to determine the area of continuously wetted ground covered by the dispersing fuel, as well as the amount of fuel remaining in this continuously wetted area. From this information a liquid depth and area coverage can be deduced. The size and depth of the pool are input conditions to the pool fire model.

The literature search was performed in three phases. The first phase was a computerized search of the national information databases. The second phase consisted of reviewing the reports from the computerized databases to identify further literature. The third phase consisted of obtaining references that were not identified in the initial search and conducting citation searches on key papers to follow technological developments.

The search was conducted on the DIALOG information system. The keywords used in the initial computer search were jet impingement/impact, drop impingement/impact, liquid jets, liquid splatter, film spread, liquid film/layer, free surface flow, hydraulic jumps, and fuel spills. Various databases were searched, the minimum set being Fluidex, Compendex Plus, National Technical Information Service (NTIS), Energy Science and Technology, and Aerospace.

Two areas for which a number of papers had been found in the first stage were ignored in the second stage of the search. The first was submerged jets, either free or wall type. Submerged jets occur in fluids of like kind, e.g., gas jets in gases or liquid jets in liquids. The second area ignored was liquid jets impinging onto liquid, as opposed to solid, surfaces. These areas were ignored because the dominant physical mechanisms are different for these jets than for liquid jets in air impinging onto solid surfaces.

The search uncovered no correlations, data, or numerical studies on the area coverage or splashing of finite-length impinging jets. However, the literature did provide some insight into the mechanisms involved in jet impingement. The discussion of the literature review is divided into two categories: transient jets and steady state jets. This discussion is followed by assessments of existing numerical methods and applicability of the literature to model development. 
The transient jet impingement literature can be divided into four areas of technology: 1) high-speed drop/cylindrical-jet impact, 2) low-speed drop impact 3) liquid-column collapse, and 4) slow flow downstream of a hydraulic jump.

Papers in the area of high-speed drop impact include those by Engel, 1955, Bowden and Brunton, 1961, Bowden and Field, 1964, Rochester and Brunton, 1979, Salem and AlHassani, 1979, Pidsley, 1983, Field, et al., 1983, and Shi and Dear, 1992. The principal objective of their work was to determine the erosion rate of turbine blades due to highspeed droplet impact. High speed droplet impact studies have also been done for thermal spray technology as reviewed by Dykhuizen, 1994. In terms of the present study, these papers demonstrate that in the first few microseconds after impact, compressibility in the liquid drop or jet is important even at moderate speeds $(\sim 100 \mathrm{~m} / \mathrm{s})$. The impingement pressure is given by the water hammer equation, which predicts a higher impact pressure than that given by the total (static plus dynamic) pressure of the drop or jet. As a result, the initial horizontal velocity of the jet is about 3 times higher than the impact velocity. The effect is even greater in drops, up to 10 times the impact velocity, due to the curvature of the drop/surface interface. The highest horizontal velocity does not occur for impacts normal to the surface but for angles 15 to $20^{\circ}$ from the normal. The high pressure and highspeed flow is sustained only until relief waves penetrate the column or drop. The time scale for this phenomenon is microseconds. Because the time scale is so small, its effect on the size of the area coverage or amount splashed into the air is expected to be small.

The second area of transient jet impingement literature is low-speed drop impact. Papers in this area include Engle, 1955, Ford and Furmidge, 1967, Levin and Hobbs, 1971, Elliot and Ford, 1972, Cheng, 1977a and 1977b, Stow and Stainer, 1977, Stow and Hadfield, 1981, Hinkle, 1989, Fiedler and Naber, 1989, and Chandra and Avedisian, 1991. These papers are generally concerned with raindrop behavior on impact with a solid surface for a range of technical applications. Although a finite-length two-dimensional jet is geometrically different from a spherical raindrop, there are a number of observations from these papers that may apply qualitatively to the current problem.

The final area coverage by droplet impact is given by a dynamic spread factor (DSF), which is defined as the final diameter of the wet spot divided by the initial drop diameter. Typical DSF experimental values are 3 to 4 , depending on the impact velocity and surface tension contact angle (Ford and Furmidge, 1967; Cheng, 1977). A typical method of measuring DSF is to dye the liquid and measure the resulting dye spot (Engel, 1955; Cheng, 1977a). Typical drop sizes for these studies are $1 \mathrm{~mm}$ or less, with velocities below a few meters per second. Cheng has data on small droplets $(200 \mu \mathrm{m})$ up to $28 \mathrm{~m} / \mathrm{s}$ with a DSF of 4.74 .

Attempts have been made to model the DSF. Ford and Furmidge, 1967, and Fiedler and Naber, 1989, use an integral formulation of conservation of mass and energy. Fiedler and Naber, 1989 report nearly a $40 \%$ overprediction in size by their method. The use of the 
energy equation requires that energy dissipation mechanisms (e.g., the hydraulic jump) be appropriately identified and modeled.

Neither Ford and Furmidge, 1967, nor Fiedler and Naber, 1989, take into account the significant dissipative effects of a hydraulic jump. Engel, 1955, noted the appearance of waves in the radial flow, with leading edge of the flow significantly thicker than the flow behind it. However, she could give no explanation for the flow structure. Chandra and Avedisian, 1991, note in their slow-speed drop impact experiments that "the varying film thickness may have been created by a hydraulic jump in the advancing liquid film, similar to the hydraulic jump that often occurs during normal impact of a laminar liquid jet on a flat surface." Energy dissipation across a jump can be substantial; in Chapter 11 of their book, Gerhart and Gross, 1985, give values of energy dissipation between 5 and $85 \%$ of the upstream energy, depending on the Froude number.

In addition to area coverage, data has been taken on splashing phenomena. Splashing is dependent on the drop diameter, impact velocity, and surface roughness. Stow and Stainer, 1977, quantify the effect of each of these parameters on the size distribution of splash products (i.e., drop fragments). The number of drop fragments increases with increasing surface roughness, drop impact velocity, initial drop size, and drop surface tension. Stow and Hadfield, 1981, find a splashing threshold that is size and impact velocity dependent. They find that splashing occurs for surface roughness that is significantly less than the liquid film thickness resulting from the impact. They attribute this to the surface roughness causing "an instability in the developing water sheet." They find that the onset to splashing can be correlated by

$$
\xi=R e^{\frac{1}{2}} W e
$$

where the droplet Reynolds number is defined as,

$$
R e=\frac{u d}{v}
$$

and the droplet Weber number is defined as,

$$
W e=\frac{\rho u^{2} d}{\sigma}
$$

In Equation $10, \xi$ is a parameter dependent only on the roughness of the surface. For a buffed surface, $\xi$ is higher, requiring a higher impact velocity in order to produce splashing. In Equations 11 and $12, u$ is the impingement velocity at the onset of splashing, $d$ is the diameter of the droplet, $v$ is the liquid kinematic viscosity, $\rho$ is the liquid density, and $\sigma$ is the surface tension. 
Although experiments showed the phenomenon of splashing from drop impact, no literature was found that modeled the phenomenon of splashing. The work of Stow and Hadfield, 1981, is essentially empirical. Heuristic explanations, such those as given by Levin and Hobbs, 1971, are somewhat unconvincing. The actual mechanism(s) for splashing from low-speed droplet impact have not been elucidated.

The literature reviewed above is for either a cylindrical jet or a spherical drop. Of interest in the current study is a two-dimensional jet. Literature for this geometry is limited (excluding submerged jets) to slow-speed flows or zero-speed flows (liquid-column collapse). Slow-speed flows have application to coating technology. An example of this work is given by Kistler, 1983. Column collapse has been studied with respect to dam failure. Examples of this literature include Martin and Moyce, 1952, Whitham 1955, and Hill, et al., 1980. Due to the very low speeds, the relevance of this literature to the current problem is questionable. However, it is interesting to note that column collapse on a dry surface produced no large free surface waves, whereas column collapse onto water produced a large shock-like traveling free surface wave. This effect may be related to the phenomenon of drop splashing. If the surface is smooth and dry, no splashing results; if it is wet, splashing occurs.

The final area of transient flow literature is low-speed flow downstream of a hydraulic jump. As will be discussed in the steady state literature section, the hydraulic jump separates flow into high- and low-speed regimes. The flows of interest in the current study are high-speed flows; however, at some point downstream a hydraulic jump will occur and low-speed flow will result. The unsteady solution for low-speed flow in thin layers is termed lubrication theory (for details, see Chapter 11 of Sherman, 1990). Transient solutions of the liquid layer depth and frontal radius for point and two-dimensional (line) sources are given by Didden and Maxworthy, 1982, and Huppert, 1982. Flow on an incline plane is given by Lister, 1992. All these papers have developed similarity solutions to the slow-flow problem. As a result, the radius of the front is given by an algebraic solution. For the two-dimensional line source, of interest in the current study, the distance to the leading edge from flow source (in this case the location of the hydraulic jump) is given by,

$$
x(t)=1.411 \times\left(\frac{g q^{3}}{3 v}\right)^{1 / 5} t^{(3 \alpha+1) / 5}
$$

where, $q t^{\alpha}$ defines the volumetric source, $g$ is gravity, and $v$ is the fluid viscosity. Interestingly, Huppert, 1982, indicates that surface tension does not affect the flow of liquid layer except very near the leading edge. The forces resisting the spread of the fluid are inertial and viscous.

\section{Steady state jet impingement literature}

The problem of interest in the current study is the transient impact of a finite-length, twodimensional slot jet. If the jet were infinite in length (i.e., the wing had an infinitely long 
chord), then the flow would reach a steady state. No information was found in the transient jet literature to indicate how long an impinging jet has to be to approximate a steady condition. The length of jet in the current problem is about 7 times the thickness (see forthcoming discussion of the experimental test plan).

The most common form of a steady impinging jet is the discharge of water striking a flat surface, such as a disk, with a normal impact angle. As a result of interest in this problem for cooling applications, cylindrical (axisymmetric) jet impingement has been extensively studied. As shown in Figure 13, the steady state jet impingement literature can be divided into three regimes: the inner regime, the hydraulic jump, and the outer regime.

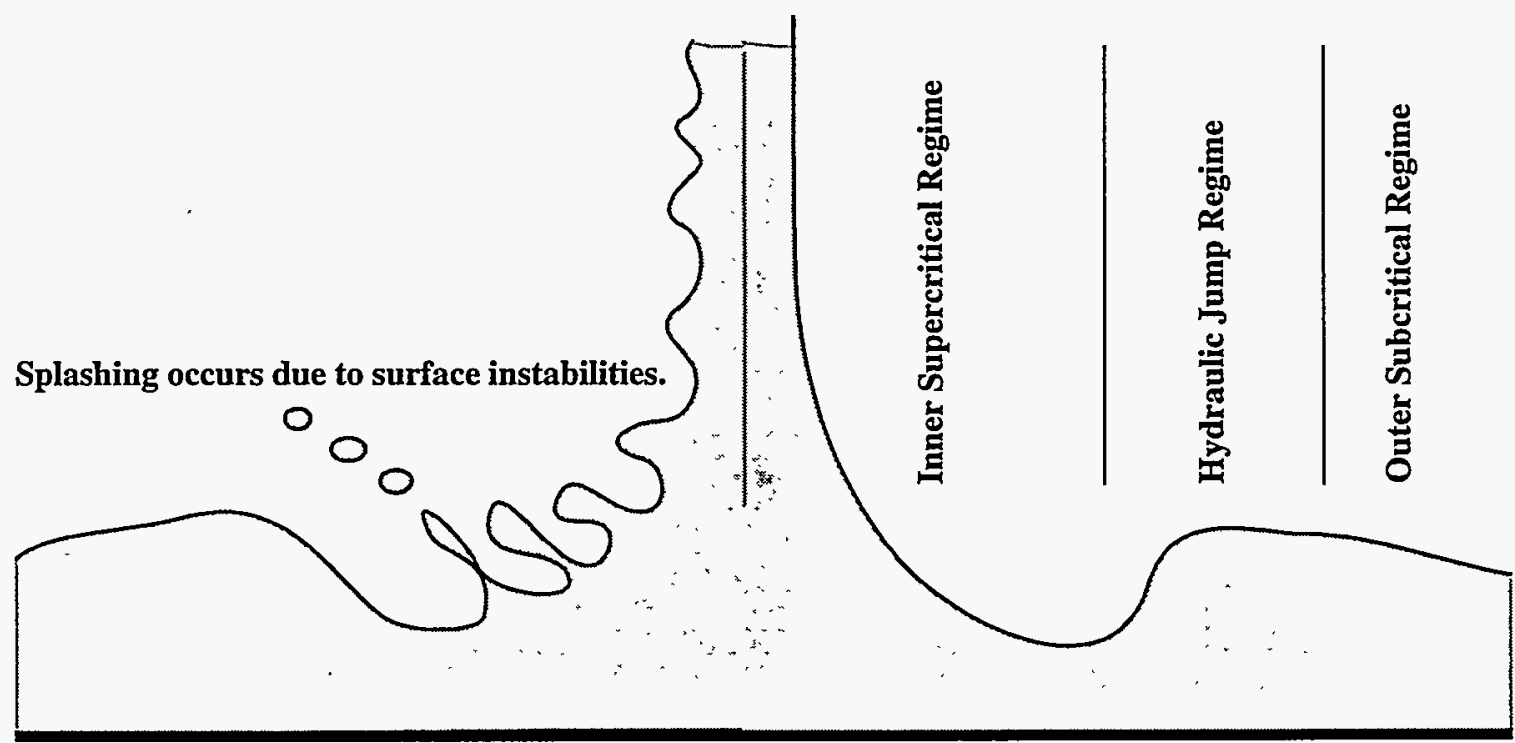

Figure 13. Steady state jet impingement. Image on the left has surface instabilities, which break off and become droplets. Image on the right has no surface instabilities, so no splashing occurs. Three flow regimes exist in steady state impingement, as shown on the right image.

The inner regime is the flow prior to the hydraulic jump. Flow in this regime is referred to as supercritical flow because the Froude number is greater than 1 . The Froude number is defined as,

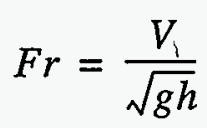

where, $V$ is the flow velocity, $g$ is gravity, and $h$ is the thickness of the liquid layer.

In free surface flow, the Froude number has an analogous meaning as the Mach number in compressible flow. The difference between the flows is that in compressible fluid flows, compressible disturbances travel at the speed of sound. In free surface flow, transverse 
amplitude disturbances (i.e., surface waves) travel at the gravity wave velocity given by the denominator in Equation 11. For the inner regime, the flow velocity is higher than the gravity wave velocity, and therefore, downstream conditions cannot influence upstream conditions. The expected depth of the liquid in this regime for aircraft impacts is expected to be on the order of, at most, tenths of meters. Therefore, the gravity wave velocity for the current problem is quite low. From the denominator in Equation 11, the gravity wave velocity is on the order of meters per second. In reality, the inner regime ends in a hydraulic jump of substantial strength, i.e., $F r>1$.

Splashing mechanisms in the inner regime have recently been studied by Errico, 1986, Lienhard, et al., 1992, and Bhunia and Lienhard, 1994a and 1994b. The mechanism for splashing in this regime is the pinching off of free surface perturbations on the impinging jet as shown on the left side of Figure 13. If the free surface of the impinging jet is wavy, the waves grow in amplitude as the free surface turns the corner from vertical to horizontal flow. These large-amplitude waves break off as free droplets in the same manner that liquid sheets break up. Errico, 1986, notes that there is no splashing whatsoever from a smooth jet, even at higher Reynolds numbers. However, the onset of splashing is given by

$$
\frac{a}{d}=R e^{\frac{1}{2}} W e
$$

where $\mathrm{a} / \mathrm{d}$ is the amplitude of the surface disturbance. In Equation 15, the Reynolds number for a round jet is defined as in Equation 11 and the Weber number is defined as in Equation 12 where $d$ is the diameter of the jet.

Comparing Equation 10 and Equation 15, it is seen that the impact velocity at the onset of splashing, whether from a single drop or from a steady state jet, is given by a roughness parameter that determines the amplitude of the disturbance of the free surface on the lefthand side of each equation. The right-hand side of each equation is given to be the squareroot of the Reynolds number times the Weber number. The fact that these equations have similar forms indicates that the mechanism for splashing is the same in each instance, i.e., disturbances in the free surface of the radially expanding liquid result in splashing.

However, it should be cautioned that both Equations 10 and 15 are empirically derived and that Bhunia and Lienhard, 1994a, correlate their data with a different empirical relation.

The fractional amount of fluid in the turbulent jet that is splashed on impact has increased as the scale and velocity of the experiments has increased. The earlier papers by Errico, 1986, and Lienhard, et al., 1992, present data indicating that less than 7\% and 40\%, respectively, of the incoming mass can be splashed. However, the later paper by Bhunia and Lienhard, 1994a, shows data with up to $80 \%$ of the impinging jet being splashed. The amount that can be splashed is a function of the Weber number and the surface disturbance amplitude. Since even the jets used by Bhunia and Lienhard are small laboratory-scale jets, there is nothing to preclude $100 \%$ splashing at very high Weber numbers, which can exist during an aircraft crash. 
The size of the inner regime is determined by the location of the hydraulic jump. Hydraulic jumps are of interest in that they can result in boundary layer separation. Flow separation away from a surface is one possible mechanism for splashing in addition to the growth and separation of free surface disturbances. The hydraulic jumps produced by jet impingement are different than those found in traditional civil engineering applications. Studies have been conducted for round, axisymmetric, jet impingement by Tani, 1948, Olsson and Turkdogan, 1966, Nakoryakov, et al.,1978, Craik, et al., 1981, and Thomas, et al., 1991. In all cases except Thomas, et al., 1991, the high-speed flow separates and flows over the top of the low-speed flow as shown in Figure 14a. Boundary layer separation occurs under the jump, which causes the high-speed flow to separate.

The typical jump found in civil engineering flows has the high-speed flow undershooting a roller as shown in Figure 14b. The difference between that and the hydraulic jump formed

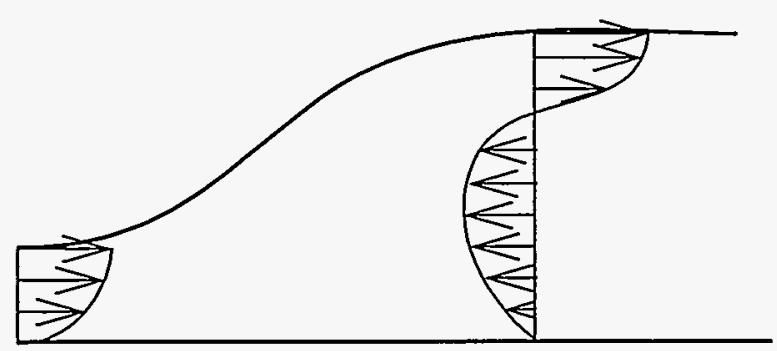

(a)

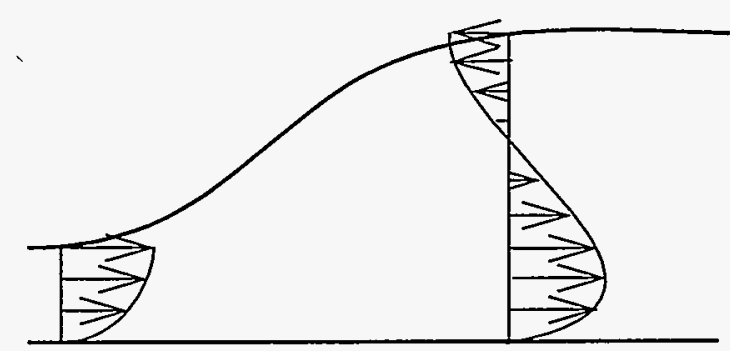

(b)

Figure 14. Hydraulic jumps. a) Typical jump found in jet impingement, with the highspeed flow separating and flowing over the top of the low-speed flow. b) Typical jump found in a civil engineering application, with the high-speed flow undershooting the lowspeed flow.

by a round impinging jet is not due solely to the circular nature of the jump. Civil engineering applications include radial stilling basins. Jumps formed in these basins show the high-speed flow undershooting a roller. Examples of papers include Koloseus and Ahmad, 1969, Mehrotra, 1974, Nettleton and McCorquodale, 1983, and Khalifa and McCorquodale, 1992. Khalifa and McCorquodale, 1992, have velocity measurements clearly showing the high-speed flow undershooting a roller as in Figure 14b.

The boundary layer separation at the hydraulic jump is due to a viscous-inviscid interaction, according to Gajjar and Smith, 1983, and Bowles and Smith, 1992. Basically, flow separation occurs because there is little momentum in the viscous boundary layer. At the jump there is an adverse pressure gradient formed resulting from an increase in hydrostatic head due to the thicker fluid layer on the downstream side of the jump. If the adverse pressure gradient is sufficiently high, then the flow near the wall, which has little momentum, will reverse. This flow reversal near the wall will cause the main flow to separate, and the high-speed fluid will flow over the top of the lower-speed fluid. 
However, it should be noted that the terms high-speed and low-speed are relative. As noted earlier, the hydraulic jump can form for $F r>1$, so that the velocity of the high-speed flow could be as low as a few meters per second. For velocities this low, even if the flow were to splash, the splash products would not travel very far before falling back to the surface from which they separated.

Downstream of the hydraulic jump is the outer subcritical regime, as shown in Figure 14. The steady state solution in this regime is not of interest to the current study, but the slow, transient growth of this regime is. As noted in the discussion of transient jet impingement literature, solutions for creeping flow for two-dimensional (line) sources are given by Didden and Maxworthy, 1982, and Huppert, 1982. The thickness of the liquid layer is determined by the resistance presented to the incoming flow. The resistance is due to inertia of the existing fluid and drag on the surface.

The three steady-state flow regimes are coupled. Upstream of the jump, the flow is supercritical and is affected only by the inflow conditions. Downstream of the jump, the flow is subcritical and is affected by the downstream conditions. The location of the jump is dependent on both the upstream conditions (velocity profiles) and the downstream conditions (liquid-layer thickness).

\section{Applicability of existing numerical methods}

To numerically solve the current problem, a numerical method must have the capability for resolving transient, turbulent, two-dimensional viscous flows with free surfaces. To predict the area covered by the fuel, the method must also be able to predict the splashing phenomena, either from a hydraulic jump or from separation of free surface perturbations. Further, the aerodynamic breakup and coalescence of droplets would have to be tracked to ensure that the splash products did not re-impinge a short distance downstream of the separation point. No numerical code can completely resolve the complexities of the problem within a realistic computational time.

Transient multidimensional flow codes that resolve free surfaces have undergone substantial development along two lines: finite difference and finite element. Each type has advantages and disadvantages. In general, finite difference codes run faster for simpler geometries but become very slow for more complex geometries. Finite difference codes require a very large number of grid points to resolve complex geometry. Finite element codes are more adept at meshing complex geometries but are, in general, slower running for simple geometries.

Current commercially available codes that resolve free surfaces have fixed rather than adaptive meshes. This means that the entire computational domain is meshed in advance and liquid flows into the domain. The accuracy of the free surface is determined by the mesh density and the tracking algorithm. One accepted tracking algorithm is the volumeof-fluid (VOF) method, in which fluid volume fraction is advected as a step function. An example of a commercially available finite difference code using the VOF method is Flow- 
$3 D^{*}$. One example of a finite element code using the VOF method is ProCAST ${ }^{\dagger}$. Flow-3D is a general-purpose free-surface flow code and has been applied (according to Flow Science personnel) to channel flows with some evidence of being able to resolve hydraulic jumps. ProCAST has been developed for casting applications.

Transient codes identified in the literature include finite difference and finite element codes. Brandeis and Kansa, 1983, use a finite difference code with flux corrected transport scheme to limit numerical diffusion to solve a column-collapse problem. Sweeney and Nau, 1980, and Sweeney, 1980, describe a finite difference code (MIXWEL) for solving free-surface flows with vertically integrated Navier-Stokes equations. Soulaimani, et al., 1986, describe a transient, three-dimensional finite element algorithm for free-surface flow.

Numerical solutions of the impinging jet problem reported in the literature have been limited to steady state solutions. Examples include Hunt, 1989, Gribben and Hunt, 1990, and Rahman, et al., 1992. Gribben and Hunt, 1990, compare a numerical technique with the experimental data for the supercritical inner flow regime. Rahman, et al, 1992 culminate a series of papers on a technique that matches the inner supercritical and outer subcritical regimes in a hydraulic jump.

No numerical predictions of the breakup of a liquid jet into droplets are known to the author. The exception to this is that Flow-3D can be used to predict the breakup of an ink jet stream into droplets if sufficient grid resolution is provided. In the problem of interest, the global length scales to be modeled are on the order of meters. To resolve drop breakup, the grid would have to resolve sub-millimeter size drops. For a three-dimensional solution, this would mean that more than $10^{9}$ computational cells would be required. This is beyond the capability of any existing computer.

\section{Applicability of existing literature to model development}

The literature search uncovered no correlations, data, or numerical studies that could be used to predict splashing of finite-length impinging jets. However, the literature does provide some insight into the mechanisms involved in jet impingement. In general, the literature brackets the problem of interest, i.e., finite-length, two-dimensional jet impingement. The droplet impact literature can be thought of (at least qualitatively) as the impact of a jet with a length-to-diameter ratio of unity. The steady state jet impingement literature treats the impact of a jet with a length-to-diameter ratio of infinity. The current problem is a jet with a length-to-thickness ratio of about 7. It is unknown whether a finite jet with a length-to-thickness ratio of about 7 is closer to unity or infinity in character.

For those mechanisms identified in the literature that are common to both transient drop impact literature and steady state jet impingement literature, one can reasonably expect those same mechanisms to play a role in the impingement of finite-length jets. For example,

*Available from Flow Sciences Inc., 1325 Trinity Drive, Los Alamos, NM 87544.

$\dagger$ Available from Universal Energy Systems, 4401 Dayton-Xenia Rd., Dayton, OH 45459. 
both hydraulic jumps and the separation of free surface perturbations appear to be common to both the transient droplet impact literature and the steady state jet impingement literature. It can therefore be expected that both will exist in the current problem. The area covered by a continuous liquid film will likely be determined by how much is splashed, by the energy dissipation due to viscous drag in both the super- and sub-critical regimes, and by the hydraulic jump.

Although the literature provides some insight into the controlling mechanisms, it does not sufficiently characterize the phenomenon of transient, two-dimensional jet impingement to the degree necessary to build a model from the literature alone. The literature does show that the phenomenon of jet impingement, even steady state impingement, is very complex. Nondimensional numbers affecting the flow include $\operatorname{Re}, W e$, and $\operatorname{Fr}$ (Equations 11, 12, and 14). Unfortunately, transient numerical models that may have the capability to model this complex flow have not been validated for this problem.

From these observations, two conclusions are drawn. First, it will be necessary to generate experimental data for transient, two-dimensional liquid jets in order to build the splash model. Second, because the problem is so complex, the test series should focus on measuring 1) the continuously wetted area and 2) the amount of liquid in that area. This approach parallels that used in the droplet impact literature for the development of the dynamic spread factor, DSF. The DSF was defined for use in area coverage correlations even though the physics controlling the DSF is not fully understood. Similarly, experimental data will be obtained to build the splash model and develop correlations for a WSSA, although it is unlikely that the controlling physics will be identified due to the complexity of the problem. 


\section{Phenomenological Testing to Provide Data for Model Development}

\section{Experimental Test Plan}

A test plan was developed to provide data to fill voids in the state of knowledge required for development of the splash model. A test series was conducted to determine the fuel distribution characteristics due to impact on a hard, flat, concrete surface.The test series was designed to measure three important parameters: the area covered by fuel from the impinging jet, the amount of fuel in that area, and the location of that area relative to the impact line. The objective of the test series was to determine these three variables as functions of important WSSA scenario variables, namely, 1) impact velocity, 2) impact angle, and 3) fuel mass at impact.

For the first dependent variable, area coverage, $A$, it was anticipated that the demarkation of a continuous wet area for liquid pooling would be clearly visible. From this, dynamic spread factor (DSF) could be defined that would characterize the splash from the finitelength, two-dimensional, slot jet in a manner consistent with droplet impact studies. However, as will be discussed in the results section, the splashing phenomenon was sufficiently complex that this approach was abandoned.

Instead, the decision was made to record area coverage for different zones according to the amount of liquid within a zone. The three zones that were defined represent 1) the area covered by a continuous liquid film, 2) the area with discontinuous, but significant, droplet coverage, and 3) the area with insignificant, but still measurable, droplet coverage. The choice of the levels separating the three regimes was somewhat arbitrary. The first level was chosen to be $1 \mathrm{~mm}$, consistent with the minimum thickness of a continuous film of liquid. The second level was chosen to be $0.1 \mathrm{~mm}$. This level corresponds to a zone that has droplets covering about $10 \%$ of its area, with height of the liquid droplets taken to be about $1 \mathrm{~mm}$. The actual minimum continuous film thickness and droplet heights are dependent on the fuel/air/surface surface tensions and therefore will vary among fuels and surfaces. However, for purposes of this test series, the area coverage was recorded as these levels: $1.0 \mathrm{~mm},>0.1 \mathrm{~mm}$, and $>0.0 \mathrm{~mm}$.

The second variable of interest is the amount of fuel contained in the wetted area. A residual or pooled mass fraction, $Y$, is determined by measuring the amount of fuel in the wet area divided by the total fuel in the jet. This mass fraction is calculated for each of the three area coverage zones defined above.

The third variable of interest is the location of the pool relative to the point of impact. This distance, $X$, is determined by taking the sum of the fuel mass for each of the 
measurement areas times the axial distance to the point of impact and dividing by the total fuel mass. This distance is calculated for each of the three area coverage zones defined above.

The three dependent variables $A, Y$, and $X$ are functions of the three independent variables, impact angle, $\alpha$, impact velocity, $V$, and mass at impact, $M_{j e t}$. Ideally, a test series would be conducted at full scale to avoid scaling issues. The actual test series was conducted at about $1 / 9$ linear scale on a $1 / 4$ span wing section of a C-141. These scales were chosen to take advantage of an intermediate-scale test apparatus that will be discussed in the next section.

The three levels of impact angle chosen were $22.5^{\circ}, 45^{\circ}$, and $67.5^{\circ}$. These levels represent a broad spectrum of crash scenarios. Four impact velocities were chosen: $12,16,61$, and $91 \mathrm{~m} / \mathrm{s}$. The higher two impact velocities were chosen to represent speeds above the value for wing disintegration given by Wittlin, 1987. Because the actual speed at which a C-141 wing will disintegrate upon impact is not known with certainty, two lower impact velocities were also chosen.

\section{Test Apparatus}

The discussion of the test apparatus is divided into three sections: 1) test setup, 2) test item (the wing section), and 3 ) diagnostics.

\section{Test setup}

Intermediate-scale tests were conducted at the Rocket Launch Facility in Technical Area III at Sandia National Laboratories in Albuquerque, New Mexico. An overall view of the facility is shown in Figure 15. The horizontal 20-m-long steel I-beam shown in Figure 15 can be rotated upward about the pivot on its right end. The beam can be rotated from horizontal to about $70^{\circ}$ from the horizontal. A carriage that rides on the beam was used to propel the test item down the beam.

The width of the test item was limited by the distance $(2.1 \mathrm{~m})$ between the uprights used to raise and lower the beam about its pivot point. The pivot point of the beam was positioned $0.5 \mathrm{~m}$ above the ground. This distance was chosen to minimize the breakup of the liquid jet caused by drag as the liquid jet travels in the air prior to impact with the concrete target.

For economic reasons, the same carriage and test item were reused for the entire test series. This approach required deceleration of the carriage on the I-beam at $g$ levels that could be tolerated by the carriage and test item. The deceleration distance required minimization for two reasons. First, the beam is of fixed length, so the section of the beam used for deceleration was not available for acceleration, thereby fixing the top speed of the carriage. Second, if the deceleration section were long, the distance the liquid jet would have to fly through the air before impacting the ground would also be long. The reason is that it is 


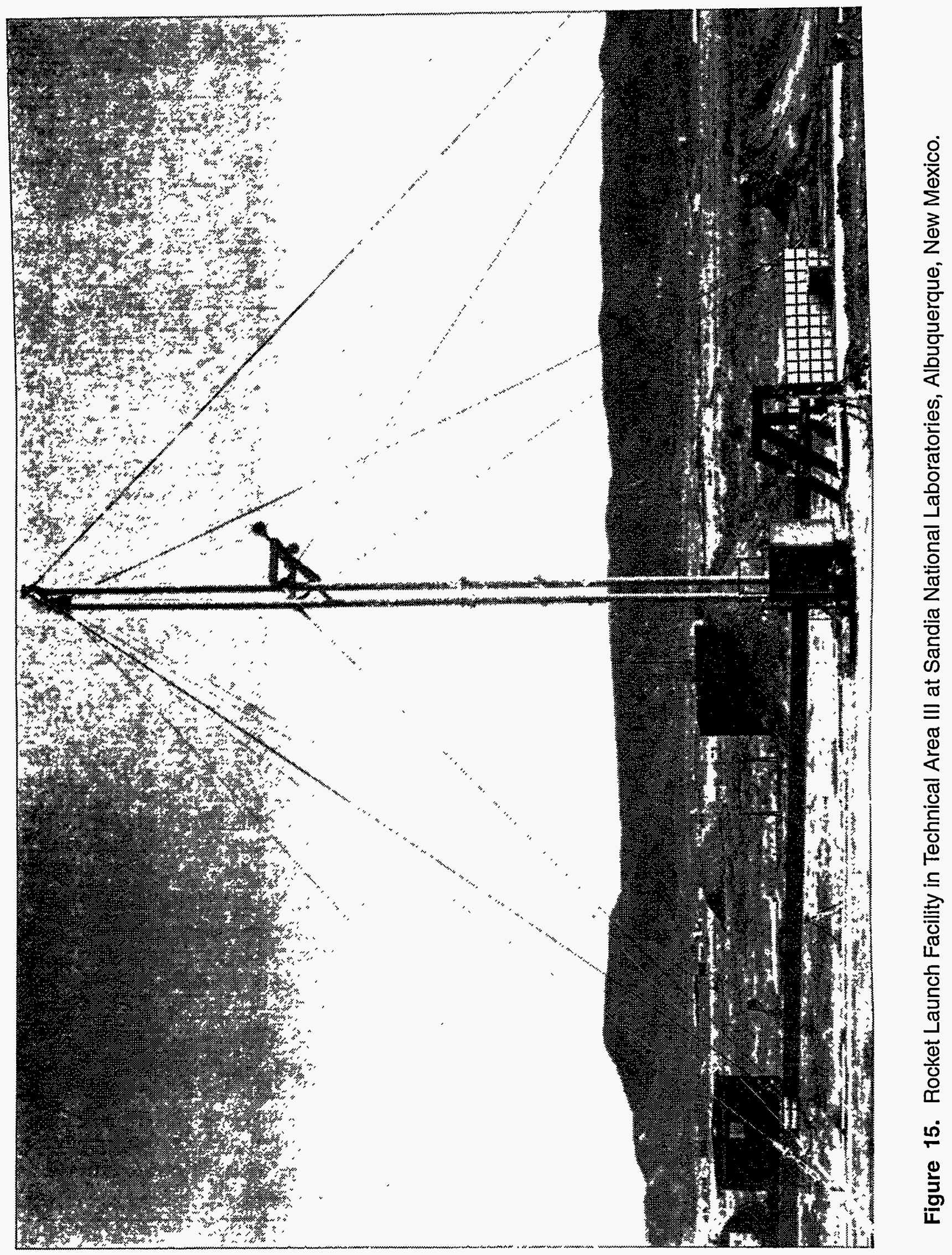


necessary to release the liquid at the maximum speed of the carriage, which will occur at the start of the deceleration section. Therefore, the longer the deceleration section, the longer the jet has to travel through the air before reaching the impact line. Tikhomirov, et al., 1992, have shown that at the speeds involved in the present study, axisymmetric jets will break up in 50 to 100 diameters. In the current case the jet is two-dimensional; but based on its thickness, it can be expected to be a spray with no continuous liquid core after traveling about 3 to $6 \mathrm{~m}$ through air.

The deceleration requirements limited the overall weight of the carriage and test item. Loaded with two rocket motors, the carriage and test item with simulated fuel weighed about $235 \mathrm{~kg}$. Crushable honeycomb blocks were used to decelerate the carriage and test item. Sets of blocks, each $0.15 \mathrm{~m}$ long, were positioned on each side of the I-beam as shown in Figure 16. The frontal area of the blocks was about $0.09 \mathrm{~m}^{2}$. The honeycomb used was 5052 aluminum alloy, $3.18 \mathrm{~mm}$ cell size, with an apparent density of $98 \mathrm{~kg} / \mathrm{m}^{3}$. The nominal crush pressure of the honeycomb is $5.5 \mathrm{MN} / \mathrm{m}^{2}$. Spacers were used between the blocks to allow for the air trapped within the honeycomb to escape without fracturing the honeycomb. The setup shown in Figure 16 was for the $91 \mathrm{~m} / \mathrm{s}$ tests, which required 2.25 $\mathrm{m}$ of honeycomb to decelerate the carriage and test item. For the $61 \mathrm{~m} / \mathrm{s}$ tests, $0.9 \mathrm{~m}$ of honeycomb was required. For the lower-speed tests, only $0.15 \mathrm{~m}$ of honeycomb was required.

The carriage and wing were accelerated by gravity for the nominally 12 and $16 \mathrm{~m} / \mathrm{s}$ tests. One Zuni rocket motor was used for the $61 \mathrm{~m} / \mathrm{s}$ tests. Two were used for the $91 \mathrm{~m} / \mathrm{s}$ tests. The Zuni rocket motors are $0.127 \mathrm{~m}$ in diameter; they have a peak thrust of $27.5 \mathrm{kN}$ and a duration of 1.3 seconds.

The Rocket Launch Facility is positioned on top of a large concrete pad. Forward of the impact line, the pad is $4.5 \mathrm{~m}$ wide by about $40 \mathrm{~m}$ long. Aft of the impact line, the pad is 3.7 $\mathrm{m}$ wide by about $21 \mathrm{~m}$ long. The pad is flat and horizontal except for a gradual increase in elevation aft of the impact line from about $5 \mathrm{~m}$ to $21 \mathrm{~m}$. The pad is segmented, and there are slight imperfections at several of the joints-most noticeably at a point about $2 \mathrm{~m}$ forward of the impact line where there is a drop of approximately $1 \mathrm{~cm}$. It was also determined, based on observations of water motion on the pad, that the concrete pad segment in the impact zone has a slight tilt downward to the left as viewed from an observer on the wing. Both of these imperfections are noticeable in the data collected.

The concrete pad was sealed with white latex paint to minimize absorption of liquid during the collection period after the test. The white paint also improved the contrast between the pad and the jet, enhancing overhead cinematography.

\section{Test item}

The test item was a nominal $1 / 9$ scale model wing section of a C-141. This study assigns for the C-141 fuel tanks a rectangular box with dimensions proportional to the thickness: chord: span of the actual C-141 wing tanks. The baseline proportions for fully loaded wing 


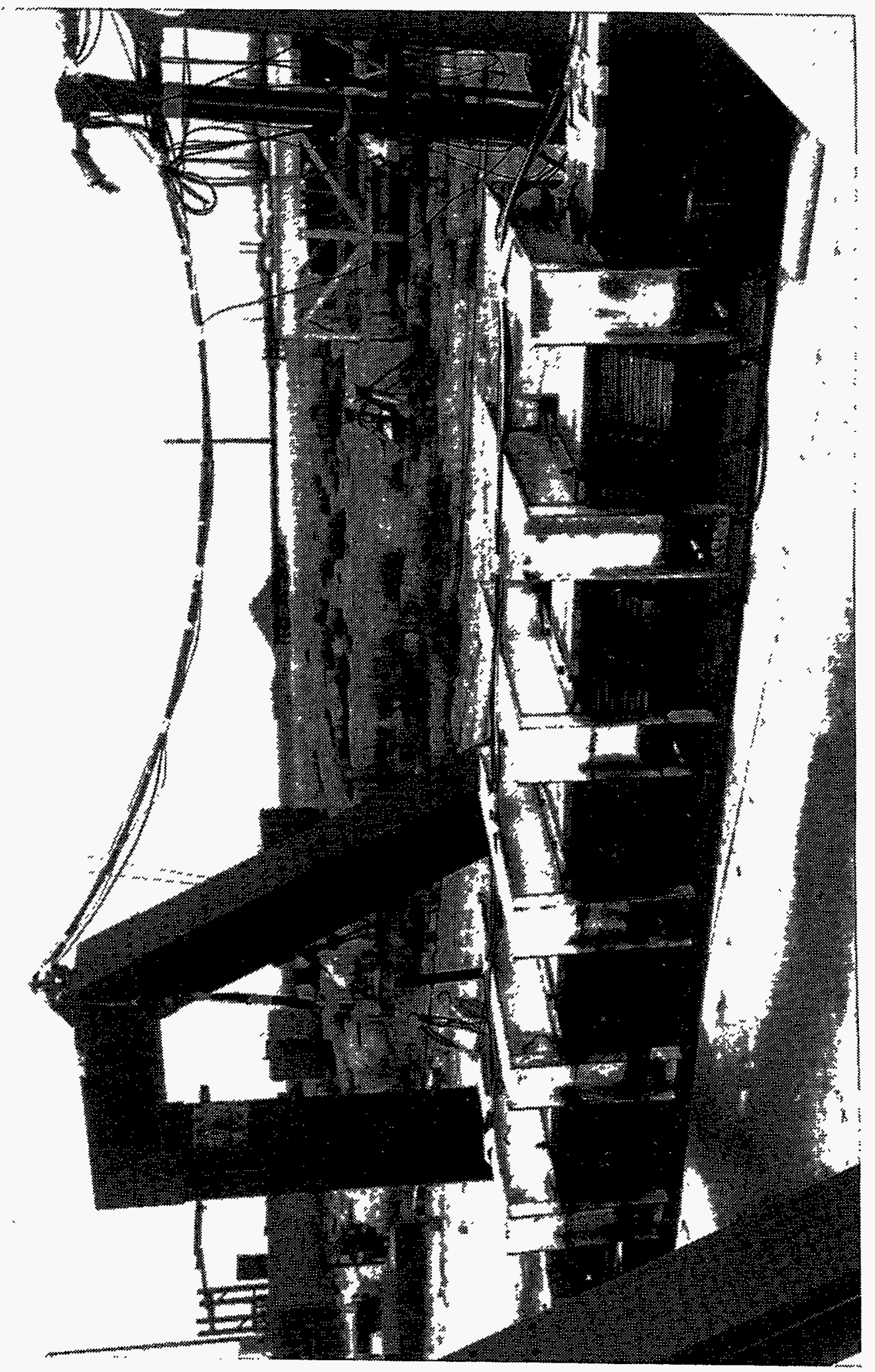

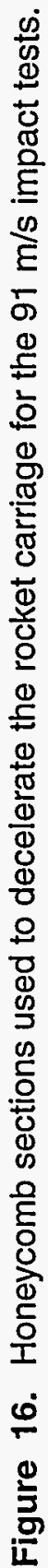


tanks were determined to be $0.49 \mathrm{~m}: 3.52 \mathrm{~m}: 51.0 \mathrm{~m}$ (thickness : chord : span). The rationale for these values is given in Appendix A. In terms of the thickness of the jet, $T$, the ratios are $T: 7.2 T: 104 T$.

The test item could not have a span greater than $2.1 \mathrm{~m}$ and still fit between the pivot supports. If a full-span wing were used, then the result would be a $1 / 24$ scale model. For this reason, a 1/4 span of the wing was used, thus allowing for a larger-scale model that was still within the weight constraint for deceleration. The as-built dimensions of the wing section were $0.062 \mathrm{~m}: 0.448 \mathrm{~m}: 1.62 \mathrm{~m}$ (thickness : chord : span), which corresponds to a scale factor of $1 / 7.89$ compared to the fully loaded C-141 wing. Figure 17 and Figure 18 show the carriage and wing section.

The as-built dimensions changed slightly for the as-tested wing. During the first three tests, which were used for diagnostic development, the deceleration loads on the wing section resulted in inward bowing of its lower panel, thus reducing the frontal area of the wing midspan. Two attempts were made to reduce the bowing. One attempt was to reduce the vacuum loads created in the wing by the exiting liquid. The second attempt was to stiffen the front of the wing along the span. Both attempts failed. The deformation was permanent but did not increase during the course of the tests. For all tests, the average thickness of the jet was $0.054 \mathrm{~m} \pm 0.008 \mathrm{~m}$. The as-tested wing dimensions were $0.054 \mathrm{~m}: 0.447 \mathrm{~m}: 1.613$ $\mathrm{m}$ (thickness : chord : span), which corresponds to a $T: 8.3 T: 30 T$ ratio and results in a scale factor of $1 / 9.1$ for the as-tested wing section.

Water was used as a simulant for JP-4 jet fuel in the tests. Using water simplified the environmental and safety considerations associated with the testing. A small amount of red food coloring was used to enhance the visibility of the liquid jet. The total water mass for each test was $38.7 \mathrm{~kg}$. This amount was determined by draining a full wing and weighing the resultant mass at the end of the test series.

\section{Diagnostics}

Diagnostics for the tests consisted of high-speed cinematography and mass distribution measurements. Four motion picture cameras were used in each test in addition to standard real-time video. Three of the motion picture cameras were Photosonics 1PL, pin registered cameras, running at 400 frames per second (fps); the fourth was a Red Lakes, Hycam II, shuttered rotating-prism camera, running at $2000 \mathrm{fps}$. One of the $400 \mathrm{fps}$ cameras had a narrow field of view perpendicular to the direction of travel and covered the region between the wing impact with the honeycomb and liquid jet impact with the ground. The second was located at the forward end of the pad with an axial view of the forward splash zone. The third was located overhead of the pad looking downward. Its field of view included the region from the impact line to about $5 \mathrm{~m}$ forward of the impact line. The $2000 \mathrm{fps}$ camera was located $45^{\circ}$ off axis, with a narrow field of view on the impact line. Off-axis placement of this camera was necessary because the uprights holding the I-beam pivot point blocked the perpendicular view for some impact angles. 


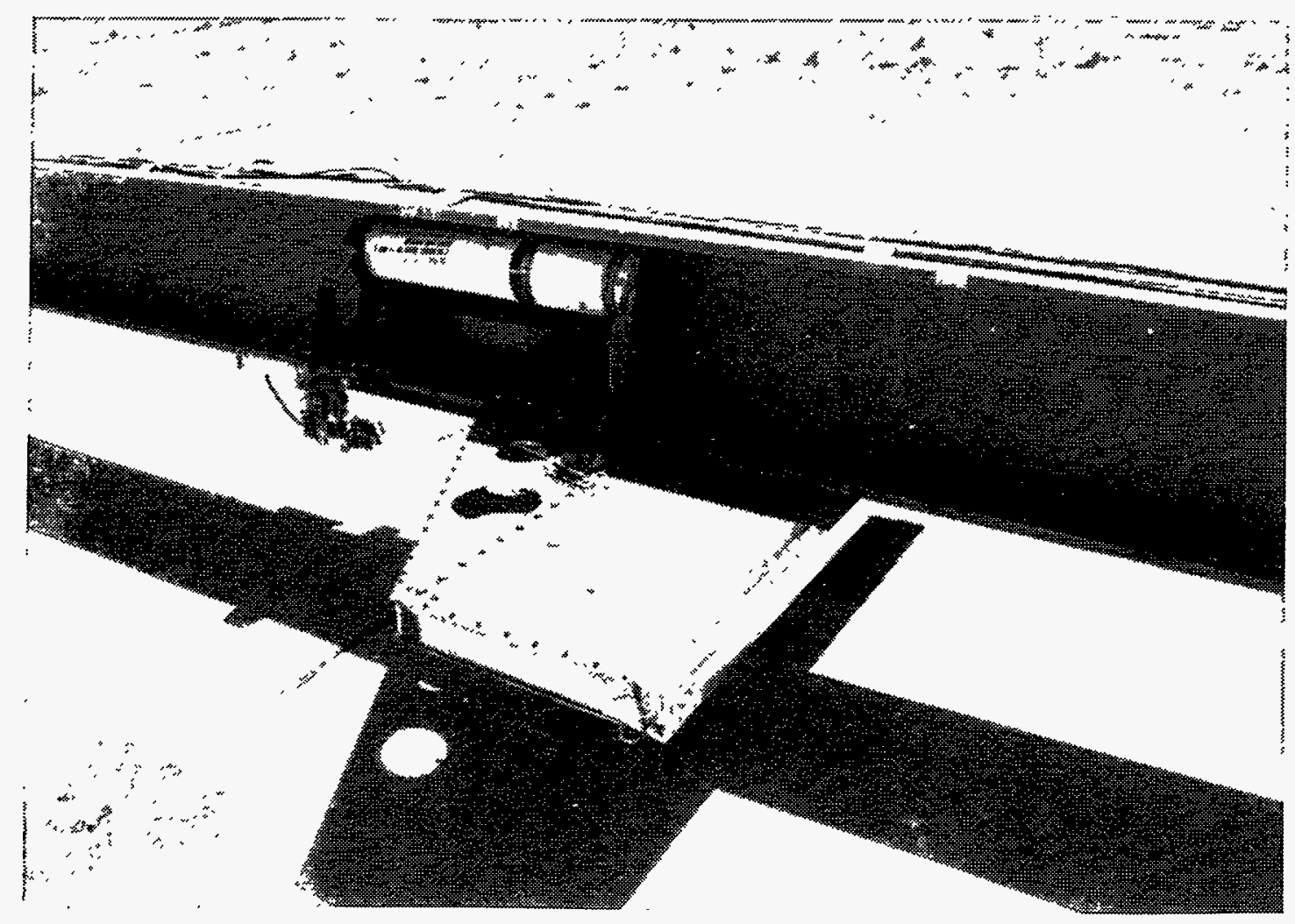

(a)

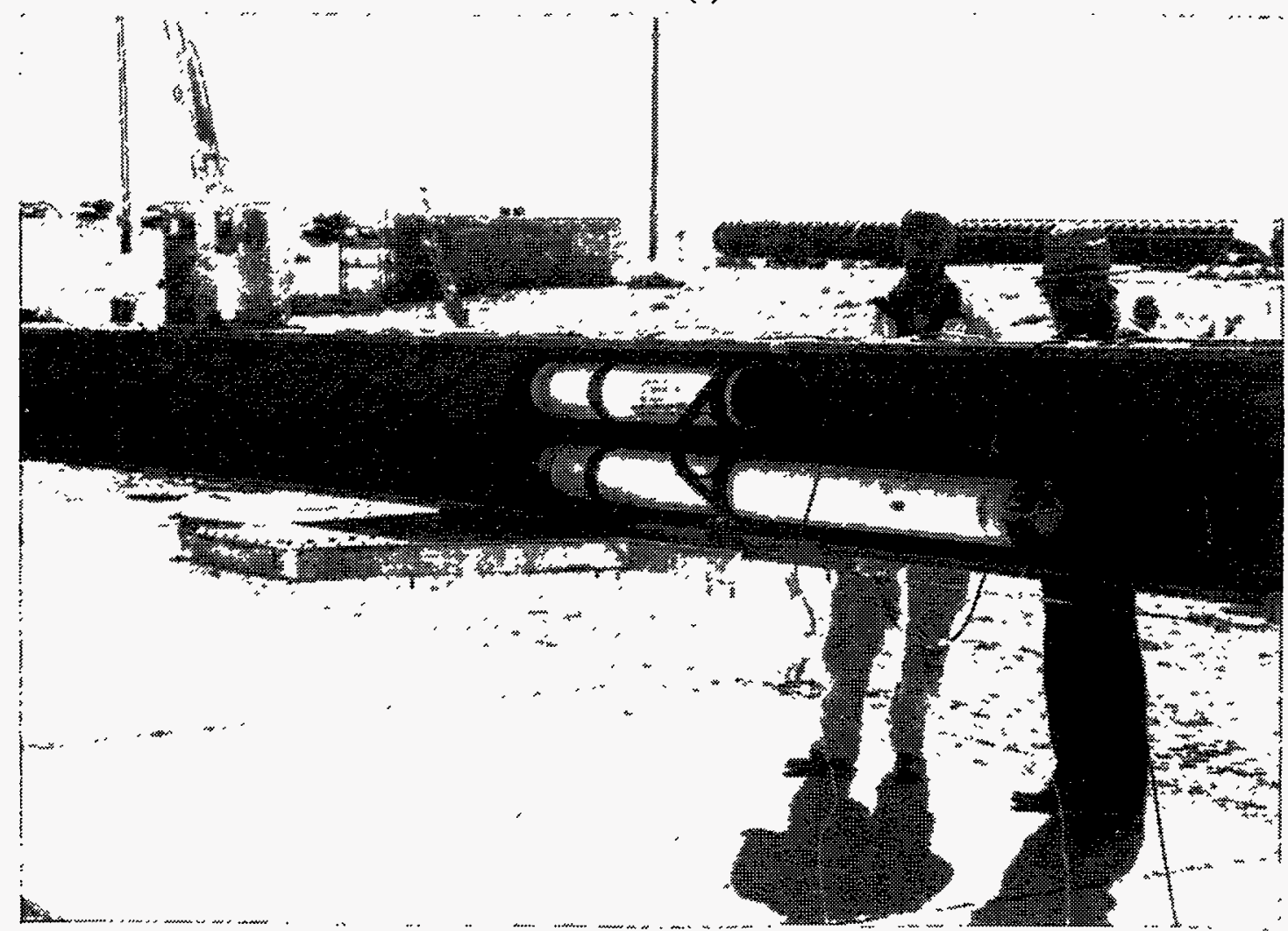

(b)

Figure 17. Wing assembly. (a) Front view showing the aluminum foil face. (b) Rear view showing a Zuni rocket motor. Note that in both (a) and (b) the short cylinders are not rocket motors, but old casings that increased the structural rigidity of the carriage. 


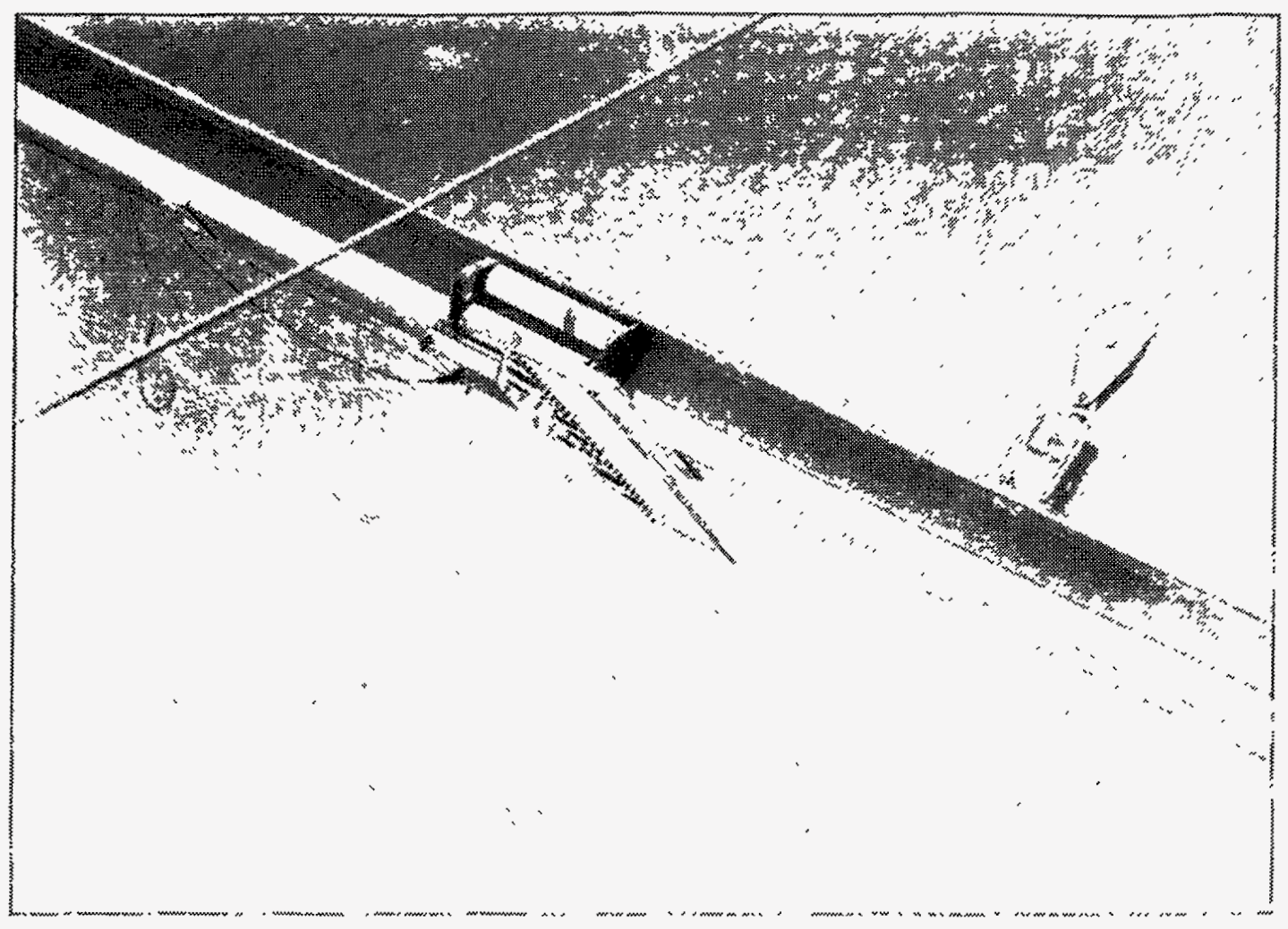

(a)

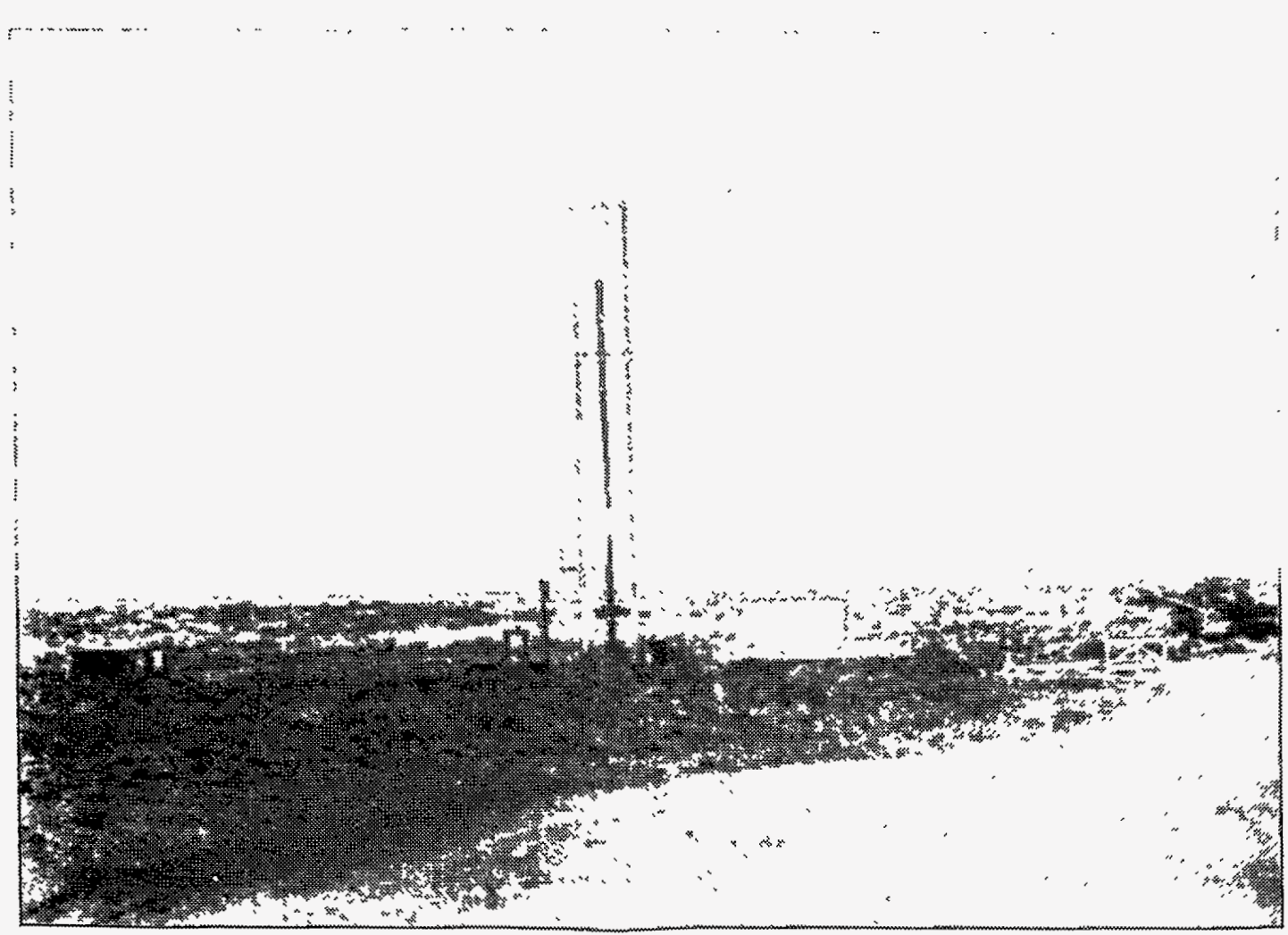

(b)

Figure 18. Wing at launch time. (a) Elevated on the l-beam just prior to launch. (b) Accelerating down the rail. 
In addition to the cinematography, detailed mass distribution measurements were made for each test. The concrete test pad was divided into measurement zones, and between 116 and 174 measurement zones were used for each test. The mass of liquid remaining in each measurement zone after a test was collected and weighed. For reporting purposes, the mass per measurement zone was converted to an average liquid-layer thickness over the corresponding measurement zone.

The liquid mass was collected in sections using cost-effective, absorptive commercial towels. The towels provided a wide and flexible measurement range. They were able to absorb up to 5 times their mass and could easily be folded double or triple thickness to expand the measurement range to heavier masses. Doubling and tripling was used for the lower impact velocity tests near the impact line where pooling did occur. Two sizes of towels were used: $0.279 \mathrm{~m}$ by $1.118 \mathrm{~m}$, and $0.559 \mathrm{~m}$ by $1.118 \mathrm{~m}$. The measurement uncertainty in weighing the towels was dominated by the change in towel mass over the test series, which was typically less than 10 grams for the larger towels. The change in mass was typically an increase due to use of the towels in the field environment, i.e., they got dirty. This converts to a measurement uncertainty in the average liquid-layer thickness of less than $0.02 \mathrm{~mm}$, well within the needs of the study.

For the higher impact velocity tests, spray from the tests exceeded the range covered by the towels. Although it was not necessary to collect this overspray to satisfy test objectives, large areas were covered with large cotton panels to determine the mass distribution of the atomized spray. After a test, the large cotton panels were individually collected and weighed. Using this technique, virtually all the mass that was not evaporated in flight was recovered. No large areas containing significant amounts of spray were found that were not collected, with the possible exception of test \#14 $\left(22.5^{\circ}, 91 \mathrm{~m} / \mathrm{s}\right)$ in which the wind blew some of the fine mist off to the left side (as viewed from the wing) of the pad.

Figure 19 shows the technique for the measurements of liquid mass. First, towels were laid out in each measurement zone, as shown in Figure 19a. Then a waterproof, vinyl test bed cover with velcro strips was rolled over the towels, as in Figure 19b. The velcro strips on the test bed cover served to attach the towels to the cover. The test bed cover was then rolled up with the towels, as shown in Figure 19c. Rolling the towels up in the test bed covers cleared the impact zone so the liquid jet could impact the hard concrete surface without interference from the towels. Only towels in the area around the feet of the uprights used to support the I-beam pivot could not be rolled up. In those areas the towels were taped to the concrete.

For each test, two test bed covers were used, one aft of the impact line and one forward of the impact line. For all tests, the rolled-up test bed cover aft of the impact line was located about $4.5 \mathrm{~m}$ from the impact line at the time of impact. The rolled-up test bed cover forward of the impact line was located, at the time of impact, about $11 \mathrm{~m}$ forward of the impact line for the $12 \mathrm{~m} / \mathrm{s}$ and $16 \mathrm{~m} / \mathrm{s}$ tests, and about $18 \mathrm{~m}$ forward of the impact line for the $61 \mathrm{~m} / \mathrm{s}$ and $91 \mathrm{~m} / \mathrm{s}$ tests. 


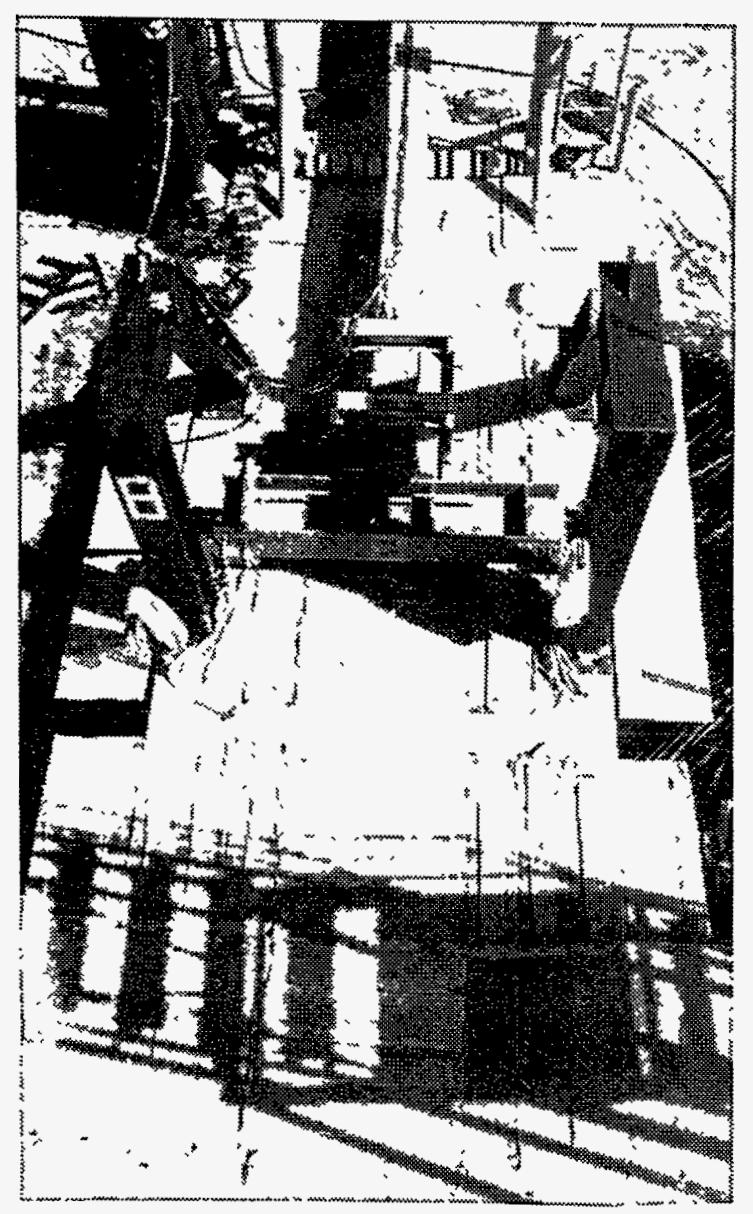

(a)

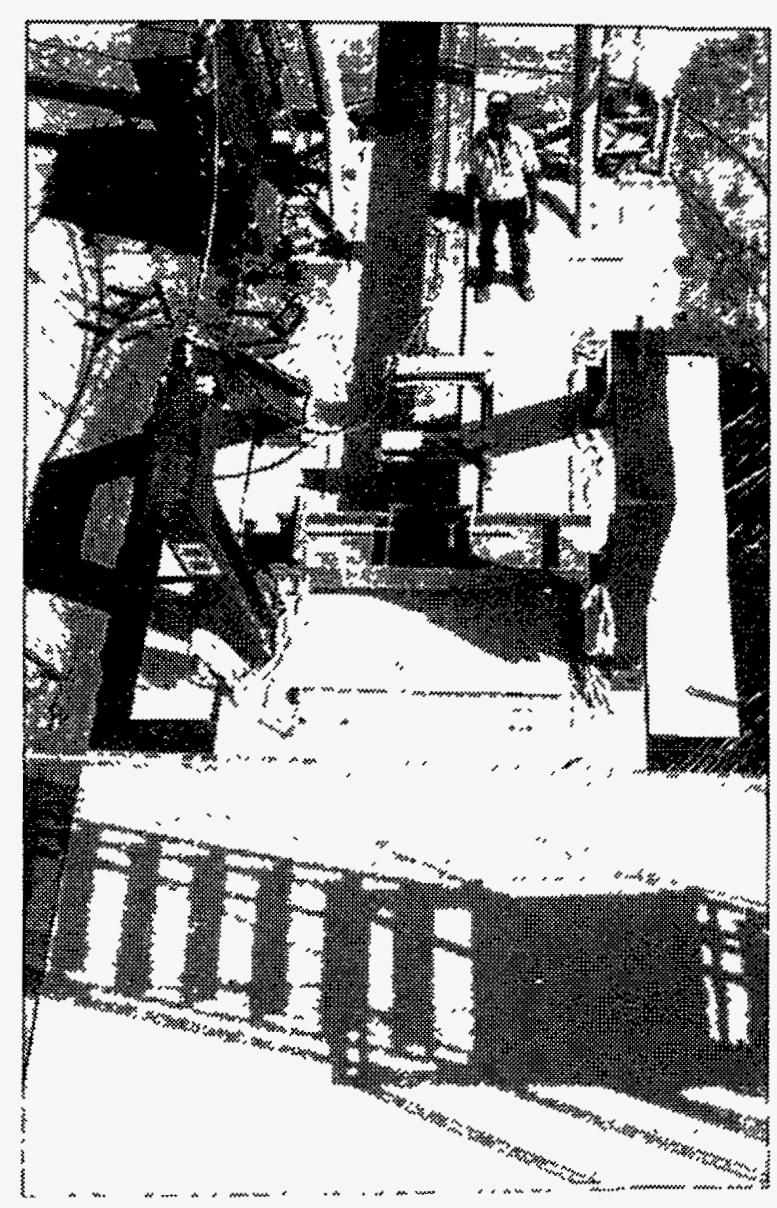

(b)

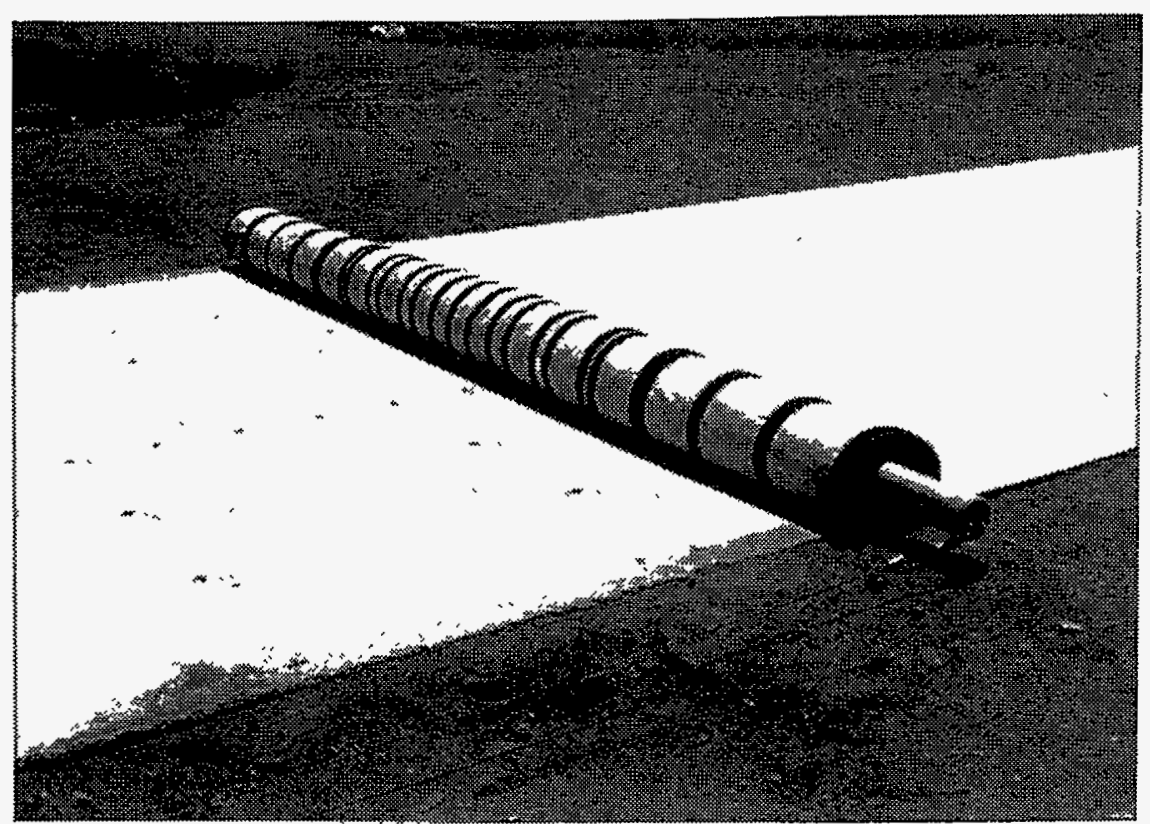

(c)

Figure 19. Preparation for measurements of liquid mass. (a) Mass-absorbing towels are laid over the concrete pad. (b) A waterproof vinyl cover with velcro strips is rolled over the towels. (c) The cover and towels are rolled away from the impact area. 
After the impact of the liquid jet, the towels were rapidly unrolled over the dispersed liquid on the test pad by means of a winch-and-pulley system. For the lower impact velocity tests, the test bed was covered in 10 to 15 seconds. For the higher impact velocity tests, in which the test bed cover was forward of, and farther away from the impact line, it took 20 to 30 seconds to cover the test bed. One exception was test \#10, in which the pulley system became entangled and power to the winch was interrupted. For this test, it took about 120 seconds to manually unroll the towels.

Manual collection of the water-soaked sheets and towels began within 2 to 3 minutes after a test. The entire collection process took 30 minutes to an hour. Each towel and sheet was individually bagged and sealed in zip-lock type plastic bags. The collection of towels progressed as follows: First the exposed sheets and towels that were not under the test bed cover were collected to minimize evaporation losses. The towels under the test bed cover were protected from evaporation losses because they were trapped between the paint-sealed concrete and the waterproof test bed cover. The cover was rolled back in small increments, and the towels were quickly bagged.

Measurement uncertainty in the technique arose from four sources. The first was collection efficiency. Some of the liquid on the pad could not be collected because either it drained or splashed beyond regions covered by towels. This source of uncertainty was minimized by covering as large an area as possible. The second source of uncertainty was absorption by the test bed or test bed cover. This source of uncertainty was minimized to the extent possible by painting the concrete test bed to seal it from absorption, and by using a waterproof vinyl test bed cover. The third source of uncertainty was evaporation of the water from the sheets and towels during the collection process. The uncertainty of this process was minimized by minimizing the exposure time of the towels to the air after the test bed cover was peeled back. The fourth source of uncertainty was in the measurement of the liquid mass. This uncertainty was dominated by the change in the dry towel mass over the test series. The dry towel weights were not measured test-to-test. The scale used to measure the towels was an A\&D Model FX-3000 accurate to 0.01 gram, with the measurements made to $0.1 \mathrm{gram}$. In spite of these sources of uncertainty, the collected mass was about 90 to $95 \%$ of the initial liquid mass. Therefore, the mass distribution measurement technique has an integrated experimental uncertainty of about $10 \%$.

\section{Results}

The numerals from 4 through 15 in the body of Table 6 indicate the order in which the tests were conducted. Tests \#1, \#2, and \#3 are not included in the matrix because they were diagnostic development tests in which no data was collected. The three dependent variables (area covered by the fuel, $A$; mass fraction of fuel in that area, $Y$; and distance of the area 
from the impact line, $X$ ) were measured as functions of impact angle, $\alpha$, and impact velocity, $V$.

\begin{tabular}{|c|c|c|c|c|}
\hline \multirow[t]{3}{*}{ Table 6.} & \multicolumn{4}{|c|}{ Test Matrix } \\
\hline & & \multicolumn{3}{|c|}{ Impact Angle (Degrees) } \\
\hline & & 22.5 & 45 & 67.5 \\
\hline \multirow{4}{*}{$\begin{array}{l}\text { Impact } \\
\text { Velocity } \\
(\mathrm{m} / \mathrm{s})\end{array}$} & 12 & 6 & 7 & 8 \\
\hline & 16 & & 4,9 & 5 \\
\hline & 61 & 10 & 12 & 11 \\
\hline & 91 & 14 & 13 & 15 \\
\hline
\end{tabular}

\section{Photometric results}

Figure 20 and Figure 21 show results for an impact angle of $45^{\circ}$ and an impact velocity of $61 \mathrm{~m} / \mathrm{s}$. Figure 20 shows a side view of the atomized liquid jet after impact with the concrete target. Figure 21 shows an overhead view of the splash at $5 \mathrm{~ms}, 50 \mathrm{~ms}, 100 \mathrm{~ms}$, $200 \mathrm{~ms}, 300 \mathrm{~ms}$, and $500 \mathrm{~ms}$ after impact with the target. The last of the atomized liquid leaves the field of view of the camera at about $200 \mathrm{~ms}$. After that time, motion of the liquid remaining within the field of view is very slow. The discussion of photometric results is divided into the effect of impact velocity and the effect of impact angle.

\section{Effect of impact velocity}

The cinematography shows a distinct difference between the two lower velocity levels (12 $\mathrm{m} / \mathrm{s}$ and $16 \mathrm{~m} / \mathrm{s})$ and the two higher velocity levels $(61 \mathrm{~m} / \mathrm{s}$ and $91 \mathrm{~m} / \mathrm{s})$. At the higher velocities, the liquid jet is completely atomized. It can be seen from Figure 20 and Figure 21 that virtually all of the liquid is dispersed by atomization of the liquid jet into a fine mist, and therefore, no contiguous liquid zone is formed. The cinematography confirms this conclusion for all of the $61 \mathrm{~m} / \mathrm{s}$ and $91 \mathrm{~m} / \mathrm{s}$ impact tests, regardless of the impact angle, i.e., no liquid pooling occurs at these velocities. At the lower velocities, $12 \mathrm{~m} / \mathrm{s}$ and $16 \mathrm{~m} / \mathrm{s}$, some pooling did occur. However, even at these lower impact velocities, the front portion of the liquid jet was atomized upon impacting the concrete target

The splash from both the higher and the lower impact velocity tests appears the same at the instant of impact. At that instant, the liquid jet is finely atomized. At the lower impact velocities, however, very fine atomization stops quickly. For the higher impact velocities, the fine atomization continues for the entire jet.

The cause of the fine atomization cannot be determined entirely from the photometric results. However, fine atomization is almost always associated with high relative velocities between the liquid jet and the surrounding air. Since the fine atomization occurs at the instant of impact, it is highly likely that the atomization is a result of liquid compressibility. 


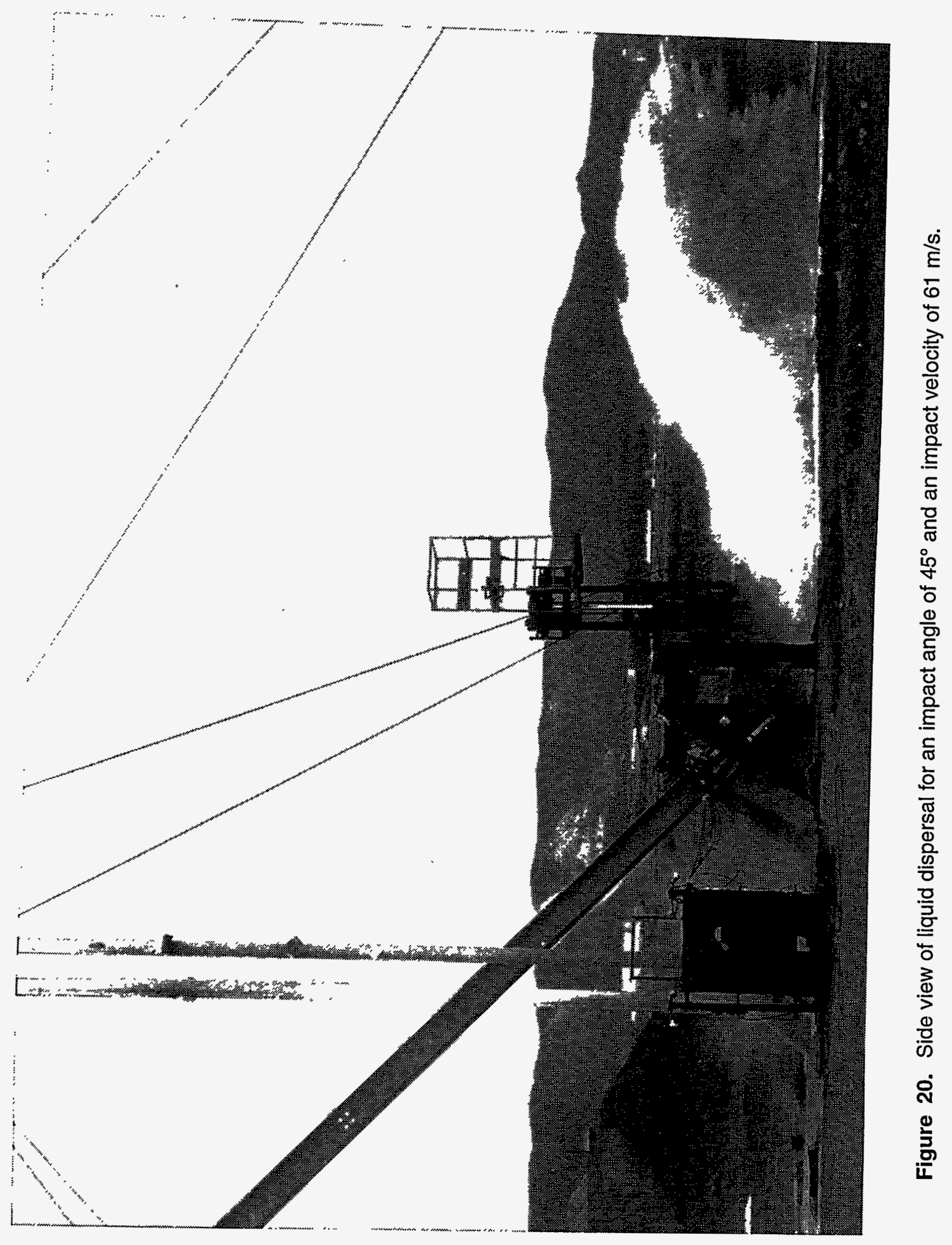




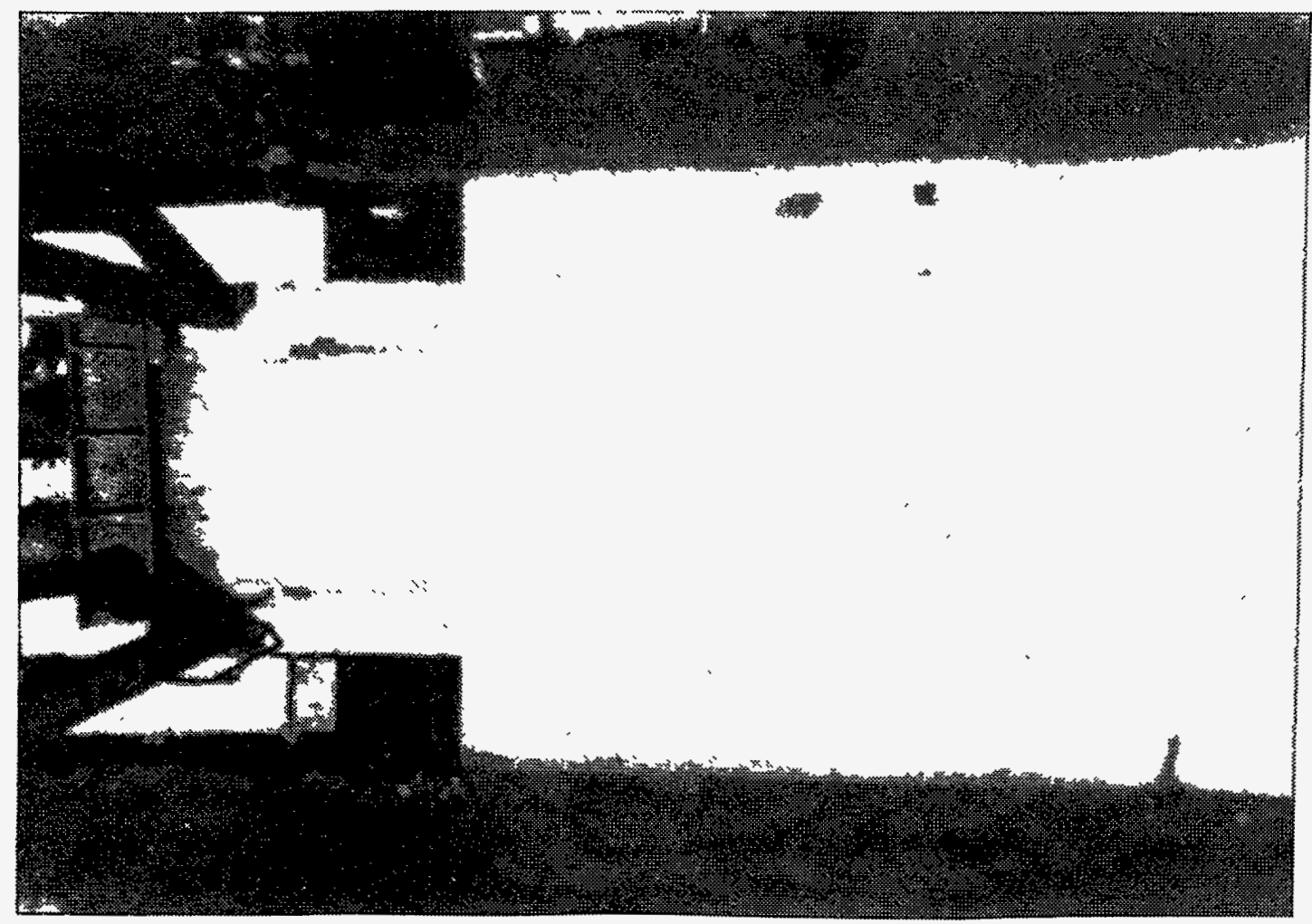

(a)

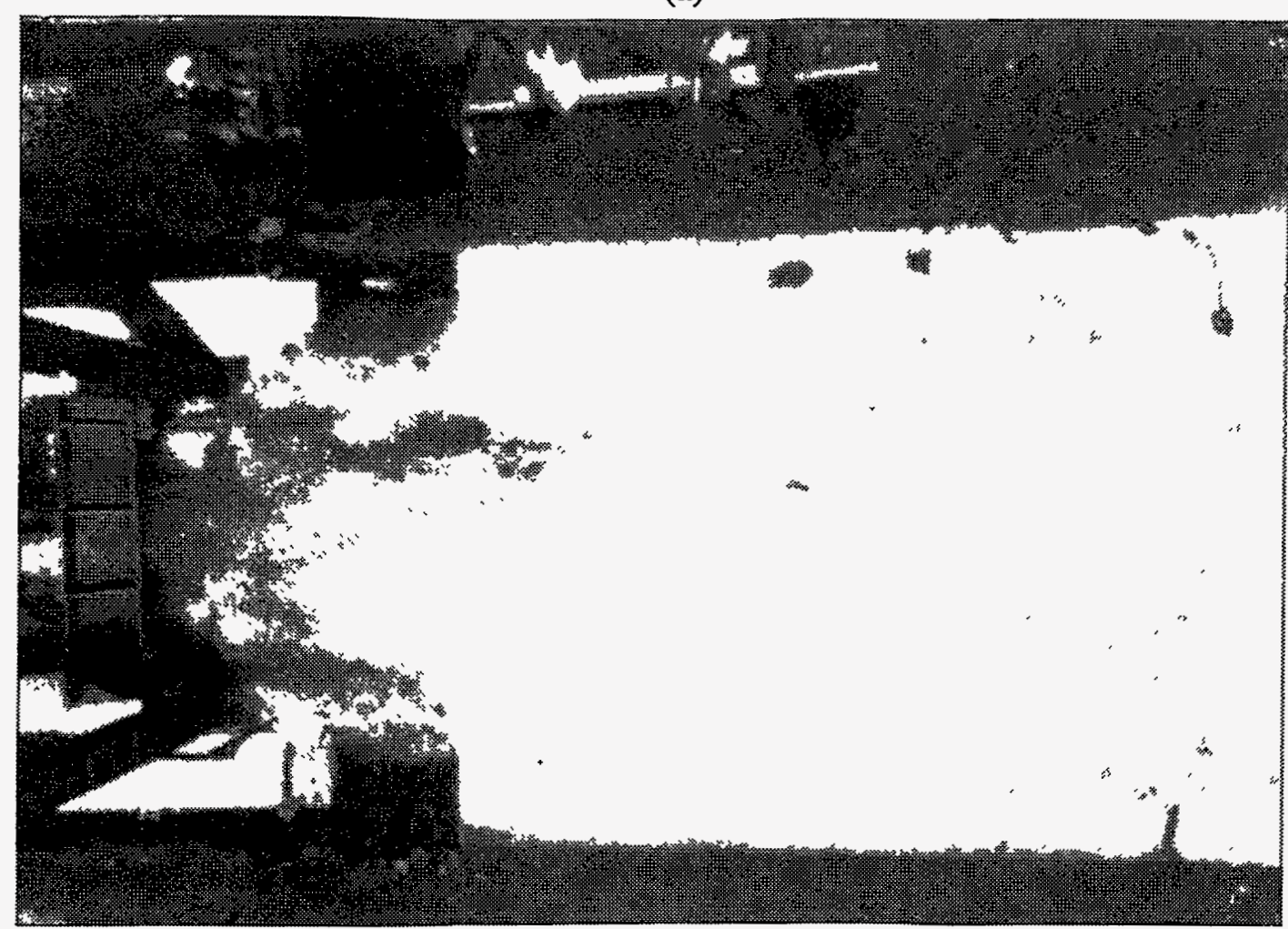

(b)

Figure 21. Overhead view of liquid dispersal for an impact angle of $45^{\circ}$ and an impact velocity of $61 \mathrm{~m} / \mathrm{s}$. Sequence is given for times after impact of (a) $5 \mathrm{~ms}$, (b) $50 \mathrm{~ms}$, 


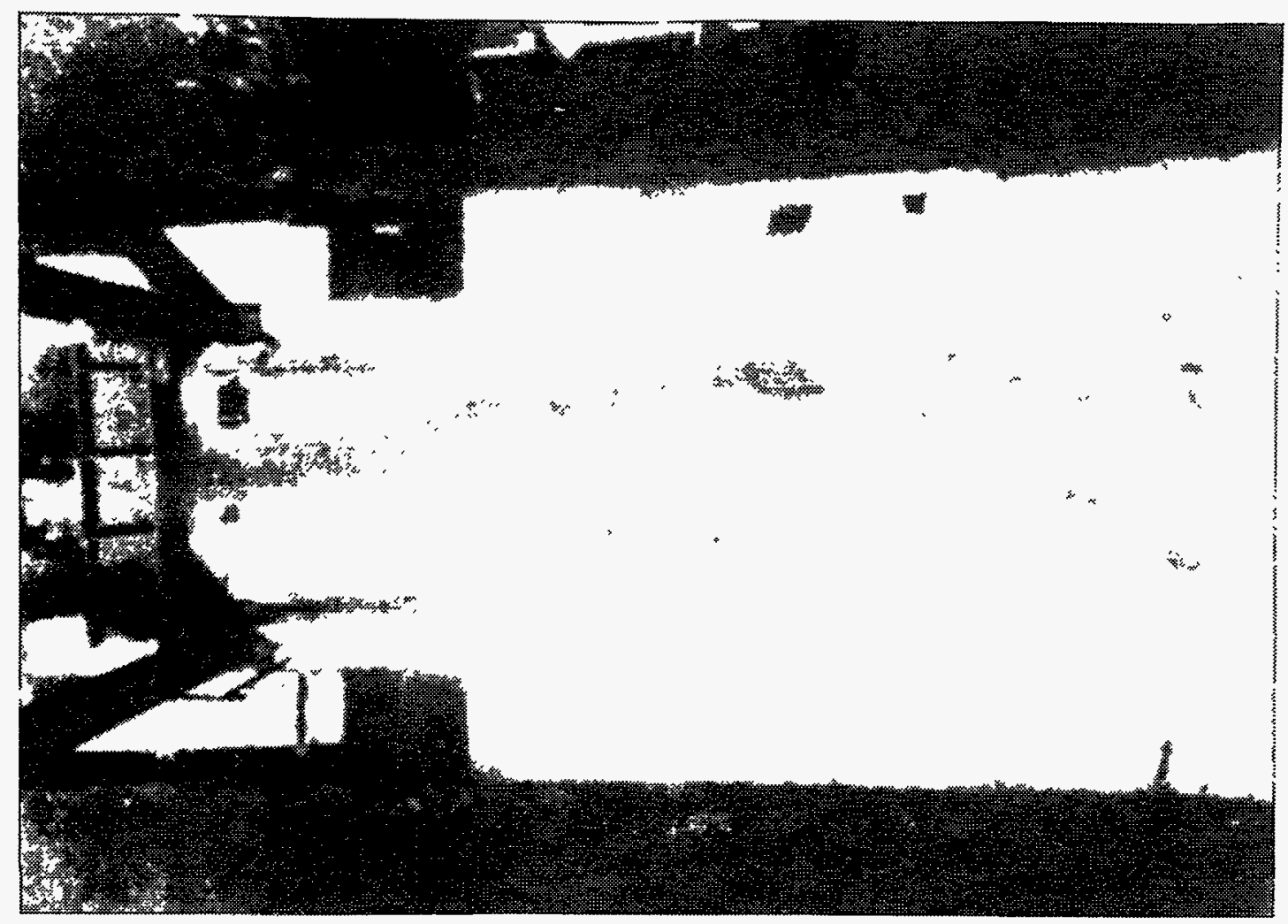

(c)

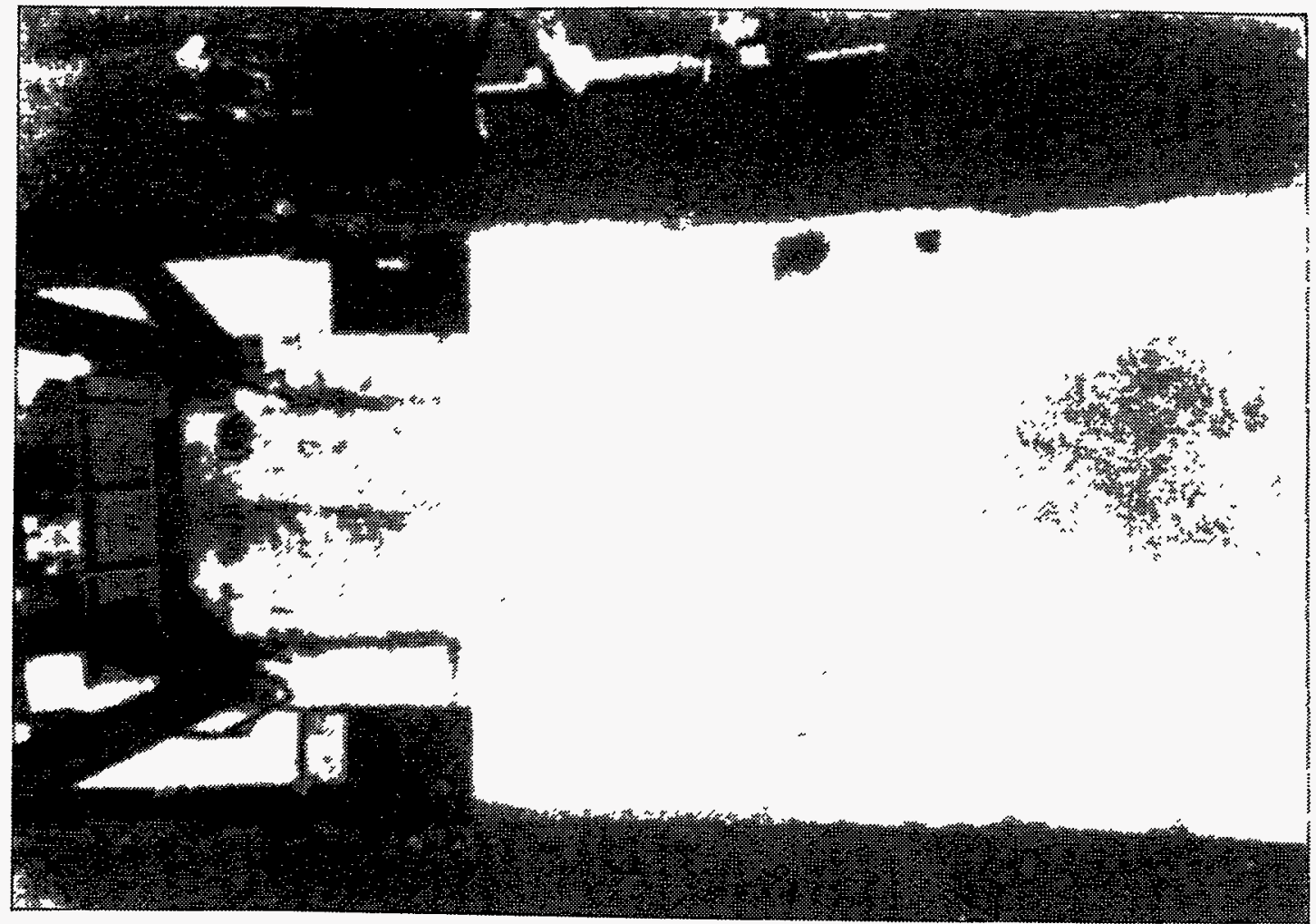

(d)

Figure 21. (Continued) (c) $100 \mathrm{~ms}$, (d) $200 \mathrm{ms,}$ 


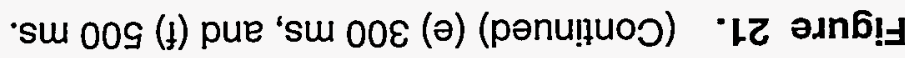

(J)

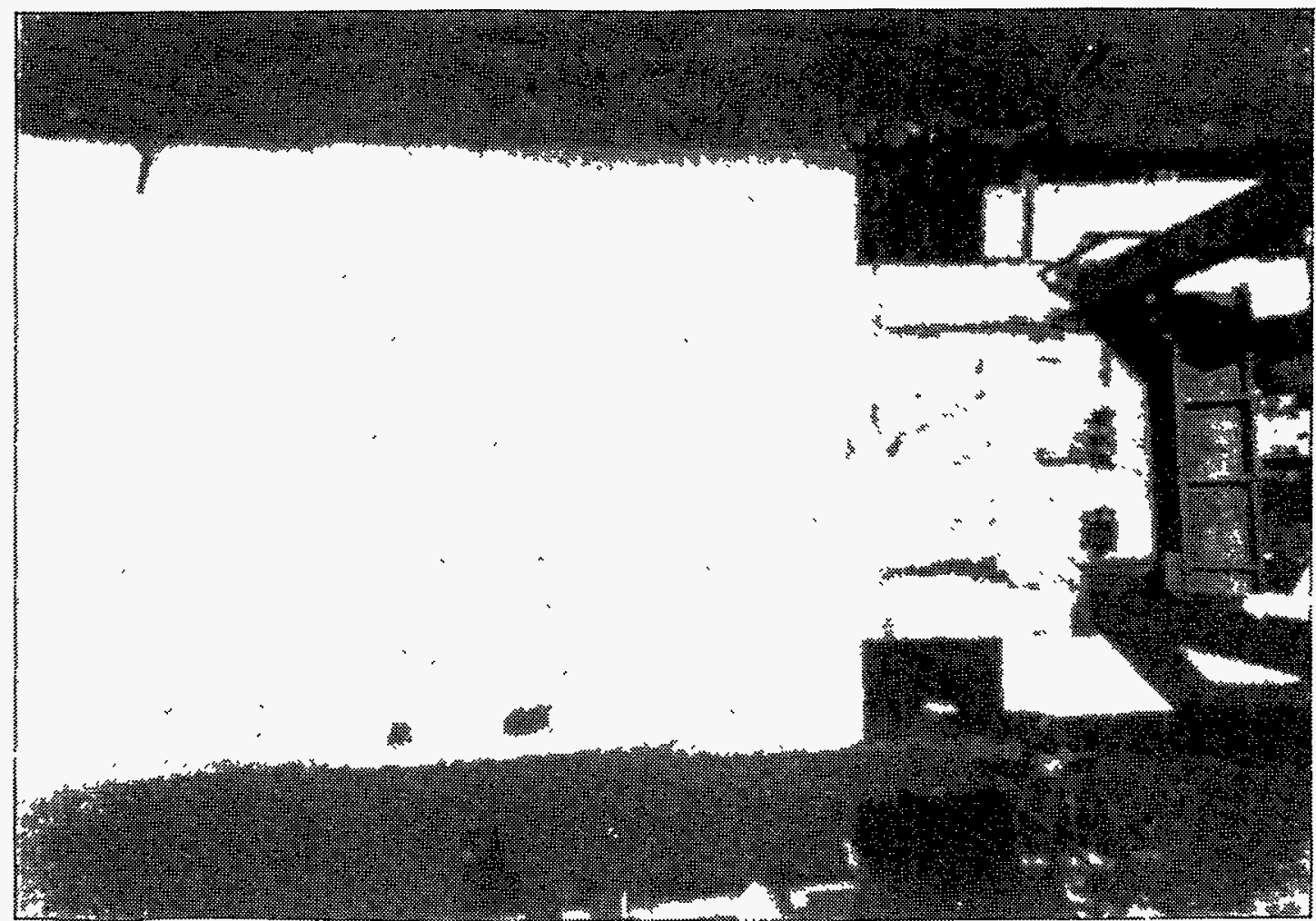

(כ)

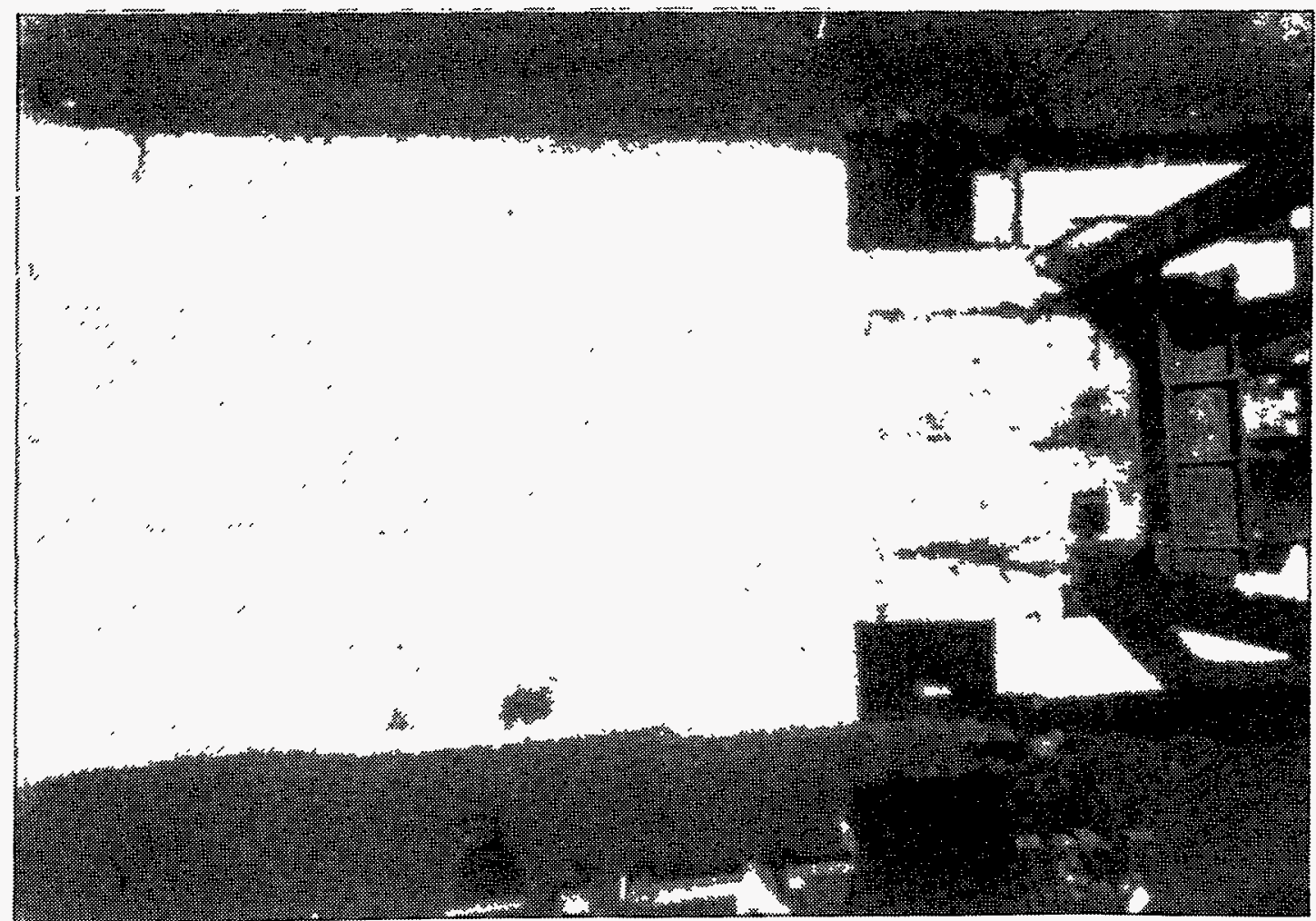


As discussed in the review of the high-speed droplet impact literature, liquid compressibility is important at the instant of impact, even for relatively low velocities. At impact, a shock wave propagates into the impacting liquid in a direction opposite to the direction the jet is traveling. The strength of the shock is such that the particle velocity normal to the surface is zero behind the shock. The presence of this shock causes the decelerated liquid to jet horizontally at a rate about 3 times that which will occur after the passage of the shock. However, the shock is a very transient event, lasting only until lateral relief waves can propagate in from the sides to the core. One could expect the length of jet that is finely atomized to be on the order of $1 / 2$ the jet thickness, which is consistent with the photometric results from the lower impact velocity tests.

Both the higher and lower impact velocity jets continued to splash beyond the initial impact, but there was a large difference in their splash products. Figure 20 and Figure 21 show that for the higher impact velocities, fine atomization continues for the duration of the jet. Cinematography shows that this atomization is much coarser for the lower impact velocities, however. The coarser the spray, the less likely the liquid would be to evaporate (or be consumed in a fireball, if it were fuel) and the more likely it would be to reimpact the ground downstream of the initial impact line. Indeed, overhead cinematography of the lower impact velocity tests appears to show the liquid resettling on the ground several meters downstream of the impact line. The mass distribution measurements to be discussed later also show this effect, which accounts for some of the pooling at lower velocities. Because the liquid mist impeded the view, it is difficult to determine from the cinematography at what point the flow actually reattached to the concrete target. In both the $12 \mathrm{~m} / \mathrm{s}$ and $16 \mathrm{~m} / \mathrm{s}$ impact velocity tests, a continuous film was present on the surface of the concrete in the vicinity of the impact line after the liquid mist had settled out. But it is impossible to determine whether this continuous film near the impact line was a) liquid mist that had settled out, or b) liquid that had not splashed, i.e., remained attached.

For the lower impact velocity tests, the jet appears to be discontinuous and drain from the wing at a slower rate toward the end of the liquid impact. This may be an artifact of the test itself that is not associated with jet impingement. For the lower velocity tests, rebound of the wing off the crushed honeycomb may occur on the same time scale as the draining of the liquid. Whatever the cause, the tail end of the jet impinges on the ground with less splashing and appears to spread out in a pool. The majority of pooling in the lower velocity tests is a result of the final drainage. Overhead views of each test clearly show that after the initial momentum is lost, the liquid continues to settle at a slow rate in those areas with pooling.

\section{Effect of impact angle}

From the cinematography, the effect of impact angle appears to be of secondary importance. Little difference can be seen in the results for impact angles ranging from $22.5^{\circ}$ to $67.5^{\circ}$. Qualitatively, the observations described above for the effects of impact velocity apply across the range of impact angles between $22.5^{\circ}$ and $67.5^{\circ}$. At lower impact velocities, the initial fine atomization increases with increasing angle. This observation is consistent with the explanation of compressibility because it is the normal impact velocity 
that determines the strength of the shock wave, and the normal impact velocity increases with increasing impact angle at fixed impact velocity. At the lowest impact velocity, 11.3 $\mathrm{m} / \mathrm{s}$, and smallest impact angle, $22.5^{\circ}$, the fine atomization of the liquid jet does not occur.

\section{Measurements of mass}

Detailed mass distribution measurements were obtained for each test. The mass per unit measurement zone was converted to an average liquid-layer thickness over that zone. This conversion is useful for comparing the liquid-layer thickness to typical fuel burn rates, which are about $6 \mathrm{~mm} / \mathrm{min}$. The comparison gives an approximate time to consume the liquid layer in a fire. The results are shown as contour plots in Appendix D. For each test, summary statistics on area coverage, percent initial mass contained in the area, and axial distance from point of impact are given as a function of three liquid-layer thicknesses: 1) greater than $0.0 \mathrm{~mm}$, i.e., measurement zones that contained at least a measurable amount of liquid spray, 2) greater than $0.1 \mathrm{~mm}$, i.e., zones that contained a significant amount of spray but not a continuous liquid film, and 3) greater than $1.0 \mathrm{~mm}$, i.e., zones that were continuously wetted, as in a pool of liquid. Summary statistics as a function of these three liquid-layer thicknesses are listed in Table 7, Table 8, and Table 9, respectively.

The seven mass distribution plots in Appendix $D$ can be interpreted as a single photograph taken late in time from an overhead view. In this sense, they convey less of the dynamic information than does the cinematography. Further, the cinematography has a much higher spatial resolution than the 116 to 174 measurement zones. The principal value of the plots in Appendix $D$ is that they contain quantitative information about mass that cannot be obtained from the cinematography. Discussion of mass distribution measurements includes data reproducibility, the effect of impact velocity, and the effect of impact angle.

\section{Data reproducibility/uncertainty}

Figure 22 shows the reproducibility of the data. Tests \#4 and \#9 were conducted at the same impact angle, $45^{\circ}$, and same impact velocity, $16.3 \mathrm{~m} / \mathrm{s}$. Wind conditions differed for each test. Even though the wind was from nearly opposing directions, the overall pattern of dispersal was the same. In test \#4, the first test in which data was taken, $87 \%$ of the initial mass was collected. Improvements implemented during tests \#5 and \#6 raised the collection efficiency. In test \#9,92\% of the initial mass was collected. Table 7 shows that for the $12 \mathrm{~m} / \mathrm{s}$ tests, the mass collected was between $91.7 \%$ and $95.8 \%$ of the initial mass. There was only a small amount of fine atomization in these tests, so these percentages are assumed to represent the collection efficiency. Therefore, the mass distribution data has an uncertainty of about $10 \%$.

Individual mass measurement zones may have a higher uncertainty than the total mass measurement uncertainty of $10 \%$. For example, two measurement zones had significantly more mass recorded for Test \#9 than was recorded for Test \#4. One of these measurement zones contains the impact line, 0.56 to $0.84 \mathrm{~m}$ off-axis from the impact centerline. In Test \#4 the liquid thickness is $2.27 \mathrm{~mm}$ and in Test \#9 the thickness is $4.47 \mathrm{~mm}$. This 

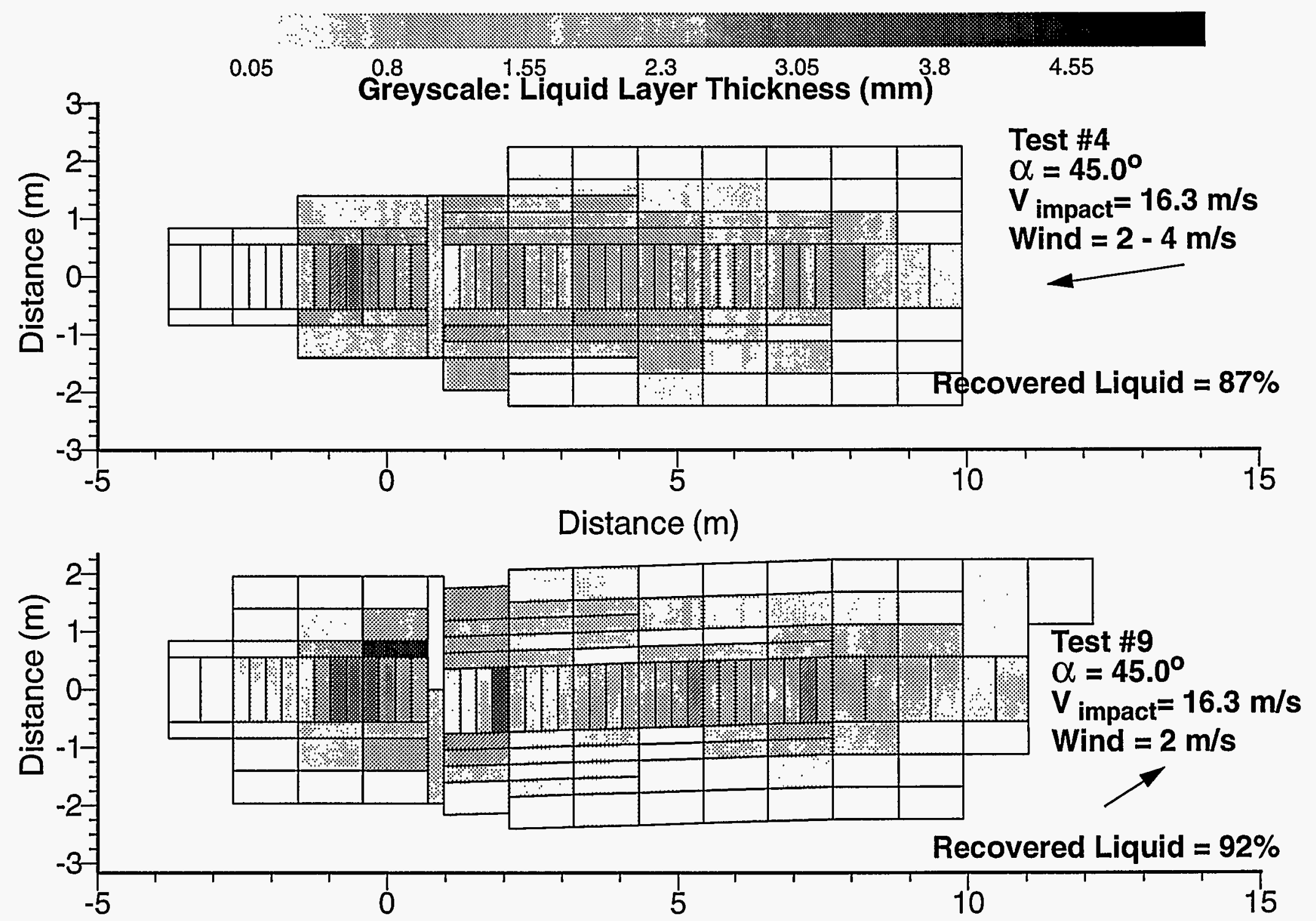

Figure 22. Mass distribution plots showing data reproducibility. 
measurement zone is at a seam in the concrete. After Test \#4 this seam was sealed with tape to prevent leakage into the joint, which accounts for the large increase in liquid-layer thickness obtained in Test \#9 for this measurement zone. In general, this measurement zone contains the greatest amount of liquid because it is in the impact zone and the concrete pad slopes downward very slightly in its direction.

The other large variation in liquid mass between Test \#4 and Test \#9 is for a measurement zone located on-axis about $2 \mathrm{~m}$ forward of the impact line. This measurement zone is also at a seam in the concrete. The leading edge of the concrete segment forward of the seam is lower than the concrete segment aft of the seam by about $1 \mathrm{~cm}$ so that the flow sees a small backward facing step between segments. Due to the low edge, the measurement zone on the forward segment tends to have a greater liquid-layer thickness than surrounding areas.

These two measurement zones represent the worst-case difference. On the average, measurements from individual towels should not vary by more than $10 \%$ of the total mass divided by the total area, or about $0.1 \mathrm{~mm}$ for impact velocities of $12 \mathrm{~m} / \mathrm{s}$ and $16 \mathrm{~m} / \mathrm{s}$, and about $0.01 \mathrm{~mm}$ for impact velocities of $61 \mathrm{~m} / \mathrm{s}$ and $91 \mathrm{~m} / \mathrm{s}$.

\section{Effect of impact velocity}

Figures D1, D2, and D3 in Appendix D show the effect of impact velocity on the mass distribution for impact angles of $22.5^{\circ}, 45^{\circ}$, and $67.5^{\circ}$, respectively. These figures show that the principal effect of increasing the impact velocity was to disperse the liquid over a larger area. Dispersing a fixed amount of liquid over a larger area required the average liquidlayer thickness to decrease. For the higher impact velocities, the average liquid-layer thicknesses were practically all less than $1 \mathrm{~mm}$, which indicates that no pooling had occurred. Test results therefore indicate that there is no potential for a pool fire for these scenarios (impact velocities $>61 \mathrm{~m} / \mathrm{s}$ onto a hard, flat target).

The maximum liquid-layer thickness measured for any location in any test was $\mathbf{5 . 2 5} \mathbf{~ m m}$ (test \#8, @ 67.5, $13.6 \mathrm{~m} / \mathrm{s}$, in the impact zone at the low, off-axis, concrete joint). Given a fuel burn velocity of $6 \mathrm{~mm}$ per minute, no test could have resulted in a burn of longer than 1 minute (ignoring the ignition and spread transients).

As illustrated in Figures D1, D2, and D3, splashing occurs even at the lower impact velocities. For both the $12 \mathrm{~m} / \mathrm{s}$ and $16 \mathrm{~m} / \mathrm{s}$ data at all impact angles, there is a skip region immediately forward of the impact line where relatively smaller amounts of liquid were collected. Except for the measurement zone covering the concrete seam, about $2 \mathrm{~m}$ forward of the impact line, all the liquid-layer thickness measurements are lower just forward of the impact line than are those farther forward, around $5 \mathrm{~m}$ forward of the impact line. The higher liguid-layer thickness immediately aft of the impact line, i.e., $-1.0 \mathrm{~m}$, are most likely due to the final drainage of the wing as noted earlier.

Tables 7, 8, and 9 give summary statistics for the tests. The tables identify several trends in liquid mass distribution with impact velocity. First in Table 7, the splash zone containing at least some liquid increases from nominally $40 \mathrm{~m}^{2}$ to nominally $120 \mathrm{~m}^{2}$ with an increase in 
impact velocity from nominally $12 \mathrm{~m} / \mathrm{s}$ to $91 \mathrm{~m} / \mathrm{s}$. Including only those areas with significant liquid mass, Table 8 , shows a qualitatively similar trend with the area increasing from $28 \mathrm{~m}^{2}$ to $60 \mathrm{~m}^{2}$ with the same increase in velocity. Increasing the dispersion area comes at the expense of reducing the area of the continuous wetted pool. Table 9 shows that the continuous wetted area decreases from nominally $15 \mathrm{~m}^{2}$ to less than $1 \mathrm{~m}^{2}$ with the same increase in impact velocity.

\section{Table 7. Summary Statistics for Areas with Average Liquid-Layer Thicknesses $>0.0 \mathrm{~mm}$}

\begin{tabular}{|c|c|c|c|c|}
\cline { 2 - 5 } & \multirow{2}{*}{$\begin{array}{c}\text { Nominal Impact } \\
\text { Velocity (m/s) }\end{array}$} & \multicolumn{3}{|c|}{ Impact Angle (Degrees) } \\
\cline { 2 - 5 } & & 22.5 & 45 & 67.5 \\
\hline \multirow{4}{*}{$\begin{array}{c}\text { Area } \\
\text { Covered } \\
\left(\mathrm{m}^{2}\right)\end{array}$} & 12 & 46.2 & 39.3 & 49.9 \\
\cline { 2 - 5 } & 16 & & $43.9,56.3$ & 47.5 \\
\cline { 2 - 5 } & 61 & 101.3 & 138.4 & 124.3 \\
\cline { 2 - 5 } & 91 & 139.4 & 117.8 & 128.9 \\
\hline \multirow{4}{*}{$\left.\begin{array}{c}\text { Mass } \\
\text { Collected }\end{array}\right)$} & 12 & 91.7 & 95.8 & 95.2 \\
\cline { 2 - 5 } & 16 & & $87.0,91.9$ & 87.3 \\
\cline { 2 - 5 } & 61 & 42.5 & 53.5 & 36.3 \\
\cline { 2 - 5 } & 91 & 38.8 & 49.1 & 39.3 \\
\hline \multirow{4}{*}{$\begin{array}{c}\text { Distance from } \\
\text { Impact to the } \\
\text { Center of Mass } \\
\text { (m) }\end{array}$} & 12 & 2.68 & 2.74 & 1.54 \\
\cline { 2 - 5 } & 16 & 10.48 & $3.32,3.50$ & 2.39 \\
\cline { 2 - 5 } & 61 & 10.71 & 8.17 & 5.69 \\
\hline
\end{tabular}

The thinner liquid-layer thicknesses for higher velocities occurs for two reasons. As just noted, the higher velocities cause the liquid to splash farther and hence the average thickness is lower. The summary statistics also show a second reason for the decrease in liquid-layer thicknesses with increasing impact velocity. The reason is that much of the spray created from the high impact speeds is so finely atomized, it evaporates before reaching the ground. In Table 7, for example, nominally $94 \%$ of the mass is collected at the lowest impact velocity but only nominally $42 \%$ of the mass is collected at the highest impact velocity. No significant decrease in collection efficiency is expected for these higher velocity tests because no large areas of liquid were found outside of the large measurement area. Therefore, one can conclude that nominally $50 \%$ of the liquid is so finely atomized that it evaporates before reaching the ground. If this were fuel, a fireball certainly would have been the result, and in the high-temperature environment of the fireball a substantially larger fraction of the mass would have evaporated. 
A third trend in the summary statistics is that the distance from the center of mass of the dispersed liquid to the impact line increases with increasing velocity. In Table 7 and Table 8 , for example, the distance from the impact point to the center of mass, for impact angles of $22.5^{\circ}$ and $45^{\circ}$, increases from about $3 \mathrm{~m}$ to about $10 \mathrm{~m}$ with an increase in impact velocity from $12 \mathrm{~m} / \mathrm{s}$ to $91 \mathrm{~m} / \mathrm{s}$. This trend is not apparent for liquid-layer thicknesses above $1 \mathrm{~mm}$, as shown in Table 9. There are so few measurement zones with liquid-layer thickness greater than $1 \mathrm{~mm}$ for impact velocities in the $61 \mathrm{~m} / \mathrm{s}$ and $91 \mathrm{~m} / \mathrm{s}$ ranges that no statistical inference can be drawn.

\section{Table 8. Summary Statistics for Areas with Average Liquid-Layer Thicknesses $>0.1 \mathrm{~mm}$}

\begin{tabular}{|c|c|c|c|c|}
\hline & \multirow{2}{*}{$\begin{array}{l}\text { Nominal Impact } \\
\text { Velocity }(\mathrm{m} / \mathrm{s})\end{array}$} & \multicolumn{3}{|c|}{ Impact Angle (Degrees) } \\
\hline${ }^{\circ}$ & & 22.5 & 45 & 67.5 \\
\hline \multirow{4}{*}{$\begin{array}{c}\text { Area } \\
\text { Covered } \\
\left(\mathrm{m}^{2}\right)\end{array}$} & 12 & 27.8 & 28.0 & 28.6 \\
\hline & 16 & & $34.2,41.3$ & 38.1 \\
\hline & 61 & 47.7 & 61.8 & 52.7 \\
\hline & 91 & 58.4 & 76.8 & 43.7 \\
\hline \multirow{4}{*}{$\begin{array}{l}\text { Mass } \\
\text { Collected } \\
\text { (\%) }\end{array}$} & 12 & 91.0 & 95.1 & 93.9 \\
\hline & 16 & & $86.1,90.9$ & 86.4 \\
\hline & 61 & 35.1 & 44.2 & 28.8 \\
\hline & 91 & 29.2 & 44.8 & 29.9 \\
\hline \multirow{4}{*}{$\begin{array}{l}\text { Distance from } \\
\text { Impact to the } \\
\text { Center of Mass } \\
\text { (m) }\end{array}$} & 12 & 2.67 & 2.73 & 1.51 \\
\hline & 16 & & $3.32,3.50$ & 2.35 \\
\hline & 61 & 9.18 & 6.66 & 6.94 \\
\hline & 91 & 9.12 & 7.61 & 3.57 \\
\hline
\end{tabular}

\section{Effect of impact angle}

The effect of impact angle on the dispersal pattern in surprisingly small. For the lower impact velocities, the summary statistics indicate there is little variation in either area coverage or mass collected over impact angles from $22.5^{\circ}$ to $67.5^{\circ}$. At the higher impact velocity range, both the area covered and the liquid mass collected peak at an impact angle of $45^{\circ}$. The author has no explanation for this phenomenon. No obvious trends in the data exist to indicate whether this phenomenon is due to some physical process or is an artifact of the test apparatus.

The largest effect of impact angle can be seen in the distance from the mass center of the dispersed liquid to the impact line. As expected, the distance decreases with increasing 


\section{Table 9. Summary Statistics for Areas with Average Liquid-Layer Thicknesses $>1.0 \mathrm{~mm}$}

\begin{tabular}{|c|c|c|c|c|}
\hline & \multirow{2}{*}{$\begin{array}{l}\text { Nominal Impact } \\
\text { Velocity }(\mathrm{m} / \mathrm{s})\end{array}$} & \multicolumn{3}{|c|}{ Impact Angle (Degrees) } \\
\hline & & 22.5 & 45 & 67.5 \\
\hline \multirow{4}{*}{$\begin{array}{l}\text { Area } \\
\text { Covered } \\
\left(\mathrm{m}^{2}\right)\end{array}$} & 12 & 15.0 & 15.9 & 14.7 \\
\hline & 16 & & $15.3,12.4$ & 13.1 \\
\hline & 61 & 0.9 & 1.6 & 0.0 \\
\hline & 91 & 0.0 & 0.6 & 0.6 \\
\hline \multirow{4}{*}{$\begin{array}{l}\text { Mass } \\
\text { Collected } \\
(\%)\end{array}$} & 12 & 70.2 & 80.0 & 76.5 \\
\hline & 16 & & $60.7,56.7$ & 57.6 \\
\hline & 61 & 2.8 & 5.3 & 0.0 \\
\hline & 91 & 0.0 & 2.4 & 2.2 \\
\hline \multirow{4}{*}{$\begin{array}{l}\text { Distance from } \\
\text { Impact to the } \\
\text { Center of Mass } \\
\text { (m) }\end{array}$} & 12 & 2.37 & 2.72 & 1.35 \\
\hline & 16 & & $3.15,2.86$ • & 1.32 \\
\hline & 61 & 12.33 & 0.3 & N/A \\
\hline & 91 & N/A & -0.16 & -0.24 \\
\hline
\end{tabular}

impact angle. The summary statistics indicate that the distance decreases nominally a factor of 2 by increasing the impact angle from $22.5^{\circ}$ to $67.5^{\circ}$. For the impact velocity of $12 \mathrm{~m} / \mathrm{s}$, the distance from the impact line to the center of mass decreases from about $3 \mathrm{~m}$ to about $1.5 \mathrm{~m}$ for an increase in impact angle from $22.5^{\circ}$ to $67.5^{\circ}$. At $61 \mathrm{~m} / \mathrm{s}$ and $91 \mathrm{~m} / \mathrm{s}$, the distance shows more variability but generally decreases by about a factor of 2 . As noted earlier, for liquid-layer thicknesses above $1 \mathrm{~mm}$ given in Table 9, too few measurement zones are involved to determine meaningful statistics.

While Table 7, Table 8, and Table 9 give overall statistics, Figures D4 through D7 in Appendix D show the mass distribution plots for the three angles of impact. These figures are the same plots as Figures D1, D2, and D3, except that they are plotted with the velocity held fixed and the angle varied. From these figures it can be seen that not only do the overall statistics show little variation with the impact angle, but the distributions themselves show little variation with the impact angle. The largest difference is at the higher impact velocities in Figures D6 and D7, in which the mass center of the distribution can be seen to move toward the impact line.

Drawing upon the dynamic spread factor (DSF) concept in droplet impact literature, the original intent was to nondimensionalize the dispersal area by the jet thickness. Because the 
droplets are spherical and the splash is nearly cylindrical, the areas of both can be represented by a single variable, in this case diameter. It was anticipated for the current study that the spread of the jet perpendicular to the axis of impact would either be negligible or in proportion to its length. In Figures D4 through D7 it can be seen that the transverse spread is relatively constant, about 3 times the wing chord, whereas the axial distance increases considerably with impact velocity. Therefore, the results are two-dimensional; a DSF based on jet thickness would not appropriately represent the data.

\section{Discussion}

\section{Splashing mechanism(s)}

While the data collected quantify the amount of splashing that occurred, the data do not clearly identify the underlying mechanism for splashing. Two potential splashing mechanisms were identified in the literature review that are common to both transient drop impact literature and steady state jet impingement literature, i.e., flow separation from the impact surface (hydraulic jumps) and the separation of perturbations in the free surface of the liquid. Separation from the impact surface will occur if the impact surface is sufficiently rough as to disrupt the flow of the liquid layer as it spreads out. However, the separation of free surface perturbations occurs for both instabilities in the free surface of the liquid jet and roughness-induced instabilities in the spreading liquid. In the latter case, the roughness can be a small fraction of the thickness of the spreading liquid and still produce large surface perturbations.

Bhunia and Lienhard, 1994a, take sufficient data on the fraction of mass splashed in their steady state, axisymmetric jet impingement tests that it is possible to qualitatively compare theirs with the present data. The comparison is shown in Figure 23 as fraction of mass splashed versus jet free-flight distance. As Bhunia and Lienhard, 1994b, show, the amplitude of the surface disturbance in the jet can be related to the jet free-flight distance for their axisymmetric jets. Although the current study did not include quantitative measurements of the amplitude of the surface disturbances on the liquid jets at impact, the cinematography shows that the surfaces were highly roughened by both aerodynamic breakup at the leading edge of the jet, and by both transverse and axial long wave instabilities that had amplitudes on the order of the jet thickness. The axial instabilities were induced by the stopping motion induced by the honeycomb crushup, and the transverse instabilities were presumed to be due to the aerodynamic breakup of the two-dimensional liquid sheet.

The comparisons are qualitative in Figure 23 because there are some large differences between the two experiments. Bhunia and Lienhard, 1994a, used small diameter, $<6 \mathrm{~mm}$, steady-state, axisymmetric jets that impacted normal to the smooth, hard surface. Further, just downstream of the resulting hydraulic jump, Bhunia and Lienhard diverted the surface (unsplashed) flow off into a container, so that they captured all the splash products separately-including those that would have likely re-impacted the surface within the spreading liquid layer had it been allowed to continue to spread. In the current study, the 


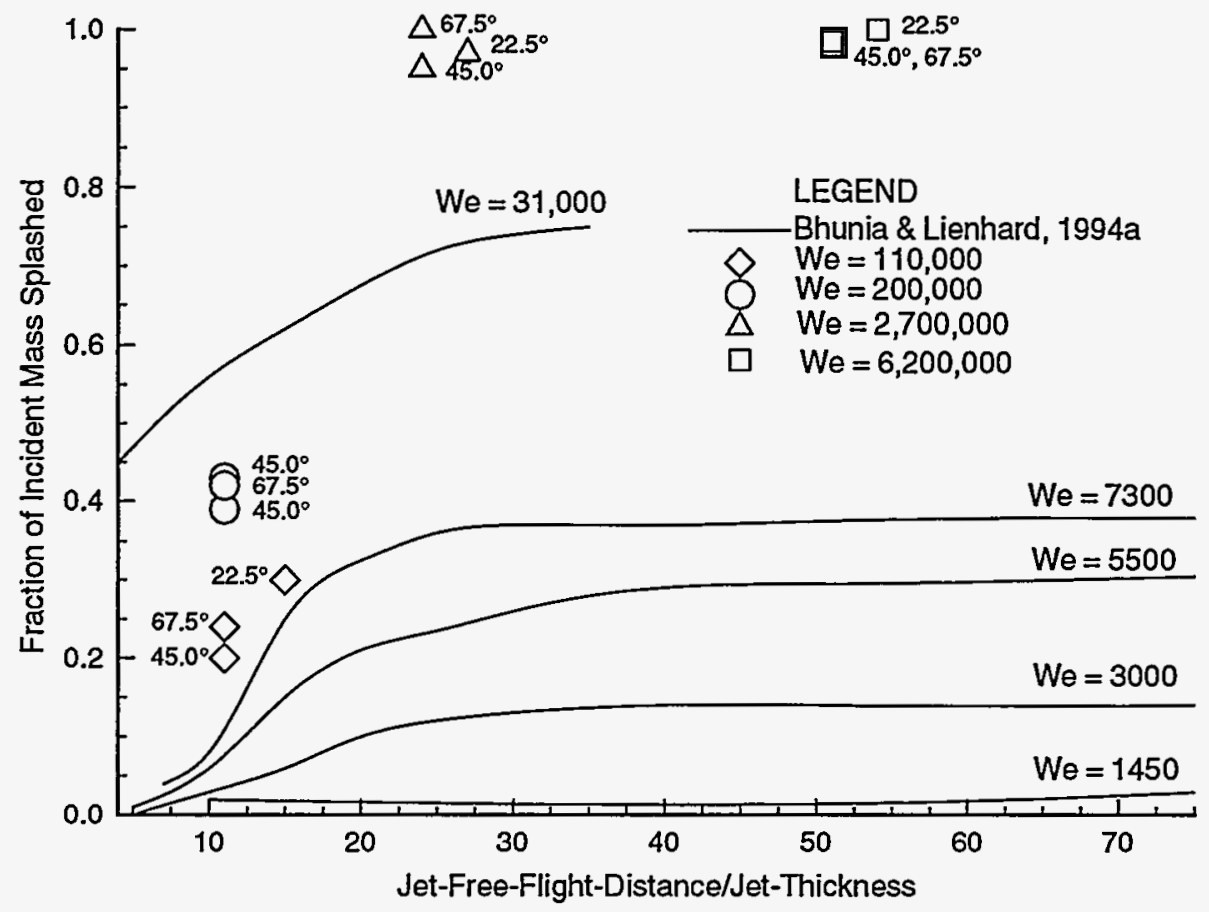

Figure 23. Mass fraction splashed vs. jet-free-flight-distance/jet-thickness. Impact angle is noted on the data. The Weber number for the Bhunia \& Lienhard, 1994a, data is based on the jet diameter, whereas the Weber number for the current study is based on jet thickness. The comparison is qualitative because the tests are quite different.

mass fraction splashed is taken as that amount that atomized so finely that it did not reentrain in the continuous liquid layer, i.e., one minus the percent mass collected (divided by 100) from Table 9 . Further, in the current tests, the nondimensional jet free-flight distance is defined as the distance from the front of the wing at initial impact with the honeycomb to the concrete surface divided by the jet thickness of $5.4 \mathrm{~cm}$. In Bhunia and Lienhard's work, the jet free-flight distance is the nozzle-to-target separation distance divided by the jet diameter. In the current tests, the impacts are at an angle rather than normal to the surface, and the jets are transient rather than steady state.

But despite the rather large differences between the two tests, the results of both do show the same trends. As seen in Figure 23, the fraction of mass splashed increases with increasing Weber number. In other words, for larger jet thicknesses or for higher velocities, a greater fraction will be splashed. For nondimensional jet free-flight distances less than about 25 , the fraction of mass splashed is dependent on the jet free-flight distance. For distances larger than about 25 , the fraction of mass splashed is no longer dependent on the jet free-flight distance. The reason that the fraction of mass splashed is dependent on jet free-flight for distances less than about 25 is that the surface disturbances are still building over this distance. The longer a jet travels in air, the stronger the perturbations on its 
surface. Bhunia and Lienhard, 1994b, quantify the growth of the instability and show that perturbations in the surface of the jet greater than about $5 \%$ result in the onset of splashing. For surface disturbances between 10 and $15 \%$, the fraction splashed is between 20 and $30 \%$. Unfortunately, Bhunia and Lienhard did not plot their data for fraction of mass splashed higher than this value. However, the curve is quite steep and one can reasonably extrapolate that surface disturbances on the order of 20 to $25 \%$ will result in nearly complete splashing. This observation is consistent with the data in the current experiment.

The results support an explanation that splashing occurs at initial impact due to compressibility for a jet length equal to about the first $1 / 2$ jet thickness; thereafter, the mechanism for continued splashing is the separation of free-surface perturbations.

\section{Applicability of test data to a WSSA program}

In applying the current test data to a WSSA, several factors need to be addressed: scale, the fluid property difference between water and JP-4 or 8, and the actual effect of the wing structure on fuel dispersal. The current test data indicates that for impact velocities above the values of 60 to $70 \mathrm{~m} / \mathrm{s}$ reported by Wittlin, 1987, for wing disintegration, there will be no pooling of fuel if the impact occurs on a hard flat surface such as a runway. Therefore, there will be no potential for a pool fire. However, the tests also showed that a transition occurs in the splash characteristics between $16 \mathrm{~m} / \mathrm{s}$ and $60 \mathrm{~m} / \mathrm{s}$, in that the data at $16 \mathrm{~m} / \mathrm{s}$ did show some pooling. The concern is that one or more of the ignored factors (i.e., scale, fluid properties, and wing structure) might shift the transition point for pooling/nonpooling to a higher impact velocity, thereby making the no-pooling conclusion a nonconservative assumption for application to a WSSA.

The question of scaling in complicated, transient flows is difficult. The difficulty is compounded in the current case by the fact that the mechanism(s) for splashing were not identified with certainty by the current study. As stated above, we will assume that splashing occurs during the first $1 / 2$ jet thickness due to compressibility. Beyond that, it occurs because of free surface perturbations that can be caused by several means. Based on these mechanisms, we can address scaling.

\section{Effect of geometric scale}

The pressure at impact is independent of scale and depends only on the normal impact velocity, the geometry of the impact zone, the shock velocity, and the water density. The duration of the shock state is determined by the time required for the relief waves to propagate to the center of the jet. This time is dependent on the sound speed in the liquid and is directly proportional to the thickness of the jet. Based on this mechanism, we conclude that the splashing at initial impact will occur at full scale, in the same manner as the current tests.

The effect of scale on the continued splashing of the jet after the pressure has equilibrated is given by the Weber number, or, 


$$
W e=\frac{\rho V^{2} T}{\sigma}
$$

where, $T$ is the jet thickness, $V$ is the impact velocity, $\rho$ is the liquid density, and $\sigma$ is the liquid surface tension. The higher the Weber number, the greater the fraction of mass that is splashed and the smaller the resultant splash products. The F-4 impact test at $215 \mathrm{~m} / \mathrm{s}$ into a concrete barrier (see section on evaluation of existing data on fuel dispersal) clearly shows that fine atomization continues throughout the aircraft impact. Therefore, we conclude that at full scale, the current test results on fraction of mass splashed will be conservative. More fuel in an actual impact will be consumed in a fireball than would be predicted by the current tests at 1/9 scale.

\section{Effect of fluid properties}

The current test series used water as a simulant for JP-4. Liquid properties of interest include surface tension, bulk modulus of compressibility, and possibly viscosity. The surface tension for water is about $70 \times 10^{-3} \mathrm{~N} / \mathrm{m}$ vs. $20-30 \times 10^{-3} \mathrm{~N} / \mathrm{m}$ for light hydrocarbons (Fox and McDonald, 1978). The isentropic bulk modulus for compressibility for water is $2.2 \times 10^{9} \mathrm{~N} / \mathrm{m}^{2}$ vs. $1.4-1.6 \times 10^{9} \mathrm{~N} / \mathrm{m}^{2}$ for hydrocarbons (Baumeister, et al., 1978). The viscosity of water at ambient temperature is $1 \times 10^{-6} \mathrm{~m}^{2} / \mathrm{s}$ vs. $0.5-0.8 \times 10^{-6} \mathrm{~m}^{2} / \mathrm{s}$ for light hydrocarbons (Fox and McDonald, 1978).

The bulk modulus of compressibility will play a role during the initial impact as the shock wave compresses the impacting liquid. The bulk modulus of compressibility relates the pressure rise to the volumetric strain. JP-4, with a lower bulk modulus, will have a lower pressure rise for a given amount of compressive strain than the water. This means that the effect of compressibility is lower for JP-4 than for water, and the initial horizontal velocity of the liquid jet at the instant of impact will be lower for JP-4. This lower velocity will lower the Weber number of the jet, which will reduce the atomization during the initial impact.

On the other hand, surface tension also affects the Weber number. JP-4, with a lower surface tension, will increase the Weber number and thereby increase the atomization. In other words, the properties of bulk modulus and surface tension produce counteracting effects. Without a quantitative correlation, it is not possible to determine the quantitative effects of these changes in properties on the atomization at the instant of impact. However, both properties change by a factor of about 2 . Given that the trends are in opposite directions, it is unlikely that the effects will be large unless the phenomenon is highly sensitive to one of the variables but not the other.

After the pressure has equilibrated from the initial impact, the effect of bulk compressibility is no longer important. Since the surface tension for light hydrocarbons is lower than that for water, the higher Weber number will result in an increase in the fraction of mass that is splashed. The use of water is therefore conservative in that more splashing is expected from the impact of light hydrocarbons. 


\section{Effect of wing structure}

In the current test series, the wing structure was ignored because it would have been prohibitively expensive (if actually technically feasible) to design a structure that would deform and then fragment in a scalable manner as the real wing. However, there are a number of ways in which the wing structure can affect the results, including causing cratering in hard surfaces such as concrete, inertially confining the liquid during the initial impact, and interfering with the spread of the liquid by its fragmentation.

If the wing causes cratering in the runway surface, the results can be expected to change. From napalm bomb development studies it is clear that some fuel will remain in the impact crater. Edwards, 1973, attributes a quote to a Lt. Royer on napalm bomb development tests: "Impact craters 1.5 to 5 feet deep and 5 to 14 feet in diameter, restricted flame fuel dissemination and ignition.... Thirty to $50 \%$ of the flame fuel from each fire bomb burned in impact craters (for 8 to 100 minutes)..." The F-4 test referred to above cannot be used as a guide to the potential for cratering concrete. The concrete block that the F-4 impacted represented an inertial mass floating on an air bearing. Impact onto a concrete runway would be different. If the concrete surface craters, the likely result would be some pooling of the fuel in the bottom of the crater.

The presence of the wing may also affect the mechanism of jet splashing. Unlike the current tests, the wing will confine the fuel until the moment of impact. Therefore, the surface perturbations caused by the flight of the liquid jet through the air will not be present in the actual wing impact. This is probably the most significant difference between the test results and an actual impact. However, perturbations in the free surface can be caused by a number of factors including the fragmentation of the wing. Since both droplets and steady state jets exhibit the same phenomena, it can be assumed that the method by which the surface distortions are created has, at most, a second order effect. Extrapolation of the data of Bhunia and Lienhard, 1994b, indicates that surface distortions on the order of 20 to $25 \%$ of the jet will result in complete splashing of the jet. The expectation is that the free surface of the fuel that is jetting under and around the fragmenting wing will be highly distorted with perturbations at least this large. The F-4 test mentioned above again provides evidence that, at least in the $200 \mathrm{~m} / \mathrm{s}$ impact velocity range, the structure does not qualitatively change the dispersal process. The liquid jet is still finely atomized and no pooling will occur.

The wing fragments can both interfere and aid the subsequent dispersal of the liquid.The fuel may become entrapped within the wing fragments themselves and therefore retain fuel. On the other hand, fragments on the ground can act as roughness elements for fuel farther back in the wing. Splashing will result in fuel being deflected into the air by fuel flowing into the fragments on the ground. 


\section{Conclusions}

The current fuel dispersal study has been undertaken to provide guidance to the Defense Nuclear Agency's Weapon System Safety Assessment (WSSA) program for C-141 transport accidents.The intent of the study was to develop an understanding of the phenomenology of fuel dispersal from aircraft impact, determine what parameters have a first order impact on the results, and develop simple models that can be exercised thousands of times, by an event tree simulation, based on input variables sampled according to their uncertainty distributions.

Based on impact angle and impact velocity, two fuel dispersal regimes were found. At intermediate normal impact velocity, fuel will leak from the damaged tank at a rate proportional to the amount of damage. For this regime, sufficient data existed to build a model, and a leakage model was developed. At high normal impact velocity, complete structural failure of the wing fuel tanks occurs, and fuel will splash on impact. For this regime, a splash model was developed.

The splash model was developed from test data conducted for this purpose. Tests were conducted at Sandia National Laboratories Rocket Launch Facility with an approximately 1/9 linear scale mass model of a 1/4 span section of the C-141 wing. The test results showed that no liquid pooling occurred for impact velocities greater than $61 \mathrm{~m} / \mathrm{s}$, independent of the angle of impact. Although it was necessary to conduct the test program at an intermediate scale and without considering the effect of the wing structure, it is argued that the conclusions from the data are applicable to the full-scale aircraft impact scenario. This includes the conclusion that no pooling of fuel occurs for impacts over $61 \mathrm{~m} / \mathrm{s}$, provided that the wing completely disintegrates on impact and no cratering occurs. If cratering does occur, pooling is expected; this scenario is the subject of future investigations.

The framework and models developed represent a first attempt to describe, in a rational scientific manner, the complexity of fuel dispersal from a spectrum of aircraft impact scenarios. Both the leakage model and the splash model are, at best, first order approximations for use in safety assessments. Both models could be improved with further development and testing. Validation tests, particularly of the effect of wing confinement on splashing, would improve confidence in the models. 


\section{References}

Ahlers, R. H., 1970, "Investigation of Two Methods for Improving the Crashworthiness of Integral Fuel Tanks," Federal Aviation Administration, Atlantic City, NJ, FAA Report FAA-RD-70-56, November.

Ahlers, R. H., 1977, "Full-Scale Aircraft Crash Tests of Modified Jet Fuel," Federal Aviation Administration, Atlantic City, NJ, FAA Report FAA/RD-77-13, July.

Alvares, N., Kokarakis, J., Hersh, J., and Yahn, C., 1992, "Results of a Fuel Cell Penetration Fire During Takeoff Roll of a Commercial Jet Aircraft," Journal of Fire Protection Engineering, Vol. 4, No. 3, pp. 93-104.

Barber, R., 1986, "CID Flight/Impact," Presented at the Full-Scale Transportation Controlled Impact Demonstration, April 10, 1985, Hampton, VA, NASA Conference Publication NASA-CP-2395, (Ed. Haduck, R. J.).

Barnett, H. C., 1956, "Properties of Aircraft Fuels," NAKA-TN3276, Lewis Flight Propulsion Laboratory, Cleveland, $\mathrm{OH}$, August.

Baumeister, T., Avallone, E. A., and Baumeister, T., III, 1978, Mark's Handbook for Mechanical Engineers, McGraw-Hill, New York, Eighth Edition, pp. 3-35.

Berens, A. P., 1971, "Accident/Incident Survey Data Analysis for Aircraft Ground Fire Suppression and Rescue Systems," University of Dayton Research Institute, Dayton, OH, UDRI Report UDRI-TR-72-02, also Aircraft Ground Fire Suppression and Rescue Systems Report AGFSRS 71-3, October.

Bhunia, S. K., Lienhard, J. H., 1994, "Splattering During Turbulent Liquid Jet Impingement on Solid Targets," ASME Journal of Fluids Engineering, Vol. 116, pp. 338344.

Bhunia, S. K., and Lienhard, J. H., 1994, "Surface Disturbance Evolution and the Splattering of Turbulent Liquid Jets," ASME Journal of Fluids Engineering, Vol. 116, pp. $721-27$.

Bowden, F. P., and Brunton, J. H., 1961,"The Deformation of Solids by Liquid Impact at Supersonic Speeds," Proceedings of the Royal Society, Series A, Vol. 263, pp. 433450.

Bowden, F. P., and Field, J. E., 1964,"The Brittle Fracture of Solids by Liquid Impact, by Solid Impact, and by Shock," Proceedings of the Royal Society, Series A, Vol. 282, pp. 331-352.

Bowles, R. I. and Smith, F. T., 1992, "The Standing Hydraulic Jump: Theory, Computations and Comparisons with Experiments," Journal of Fluid Mechanics, Vol. 242, pp. 145-168. 
Brandeis, J, and Kansa, E. J., 1983, "Numerical Simulation of Liquefied Fuel Spills: I. Instantaneous Release into a Confined Area," International Journal for Numerical Methods in Fluids, Vol. 3, pp. 333-345.

Buckson, W., Schlegel, W., and Smith, I. R., 1965, "Design, Development and Evaluation of a Crash Resistant Fuel System Installation," All American Engineering Co., Wilmington, DE, FAA Report FAA-ADS-27, December.

Byerly, D. L., 1973, "Evaluation of Various Sizes and Configurations of Fuel Tanks," Firestone Tire and Rubber Co., Magnolia, AR, USAAMRDL Technical Report 73-74, December.

Chandra S. and Avedisian, C. T., 1991, "On the Collision of a Droplet with a Solid Surface," Proceedings of the Royal Society, Series A, Vol. 432, pp. 13-41.

Cheng, L., 1977a, "Stain Method for Measurement of Drop Size," Environmental Science and Technology, Vol. 11, No. 2, pp. 192-194.

Cheng, L., 1977b, "Dynamic Spreading of Drops Impacting onto a Solid Surface," Ind. Eng. Chem., Process Des. Dev., Vol. 16, No. 2, pp. 192-197.

Cline, D. D., and Koenig, L. N., 1983, “The Transient Growth of an Unconfined Pool Fire," Fire Technology, Vol. 19. No. 3, pp. 149-162.

Cominsky, A., 1982, "Transport Aircraft Accident Dynamics,” McDonnell Douglas Aircraft Company, Long Beach, CA, NASA Contractor Report 165850, FAA Report DOT-FAA-CT-82/70, March.

Craik, A. D. D., Latham, R. C., Fawkes, M. J., and Gribbon, P. W. F., 1981, "The Circular Hydraulic Jump," Journal of Fluid Mechanics, Vol. 112, pp. 347-362.

Didden, N. and Maxworthy, T., 1982, “The Viscous Spreading of Plane and Axisymmetric Gravity Currents," Journal of Fluid Mechanics, Vol. 121, pp. 27-42.

DiTaranto, R. A., Margetich, S., Miles, J., Niemeyer, C., and Badri-nath, Y. V., 1978, "Experimental Investigation of Simulated Helicopter Fuel Cell Impact Phenomenon," Presented to the Design Engineering Technical Conference, Minneapolis, MN, Sept. 24-27., ASME Paper 78-DET-79.

Dykhuizen, R. C., 1994, "Review of Impact and Solidification of Molten Thermal Spray Droplets," Journal of Thermal Spray Technology, Vol. 3(4), pp.351-361.

Edwards, T. I., 1973, “On the Terminal Effects of Napalm B and Other Incendigels and the Principal Physical and Chemical Processes That Produce Them," Rand Corporation, Santa Monica, CA, R-1260-PR (AD-528098), June.

Elliot, T. A., and Ford, D. M., 1972, “Dynamic Contact Angles - Part 7 - Impact Spreading of Water Drops in Air and Aqueous Solutions of Surface Active Agents in Vapour on Smooth Paraffin Surfaces," Journal of the Chemical Society, Faraday Transactions 1, Vol. 68, pp. 1814-1823.

Enders, J. H., 1985, "Preserving Safety in a Hostile Environment," Flight Safety Foundation, Proceedings of Fuel /Safety Workshop, Alexandria, VA, Oct. 29 - Nov. 1, FAA Report DOT/FAA/PM-86/13, pp. 151-156. 
Engel, O. G., 1955, "Water Drop Collisions with Solid Surfaces," Journal of Research of the National Bureau of Standards, Vol. 54, pp. 281-298.

Errico, M., 1986, "A Study of the Interaction of Liquid Jets with Solid Surfaces," Ph. D. thesis, Dept. of Chemical Engineering, University of California, San Diego, CA.

Fiedler, R., and Naber, J., 1989, “Estimating Film Size Due to Drop Impact," Proceedings of the Combustion Institute Spring Technical Meeting on Combustion Fundamentals and Applications, Dearborn, MI, 30 April- 2 May.

Field, J. E., Dear, J. P., and Davies, P.N.H., 1983, "An Investigation of the Shock Structures and the Conditions for Jetting During Liquid Impact," Proceedings of the Sixth International Conference on Erosion by Solid and Liquid Impact, September 5-8, Cambridge, England.

Ford, R. E., and Furmidge, C. G. L., 1967, "Impact and Spreading of Spray Drops on Foliar Surfaces," Society of Chemical Industry, Monograph No. 25, Gordon and Breach Science Publishers, New York, NY., pp. 117-432.

Fox, R. W., and McDonald, A. T., 1978, Introduction to Fluid Mechanics, John Wiley and Sons, New York, Second Edition, pp. 611-615.

Gajjar, J. and Smith, F. T., 1983, "On Hypersonic Self-Induced Separation, Hydraulic Jumps and Boundary Layers with Algebraic Growth," Mathematika, Vol. 30, pp. 77-83.

Gerhart, P. M., and Gross, R. J., 1985, Fundamentals of Fluid Mechanics, Addison-Wesley, Reading, Massachusetts.

Gibson, R. A., 1956, "Evaluation of Fire Bomb Fuels, Test II," U.S. Naval Aviation Ordnance Test Station," Chincoteague, VA, NOATS Report No. 30-56 (AD-100560), June.

Gribben, R. J., and Hunt, R., 1990, "Evaluation of the Approximate Treatment of ThinFilm Flows," Applied Mathematical Modeling, Vol. 14, No. 8., pp. 420-426.

Hackler, L. W., 1972, "Leading Edge Fuel Tank Impact Tests," Federal Aviation Administration, Atlantic City, NJ, FAA Report FAA-RD-72-83, October.

Hill, G. A., Chenier, C. L., Shook, C. A, Esmail, M. N., 1980, "Numerical and Experimental Study of a Falling Liquid Column," The Canadian Journal of Chemical Engineering, Vol. 58, pp. 3-11.

Hinkle, S. E., 1989, "Water Drop Kinetic Energy and Momentum Measurement Considerations," Applied Engineering in Agriculture, Vol. 5 No. 3, September, pp. 386-391.

Horeff, T. G., 1975, "Research and Development of Modified Fuels for Reduction of the Postcrash Fire Hazard," Proceedings of the Symposium on Aircraft Crashworthiness, Cincinnati, OH, Oct. 6-8, pp. 684-694.

Horeff, T. G., 1982, "Aircraft Fire Mishap Experience/Crash Scenario Quantitation," Federal Aviation Administration, Washington, DC, ARGARD-LS-123, May.

Horsfall, J., 1983, "The Survivability Aspects of Post Crash Fires," International Journal of Aviation Safety, Vol. 1, September, pp. 161-168. 
Hunt, R., 1989, “The Numerical Solution of Parabolic Free Boundary Problems Arising from Thin Film Flows," Journal of Computational Physics, Vol. 84, pp. 377-402.

Huppert, H. E., 1982, "The Propagation of Two-Dimensional and Axisymmetric Viscous Gravity Currents Over a Rigid Horizontal Surface," Journal of Fluid Mechanics, Vol. 121, pp. 43-58.

Johnson, N. B., Robertson, S. H., and Hall, D. S., 1989, "Aircraft Crash Survival Design Guide Volume V - Aircraft Postcrash Survival," Simula, Inc., Phoenix, AZ, USAAVSCOM TR 89-D-22E (AD-A218438), December.

Khalifa and McCorquodale, 1992, "Simulation of the Radial Hydraulic Jump," Journal of Hydraulic Research, Vol. 30(2), pp. 149-463.

King, J. B., 1952, "Bombs and Associated Components, Tests of Bomb Mk 77," U.S. Naval Proving Ground, Dahlgren, VA, AD499457, April.

Kistler, S.F.,1983, "The Fluid Mechanics of Curtain Coating and Related Viscous Free Surface Flows with Contact Lines," Ph.D. Thesis, University of Minnesota, November.

Knapp, S. C., and Knox, F. S., 1982, "Human Response to Fire," Aircraft Fire Safety, AGARD-LS-123.

Koloseus, H. J., and Ahmad, D.,1969, "Circular Hydraulic Jump," Journal of the Hydraulics Division, Proceedings of the American Society of Civil Engineers, HY-1, Vol. 95, pp. 409-422.

Kuchta, J. M., and Clodfelter, R. G., 1985, “Aircraft Mishap Fire Pattern Investigations," Air Force Wright Aeronautical Laboratories, Wright-Patterson AFB, Ohio, AFWAL-TR-85-2057, August.

Levin, Z., and Hobbs, P. V., 1971, "Splashing of Water Drops on Solid and Wetted Surfaces: Hydrodynamics and Charge Separation," Philosophical Transactions of the Royal Society of London, Series A, Vol. 269, pp. 555-585.

Lienhard, J. H., Liu, X., Gabour, L. A., 1992, "Splattering and Heat Transfer During Impingement of a Turbulent Liquid Jet," Journal of Heat Transfer, Vol. 114, pp. 362372.

Lister, J. R., 1992, "Viscous Flows Down and Inclined Plane From Point and Line Sources," Journal of Fluid Mechanics, Vol. 242, pp. 631-653.

Magnoli, D. E., 1992, "A Model for Fuel Fire Duration and Application to the B-1B Bomber," Lawrence Livermore National Laboratory, Livermore, CA, UCRL-ID112576.

Mahood, L., and Talley, R. L., 1982, "Correlation of Flammability Test Data on Antimisting Fuels," Falcon Research and Development Co., Englewood, CO, FAA Report DOT/FAA/CT-82/29, December.

Martin, J. C., and Moyce, W. J., 1952, "Part IV. An Experimental Study of the Collapse of Liquid Columns on a Rigid Horizontal Plane," Philosophical Transactions of the Royal Society of London, Series A, Vol. 244, pp. 312-324. 
Martinez, M., 1992, ASD OL-NS/EMSA, Nuclear Weapons Integration Office, Kirtland AFB, NM, personal communication with J. L. Moya, October 13.

Mehrotra, S., 1974, "Circular Jumps," Journal of the Hydraulics Division, Proceedings of the American Society of Civil Engineers, HY-8, Vol. 40, pp. 1133-1140.

Moya, J. L., 1992, Sandia National Laboratories, Albuquerque, NM, personal communication with S. Tieszen, August 1.

Nakoryakov, V. E., Pokusaev, B. G., and Troyan, E. N., 1978, "Impingement of an Axisymmetric Liquid Jet on a Barrier," International Journal of Heat and Mass Transfer, Vol. 21, pp. 1175-1184.

Nettleton, R. C., and McCorquodale, J. A., 1983, "Radial Stilling Basins with Baffles," Proceedings of the 6th Canadian Hydrotechnical Conference, June 2-3, Ottawa, Canada, pp. 651-670.

Nissley, P. H. and Heid, T. L., 1964, "Structural Design for Fuel Containment Under Survivable Crash Conditions," General DynamicsIConvair, San Diego, CA, FAA Report FAA-ADS-19, August.

Olsson, R. G., and Turkdogan, E. T., 1966, "Radial Spread of a Liquid Stream on a Horizontal Plate," Nature, Vol. 211, pp. 813-816.

Parikh, P, Fleeter, R., and Sarohia, V., 1983, "Antimisting Fuel Break-up and Flammability," Jet Propulsion Laboratory, Pasadena, CA, FAA Report DOT/FAA/CT-82/149, December.

Pidsley, P. H., 1983, “A Numerical Investigation of Water Drop Impact,” Proceedings of the Sixth International Conference on Erosion by Solid and Liquid Impact, September 5-8, Cambridge, England.

Polymeropoulos, C. E., 1975, "Ignition and Propagation Rates for Flames in a Fuel Mist," Rutgers, The State University of New Jersey, New Brunswick, NJ, FAA Report FAA-RD-75-155, October.

Rahman, M. M., Faghri, A., and Hankey, W. L.,1992, "Fluid Flow and Heat Transfer in a Radially Spreading Thin Liquid Film," Numerical Heat Transfer, Part A., Vol. 21, pp. 71-90.

Reed, W. H., Robertson, S. H., Weinberg, L. W. T., Tyndall, L. H., 1965a, "Full-Scale Dynamic Crash Test of a Douglas DC-7 Aircraft," Aviation Safety Engineering and Research Division of Flight Safety Foundation, Phoenix, AZ, FAA Report FAAADS-37, April.

Reed, W. H., Robertson, S. H., Weinberg, L. W. T., Tyndall, L. H., 1965b, "Full-Scale Dynamic Crash Test of a Lockheed Constellation Model 1649 Aircraft," Aviation Safety Engineering and Research Division of Flight Safety Foundation, Phoenix, AZ, FAA Report FAA-ADS-38, October.

Rigdon, V. B., 1973, "Interim Report on Dynamic Test of Dissemination/Ignition Devices and Flame Agents for Firebombs," Armament Development and Test Center, Eglin Air Force Base, FL, Technical Report ADTC-TR-73-107, December. 
Rochester, M. C., and Brunton, J. H., 1979, "Pressure Distribution During Drop Impact," Proceedings of the Fifth International Conference on Erosion by Solid and Liquid Impact, September 3-6, Cambridge, England.

Russell, R. A. Jr., 1971, "Small-Scale Impact Tests of Crash-Safe Turbine Fuels," Federal Aviation Administration, Atlantic City, NJ, FAA Report FAA-RD-71-49, August.

Sabersky, R. H., Acosta, A. J., and Hauptmann, E. G., 1971, Fluid Flow - A First Course in Fluid Mechanics, Second Edition, MacMillan, New York, NY.

Salem, S. A. L. and Al-Hassani, S. T. S., 1979, "Measurements of Surface Pressure Distribution During Jet Impact by a Pressure Pin Technique," Proceedings of the Fifth International Conference on Erosion by Solid and Liquid Impact, September 3-6, Cambridge, England.

Salmon, R. F., 1981, “Wing Spillage Tests Using Antimisting Fuel," Federal Aviation Administration, Atlantic City, NJ, FAA Report FAA-CT-81-11, February.

San Miguel, A. and Williams, M. D., 1978, "Antimisting Fuel Spillage/Air Shear Tests at the Naval Weapons Center," Naval Air Warfare Center, China Lake, CA, FAA Report FAA/RD-78/50, March.

Schaible, J. J., 1982, "Large-Scale Aircraft Crash Tests of Anti-Misting Kerosene (Final Report)," Naval Air Engineering Center Report, Lakehurst, NJ, NAEC-TR190, May.

Schaible, J. J., 1983, "Crash Test of an RB-66 Aircraft Fueled with Anti-Misting Kerosene FM-9," Naval Air Engineering Center, Lakehurst, NJ, Report NAEC-TR198, September.

Scheuerman, H. P., 1971, "Crash Resistant Fuel Systems Demonstrations and Evaluations," Federal Aviation Administration, Atlantic City, NJ, FAA Report FAA-RD71-27, August.

Shaw, L. M., 1971, "Safety Evaluation of Emulsified Fuels," Marshall Industries, Phoenix, AZ, USAAMDL Technical Report 71-29 (AD 729330), June.

Sherman, F. S., 1990, Viscous Flow, McGraw-Hill, New York, NY.

Shi, H. H., and Dear, J. P., 1992, “Oblique High-Speed Liquid-Solid Impact," JSME International Journal, Series 1 Vol. 35(3), pp. 285-295.

Soulaimani, A., Dhatt, G. and Ouellet, Y., 1986, “A Three Dimensional Free Surface Flow Analysis by a Finite Element Method," Proceedings of the 6th International Symposium on Finite Element Methods in Flow Problems, June 16-20, Antibes, France, pp. 401-406.

Stow, C. D. and Hadfield, M. G., 1981, “An Experimental Investigation of Fluid Flow Resulting from the Impact of a Water Drop with an Unyielding Surface," Proceedings of the Royal Society of London, Series A, Vol. 373, pp. 49-441.

Stow, C. D. and Stainer, R. D., 1977, "The Physical Products of a Splashing Water Drop," Journal of the Meteorological Society of Japan, Vol. 55, No. 5, pp. 518-532. 
Sweeney, E. T., and Nau, B. S., 1980, "The Computational Modelling of the Vertically Integrated Navier-Stokes Equations for Free Surface Flows. Background and Review of Techniques," BHRA Fluid Engineering Corporate Report RR1610.

Sweeney, E. T., 1980, "The Computational Modelling of the Vertically Integrated NavierStokes Equations for Free Surface Flows. General Equations and Details of the Numerical Solution Procedure," BHRA Fluid Engineering Corporate Report RR1611.

Tani, I., 1948, "Water Jump in the Boundary Layer," Journal of the Physical Society of Japan, Vol. 4, pp. 212-215.

Thomas, S., Faghri, A., and Hankey, W., 1991, "Experimental Analysis and Flow Visualization of a Thin Liquid Film on a Stationary and Rotating Disk," Journal of Fluids Engineering, Vol. 113, pp. 73-80.

Thompson, R. G., and Caiafa, C., 1983, "Structural Response of Transport Airplanes in Crash Situations," National Aeronautics and Space Administration, Hampton, VA, FAA Report DOT/FAA/CT-83/42, November.

Tikhomirov, R. A., Babanin, V. F., Petukhov, E. N., and Starikov, I. D., 1992, High Pressure Jet Cutting, ASME Press, New York, pp. 12-15.

Tilston, J. R., 1989, “The Stability of Fuel Fires," Royal Aerospace Establishment, Farnborough, UK, AGARD-CP-467, October.

von Riesemann, W. A., Parrish, R. L., Bickel, D. C., Heffelfinger, S. R., Muto, K., Sugano, T., Tsubota, H., Koshika, N., Suzuki, M., Ohrui, S., 1989, "Full-Scale Aircraft Impact Test for Evaluation of Impact Forces Part 1: Test Plan, Test Method, and Test Results," Transactions of the 10th International Conference on Structural Mechanics in Reactor Technology, Vol. J (Ed. Hadjian, A. H.), American Association for Structural Mechanics, Los Angeles, CA, pp. 285-293.

Whitaker, L. W., 1945, "Investigation of the 58-Gallon Aircraft Jettisonable Fuel Tank Fire Bomb," Defense Technical Information Center document AD-5212.

Whitham, G. B., 1955, "The Effects of Hydraulic Resistance in the Dam-Break Problem," Proceedings of the Royal Society of London, Series A, Vol. 227, pp. 399-407.

Widmayer, E., and Brende, O. B., 1982, "Commercial Jet Transport Crashworthiness," Boeing Commercial Airplane Company, Seattle, WA, NASA Contractor Report 165849, FAA Report DOT/FAA/CT-82/68, March.

Wittlin, G., 1987, "Fuel Containment Concepts - Transportation Category Airplanes," Lockheed-California Company, Burbank, CA, FAA Report DOT/FAA/CT-87/18, November.

Wittlin, G., Gamon, M. A., and Shycoff, D. L., 1982, "Transport Aircraft Crash Dynamics," Lockheed-California Company, Burbank, CA, NASA Contractor Report 165851, FAA Report DOT-FAA-CT-82/69, March.

Woodford, 1992, "Draft - Logic Plan, Weapon States and Plausible Scenarios," Research and Development Associates, Washington, D.C., Report to DNA, August 20. 
Yaffee, M. L., 1986, "Antimisting Fuel Research and Development for Commercial Aircraft - Final Summary Report," Federal Aviation Administration, Atlantic City, NJ, FAA Report DOT/FAA/CT-86/7.

Zagrella, A., 1980, "Full-Scale Aircraft Crash Tests of Anti-Misting Kerosene," Naval Air Engineering Center Report, Lakehurst, NJ, NAEC-TR-183, August. 


\section{Appendix A. Rectangular Box Equivalent for Fuel Tanks}

To reduce the geometric complexity of the problem, it is desired to find a rectangular shape that is representative of the fuel tanks in the wing. The rectangular equivalent shape represents the average thickness of the tanks, the average chord length of the tanks, and the average span length of the tanks. The product of these dimensions is constrained to be the maximum allowable fuel volume. Table A lists relevant parameters, as well as the source of the information.

Table A. C-141 Information Relating to Fuel Tanks

\begin{tabular}{|l|l|l|}
\hline \multicolumn{1}{|c|}{ Variable } & \multicolumn{1}{|c|}{ Value } & \multicolumn{1}{c|}{ Source } \\
\hline Max. Fuel Weight & $68,698 \mathrm{~kg}$ & Martinez memo to Moya, 1992 \\
\hline Specific Gravity of JP4 & 0.77 & Barnett, 1956 \\
\hline Root Chord & $10.11 \mathrm{~m}$ & \multirow{2}{*}{ Jane's All the World Aircraft, 1964-1965 } \\
\cline { 1 - 2 } Mean Aerodynamic Chord & $6.77 \mathrm{~m}$ & \\
\cline { 1 - 2 } Root Thickness to Chord & $13 \%$ & \\
\cline { 1 - 2 } Tip Thickness to Chord & $10 \%$ & \\
\cline { 1 - 2 } Sweepback root to tip & $12.8 \mathrm{~m}$ & \\
\cline { 1 - 2 } Aspect Ratio & 7.9 & \\
\cline { 1 - 2 } Overall Wingspan & $48.8 \mathrm{~m}$ & \\
\cline { 1 - 2 } Fuselage Width Internal & $3.12 \mathrm{~m}$ & \\
\cline { 1 - 2 } Total Usable Capacity & $87,367 \mathrm{l}$ & \\
\hline
\end{tabular}

Average span of wing tanks: The wing span can be found from the aspect ratio times the mean aerodynamic chord. Using the values from Table A, the resultant value is $53.5 \mathrm{~m}$. The actual span of the wing tanks is less than this because they are terminated at the center wing box. Allowing $2.5 \mathrm{~m}$ for the center wing box, the average span of the wing tanks is taken to be $51.0 \mathrm{~m}$.

Average chord of the wing tanks: Figure A shows the location of the fuel tanks in the wings. Scaling from this diagram, the wing tanks cover, on average, approximately $52 \%$ of the chord length. Using the mean aerodynamic chord times 0.52 gives $3.52 \mathrm{~m}$ for the average chord length of the fuel tanks

Average thickness of the wing tanks: The maximum thickness along a chord for the wing tanks can be found from the thickness-to-chord values of $13 \%$ at the root and $10 \%$ at the tip. An average thickness is difficult to obtain. To constrain the wing tanks to have the appropriate volume, the average thickness is determined from the volume divided by the 


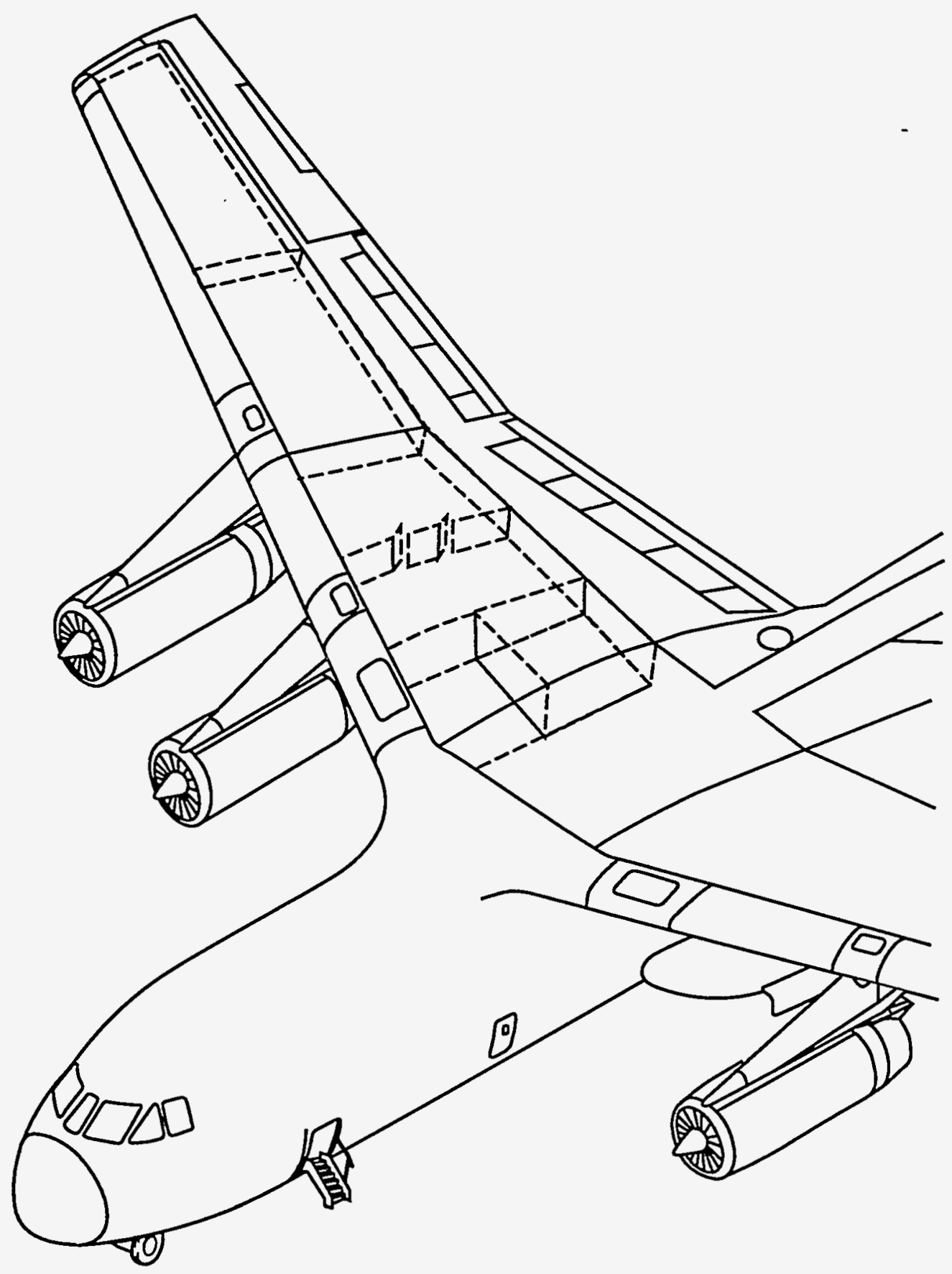

Figure A. General arrangement diagram for the C-141, showing the location of the fuel tanks in the wings. 
average chord and span values. The total usable capacity and maximum fuel weight numbers reported in Table A yield slightly different volumes of $87.4 \mathrm{~m}^{3}$ and $88.1 \mathrm{~m}^{3}$, respectively. Using the average of these numbers as the volume, $51.0 \mathrm{~m}$ for the span, and $3.52 \mathrm{~m}$ for the chord, the average thickness is determined to be $0.489 \mathrm{~m}$.

Therefore, the size of the rectangular equivalent for the fuel tanks is taken to be $0.489 \mathrm{~m}$ : $3.52 \mathrm{~m}: 51.0 \mathrm{~m}$ for thickness : chord : span, respectively. 


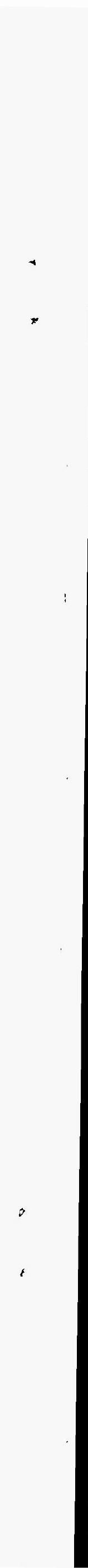




\section{Appendix B. Derivation of Stop Time}

The assumed crash scenario is shown in Figure B. The aircraft is assumed to impact the ground at an angle $\alpha$, and with a velocity $V$. The ground is assumed to be flat and infinitely rigid. As a first approximation, the aircraft is also treated as a rigid body that stays intact throughout impact and slideout, i.e., the change in mass due to fuel leakage is ignored. The landing gear of the aircraft are assumed to be retracted at the time of impact, and the tangential force is due to friction between the rigid body and rigid ground.

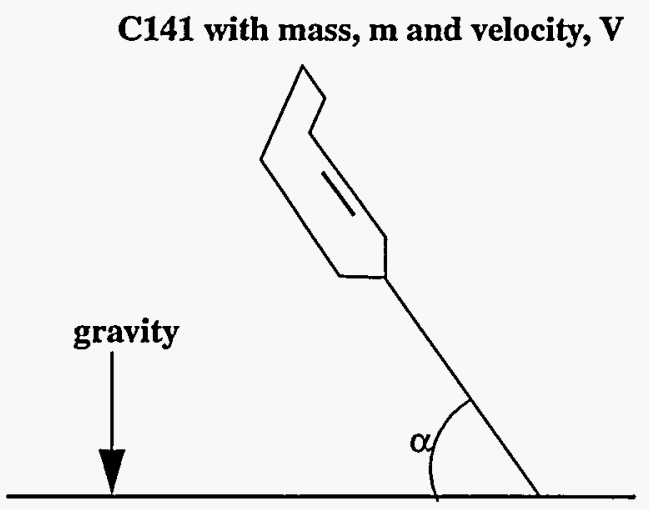

(a)

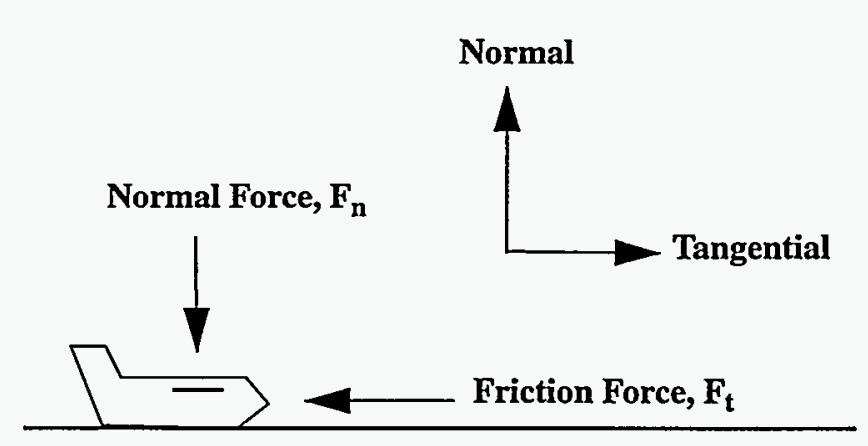

(b)

Figure B. Assumed crash scenario. (a) Prior to impact. (b) On slideout.

Conserving momentum in the normal direction gives,

$$
F_{n}=m\left(g+\frac{d V_{n}}{d t}\right)
$$

Conserving momentum in the tangential direction gives,

$$
F_{t}=m \frac{d V_{t}}{d t}
$$


where $V_{n}$ and $V_{t}$ are the normal and tangential velocities, respectively. The resistive force in the tangential direction is the frictional force, which is equal to the coefficient of friction, $\mu$, times the normal force. Using this definition in Equation 16 and substituting the normal force from Equation 15 gives,

$$
m\left(\frac{d V_{t}}{d t}\right)=\mu m\left(g+\frac{d V_{n}}{d t}\right)
$$

Integrating the terms in Equation 17,

$$
\int_{0}^{t_{\text {stop }}} \frac{d V}{d t} d t=\mu \int_{0}^{t_{\text {stop }}} g d t+\mu \int_{0}^{t_{\text {stop }}} \frac{d V_{n}}{d t} d t
$$

gives,

$$
V_{t}=\mu g t_{\text {stop }}+\mu V_{n}
$$

Rearranging, and noting that $V_{t}=V \cos \alpha$ and $V_{n}=V \sin \alpha$ gives,

$$
t_{\text {stop }}=V\left(\frac{\cos (\alpha)-\mu \sin (\alpha)}{\mu g}\right)
$$




\section{Appendix C. Rationale for Orifice Diameter}

The wing tanks can be damaged in many ways: abrasion, hitting objects such as trees, being punctured by debris from fuselage breakup, being fractured by impact with the ground, or being cracked by inertial loading. Each of these modes has a specific failure mechanism and each may depend on different crash parameters. Without specific scenario-dependent information, it is difficult to specify a particular failure mechanism. The approach proposed here is to use dimensional reasoning to approach failure in a nonspecific way and incorporate crash data to tune the parameters as required.

The impact force will be time dependent. Figure C-1a shows a time dependent force on a box-like wing structure. Assuming that the ribs are much stiffer than the wing skin, the skin will first undergo elastic deformation, then plastic deformation, and finally fractureproducing a hole (orifice) as shown in Figure C-1b.
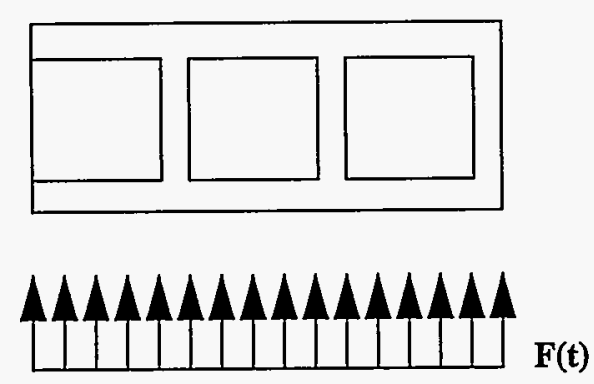

(a)

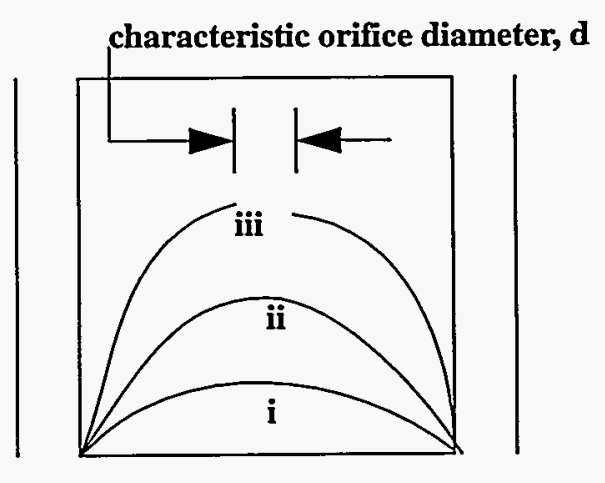

(b)

Figure C-1. Damage mechanism. (a) Time dependent impact load. (b) Response. Elastic deformation is $i$, plastic deformation is ii, and failure is iii.

Using an energy argument,

$$
\text { Work }=\text { Force } \times \text { Length }=\frac{m V_{n}^{2}}{2}
$$


where $V_{n}$ is the normal impact velocity. In this case, $V_{n}$ does not necessarily refer to the velocity of the aircraft striking the ground. It is used in this way here but can be generically used to mean the velocity at which a wing strikes an object.

Without doing a structural analysis, dimensional reasoning can be used to obtain some information about the response. The force can be generically decomposed into a stress, $\sigma$, applied over an appropriate area, $A$. The length can be generically decomposed into a strain, $\varepsilon$, over an appropriate length, $L$. Using these arguments, the work in Equation 21 is given by,

$$
\text { Work }=(\sigma \varepsilon)(A L)
$$

The first component on the right-hand side of Equation 22 is the intrinsic material properties, and the second component is the geometric factor appropriate to the load. Before the material can fracture, it must be strained past its elastic and plastic limits. This implies that there is a minimum work required before fracture.

Once fracture occurs, further displacement results in an increase in the orifice size, as shown in Figure C-2. In other words, an increase in d is directly proportional to an increase in $\delta$. The work required to achieve this can be denoted $F \delta$, or since $d \sim \delta$, Fd. Using these

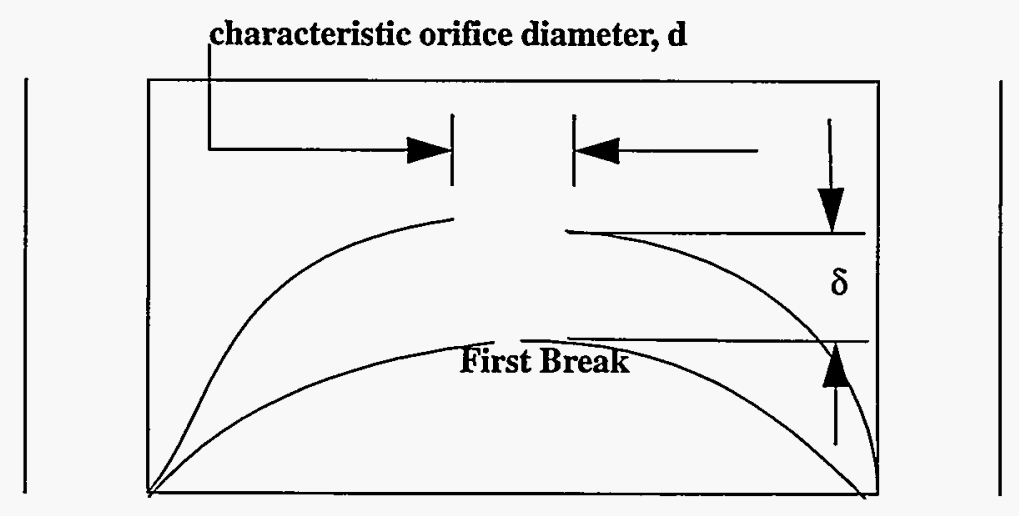

Figure $\mathbf{C - 2}$. Once failure occurs, further displacement results in an increase in the effective orifice diameter.

results, Equation 21 can be written as,

$$
F d+W_{\min }=\frac{m V_{n}^{2}}{2}
$$


where, $W_{\min }$ is the minimum work required for the material to reach fracture.

Equation 23 has the form,

$$
d=a V_{n}-b
$$

where $a$ and $b$ are unknown constants related to the minimum work and appropriate forces. These constants cannot be determined without structural analysis for a given failure mode, which is not intended in this study. Equation 24 provides the basic relation of interest, and the constants $a$ and $b$ can be determined from experimental or design (military specifications) data.

To obtain $\mathrm{a}$ and $\mathrm{b}$ from experimental data, two states must be identified. For convenience, let these be,

$$
\begin{array}{ccc}
d=0 & \text { for } & V=V_{n \min } \\
l=d_{\max } & \text { for } & V=V_{n \max }
\end{array}
$$

where, $V_{n \min }$ is the minimum normal impact velocity necessary to damage the fuel tank sufficiently to cause leakage. $V_{n \max }$ is the maximum normal impact velocity at which leakage occurs. Above this velocity, the tank will fracture and the fuel will splash. The maximum diameter of the orifice is given by $d_{\max }$. This can be taken as the characteristic length of the fuel tank under consideration.

Using these defined states, Equation 24 becomes,

$$
\frac{d}{d_{\max }}=\frac{V_{n}^{2}-V_{n \min }^{2}}{V_{n \max }^{2}-V_{n \min }^{2}}
$$




\section{Appendix D. Mass Distribution Contour Plots}

The seven contour plots in this appendix provide quantitative information about mass measurements made during the intermediate-scale testing of a $1 / 4$ span section of a C-141 aircraft wing. The testing was conducted at the Rocket Launch Facility of Sandia National Laboratories, Albuquerque, New Mexico. 


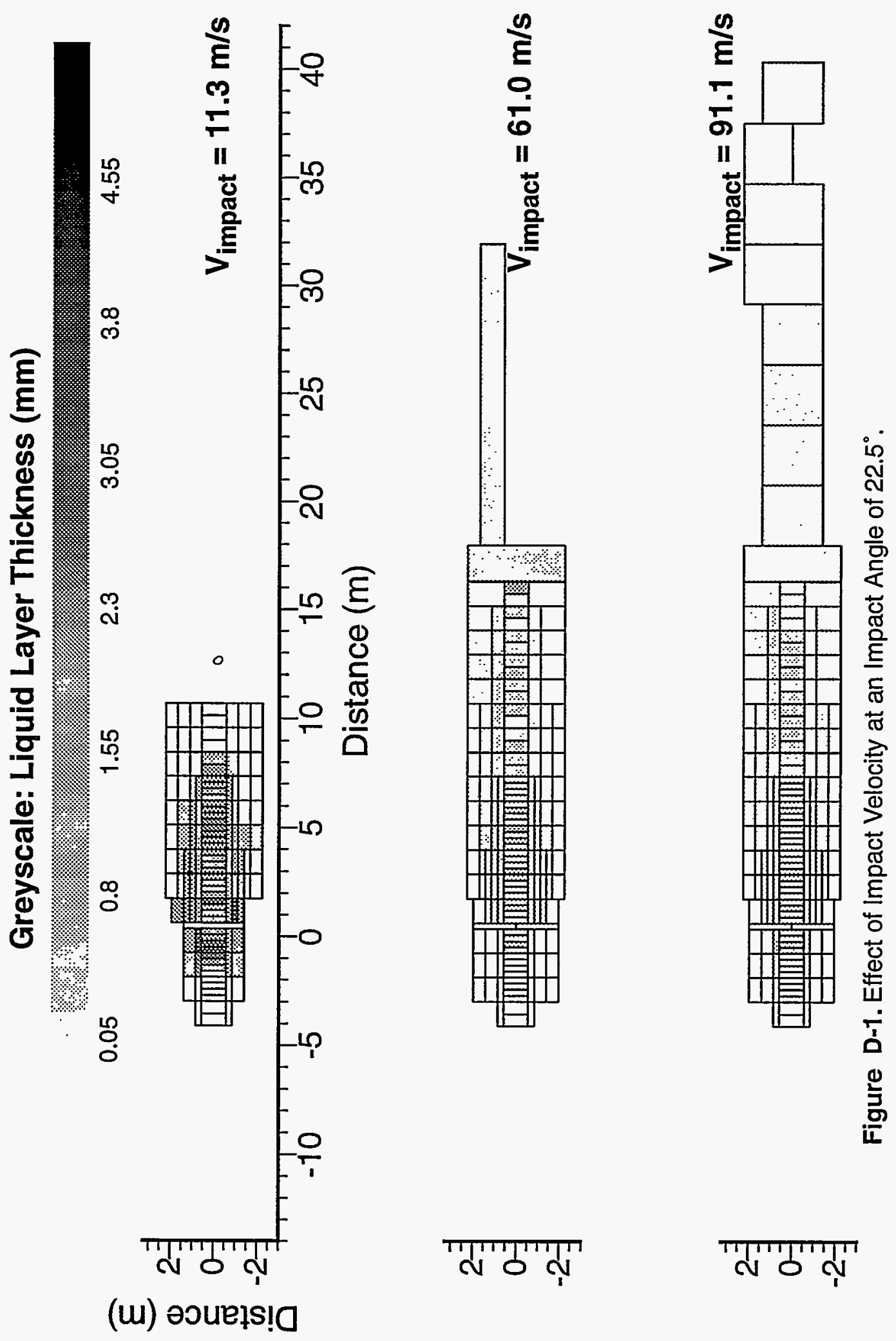




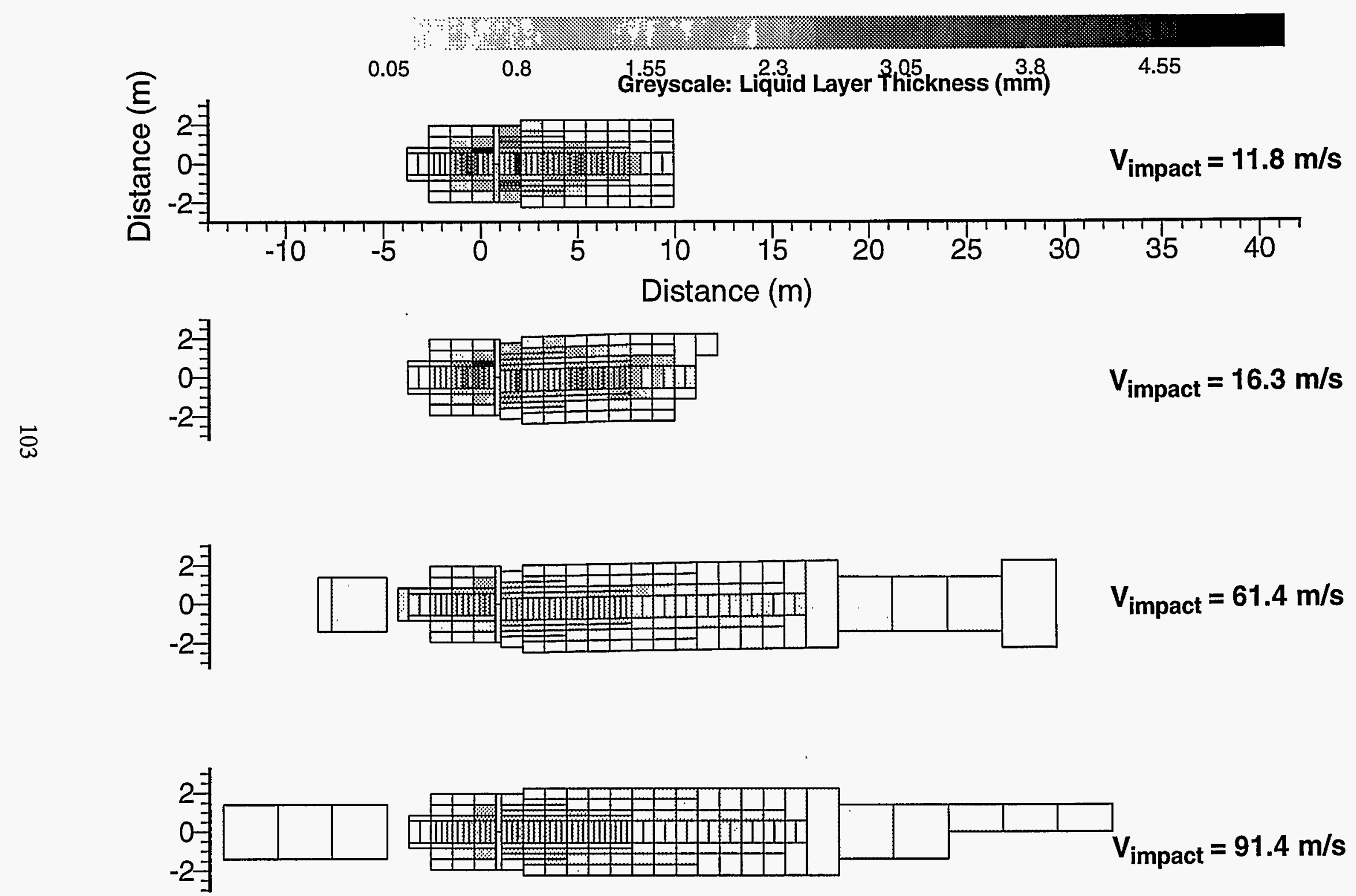

Figure D-2. Effect of Impact Velocity at an Impact Angle of $45^{\circ}$ 


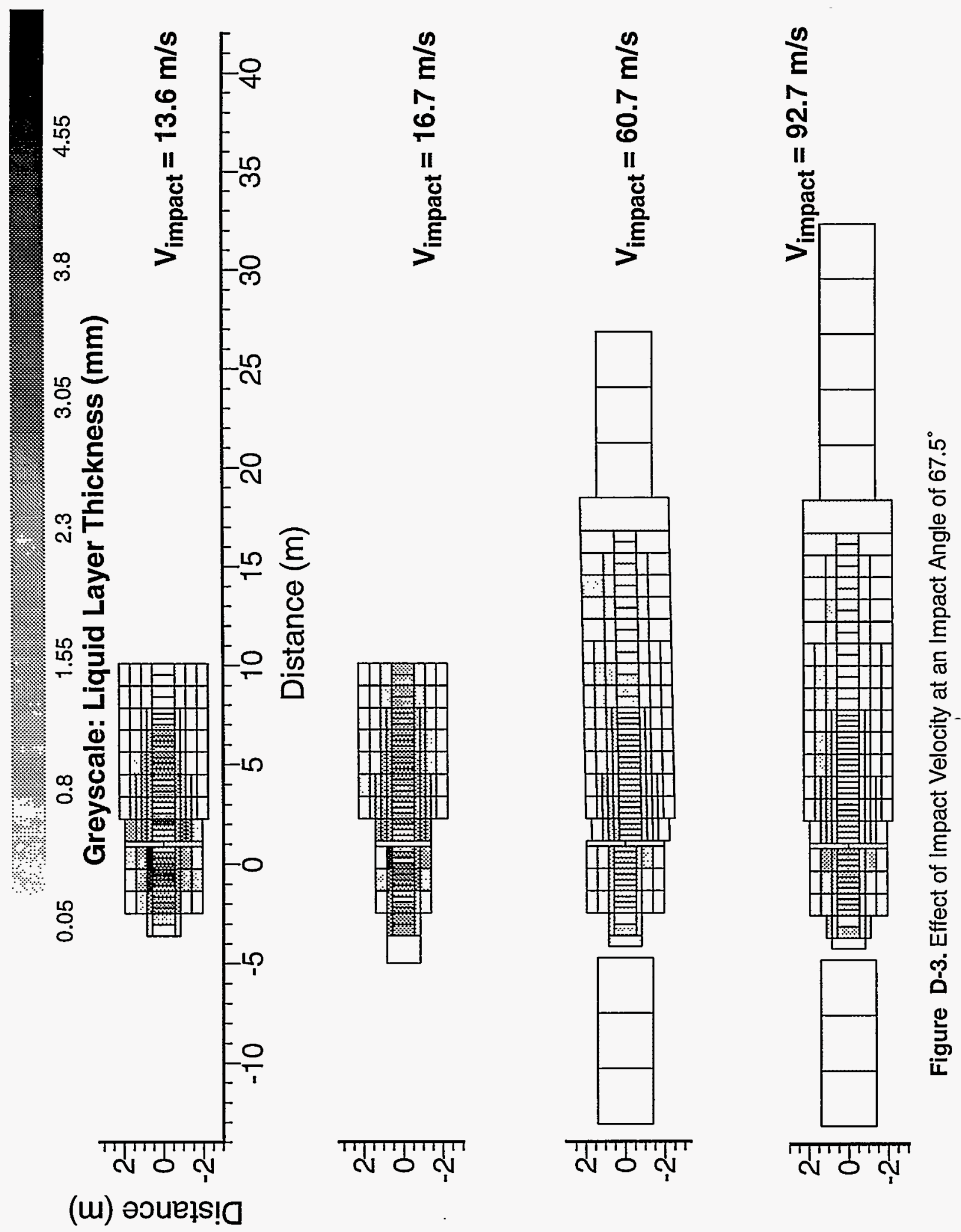



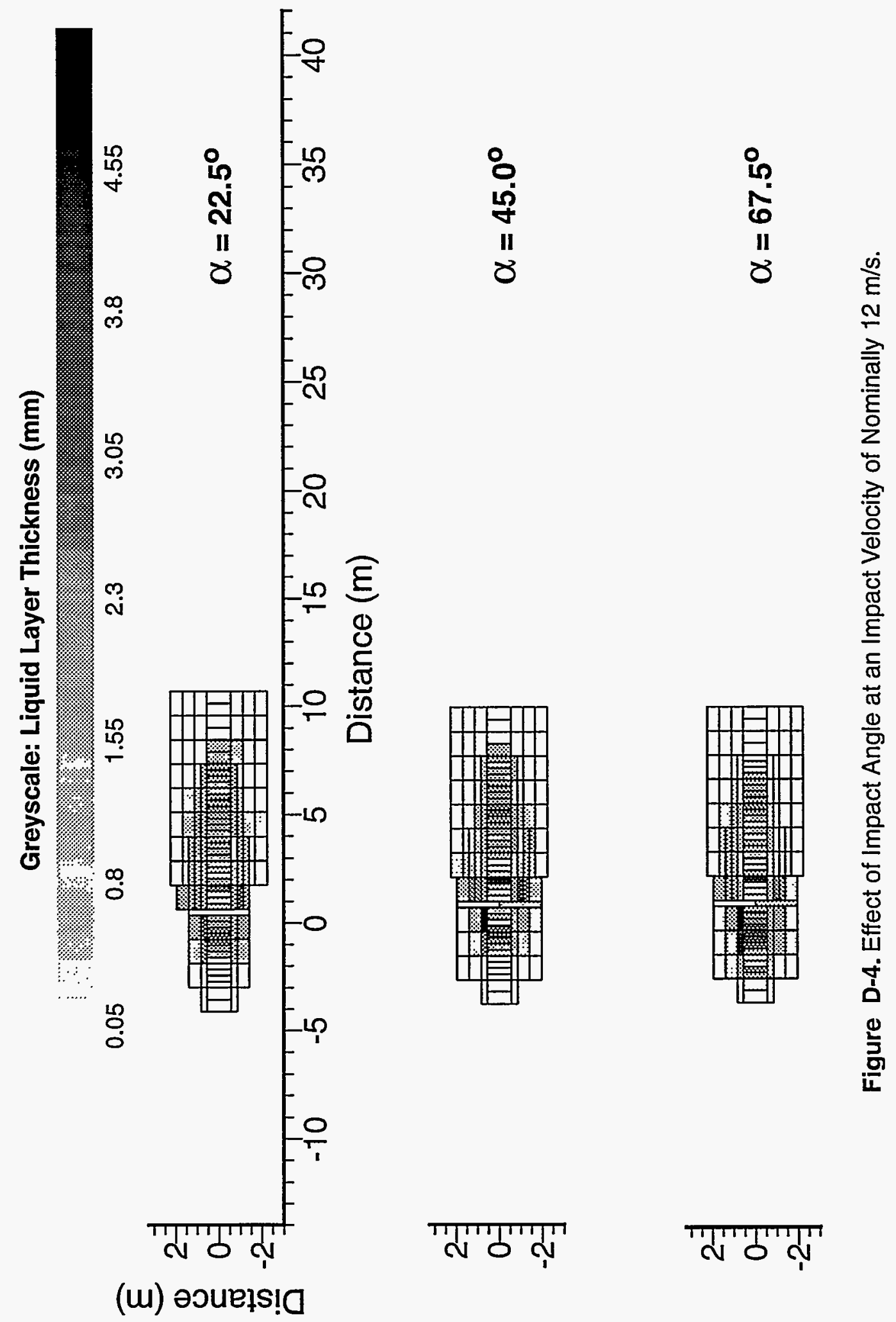


\section{Greyscale: Liquid Layer Thickness (mm)}
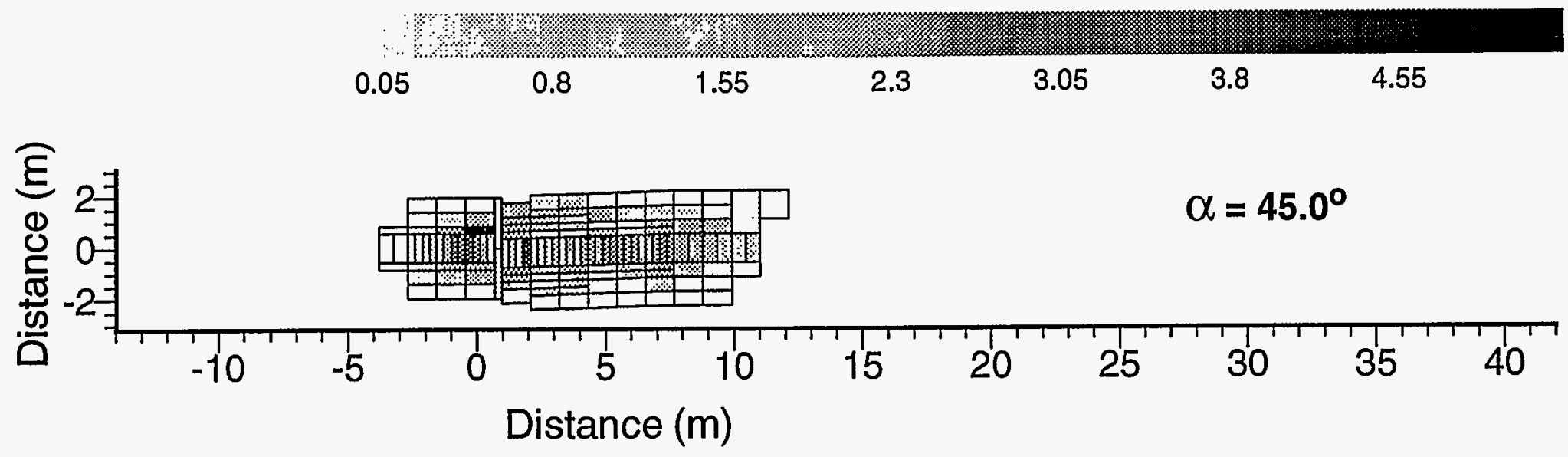

㖊寻

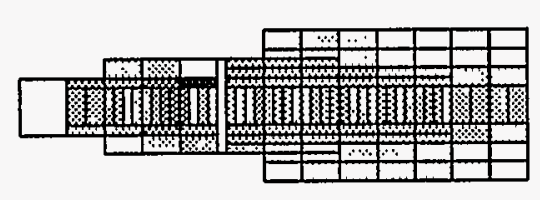

$\alpha=67.5^{\circ}$

Figure D-5. Effect of Impact Angle at an Impact Velocity of Nominally $16 \mathrm{~m} / \mathrm{s}$ 


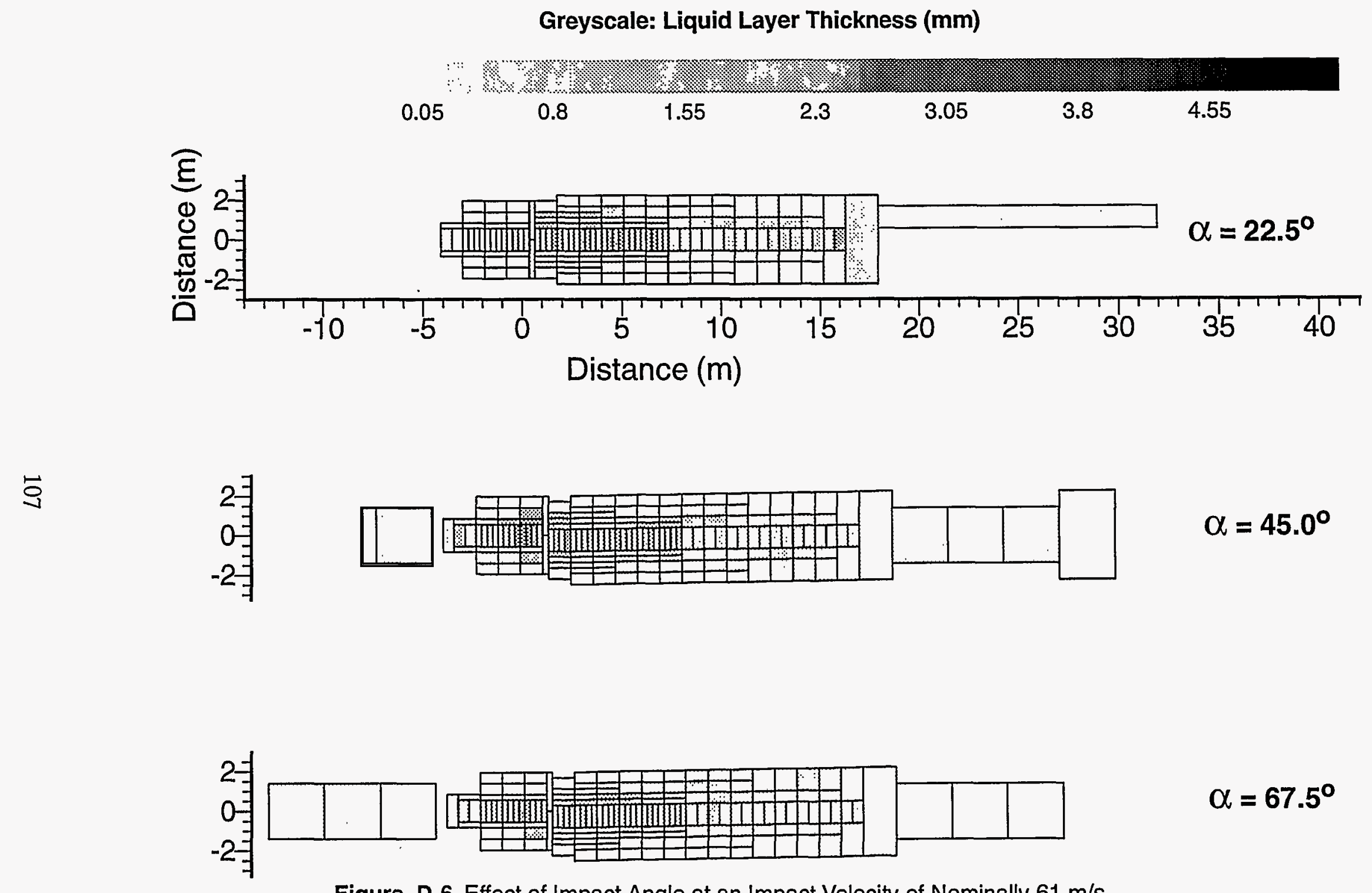

Figure D-6. Effect of Impact Angle at an Impact Velocity of Nominally $61 \mathrm{~m} / \mathrm{s}$. 


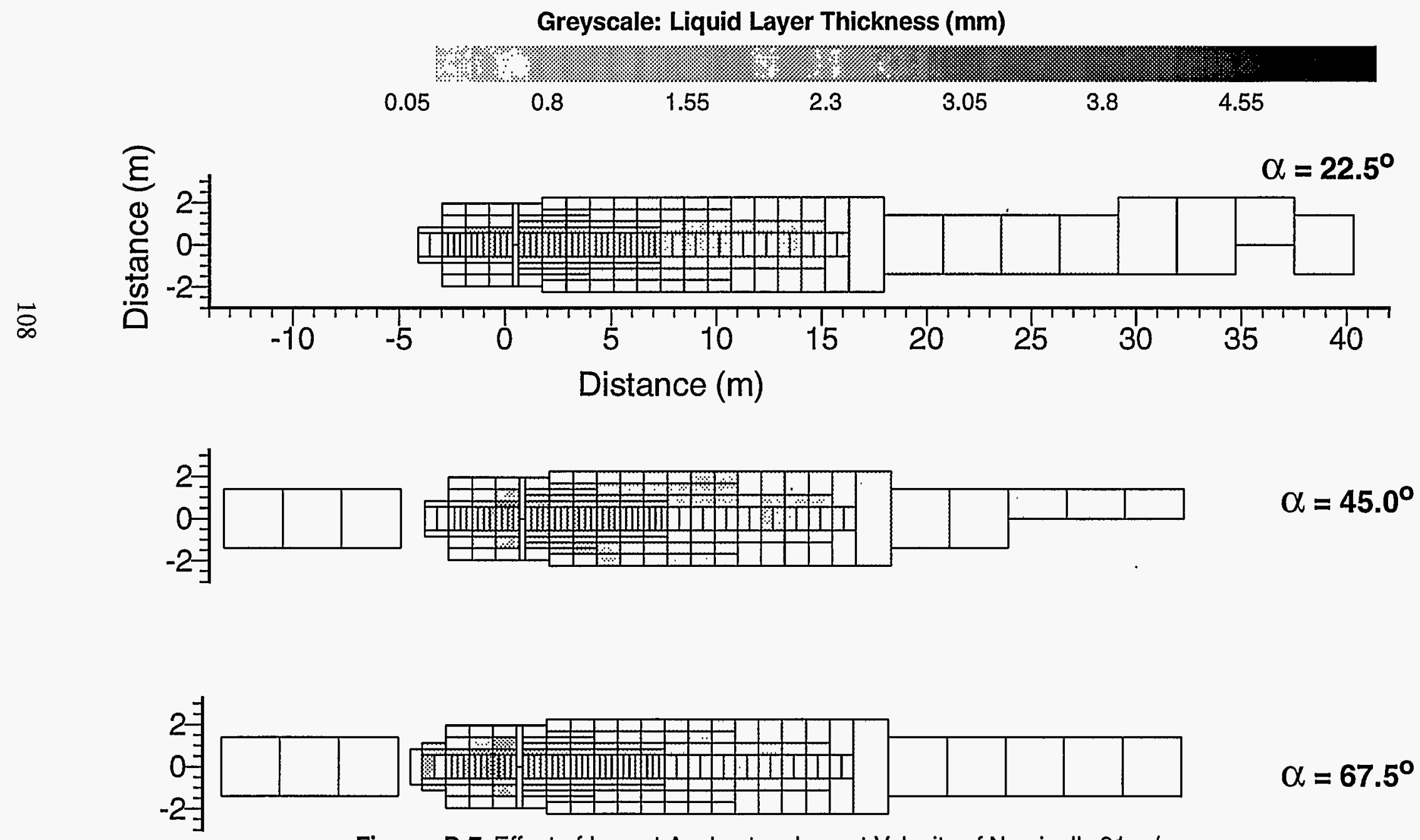

Figure D-7. Effect of Impact Angle at an Impact Velocity of Nominally $91 \mathrm{~m} / \mathrm{s}$. 


\section{DISTRIBUTION:}

1 Boeing Defense and Space Group Attn: Earl E. Wilhelm

P. O. Box 3707, MS 4C-67

Seattle, WA 98124-2207

1 Director, Defense Nuclear Agency Attn: CSTI 6801 Telegraph Road Alexandria, VA 22310-3398

1 Director, Defense Nuclear Agency Attn: Major Joe Crews 6801 Telegraph Road Alexandria, VA 22310-3398

1 Director, Defense Nuclear Agency Attn: LCDR William A. Gott 6801 Telegraph Road Alexandria, VA 22310-3398

1 Director, Defense Nuclear Agency Attn: James V. Brackett 6801 Telegraph Road Alexandria, VA 22310-3398

1 U. S. Department of Energy Albuquerque Operations Office Albuquerque Headquarters Attn: H. T. Season P. O. Box 5400 Albuquerque, NM 87115

1 U. S. Department of Energy Albuquerque Operations Office Albuquerque Headquarters Attn: R. O. Gergen, P. O. Box 5400 Albuquerque, NM 87115

1 U. S. Department of Energy Albuquerque Operations Office Albuquerque Headquarters Attn: Roger Cartee P. O. Box 5400 
Albuquerque, NM 87115

1 U. S. Department of Energy

Albuquerque Operations Office

Albuquerque Headquarters

Attn: Karl Rueb

P. O. Box 5400

Albuquerque, NM 87115

1 FAA Technical Center

Attn: Thor Eklund

ADC-250, Building 204

Atlantic City International Airport

Atlantic City, NJ 08405

1 Kaman Sciences

Attn: Wayne Young

P. O. Box 7463

Colorado Springs, CO 80933

4 Lawrence Livermore National Laboratories

Attn: Doug Stevens

P. O. Box $808, \mathrm{~L}-85$

Livermore, CA 94550

2 Logicon RDA

Attn: Steve Woodford \& Art Barondes

6940 South Kings Highway, Suite 210

Alexandria, VA 22310

3 Los Alamos National Laboratories

Attn: Ron Flurry

P. O. Box 1663, MSC931

Los Alamos, NM 87545

1 Los Alamos Technical Associates

Attn: Lou Reidl

2400 Louisiana Blvd. NE

Building 1, Suite 400

Albuquerque, NM 87110

1 NWI

Attn: Col. John Curry, Technical Director

1651 First Street SE

Kirtland AFB, NM 87117 
1 NWI

Attn: Dr. Dermod Kelleher, Technical Director

1651 First Street SE

Kirtland AFB, NM 87117

1 NWIE

Attn: Micheal Martinez

1651 First Street SE

Kirtland AFB, NM 87117

1 PLG Inc.

Attn: Vincent Ho

4590 MacArthur Blvd. Suite 400

Newport Beach, CA 92660

2 Technical Communication Services, Inc.

Attn: Nancy C. Benson

4720 Dona Rowena NE

Albuquerque, NM 87111-2412

1 Weidlinger Associates

Attn: H. Levine

4410 El Camino Real, Suite 110

Los Altos, CA 94022

1 Wright Laboratories

Attn: M. Bennett

FIVS Bldg. 63

1901 Tenth Street

Wright Patterson Air Force Base, Ohio 45433-7605

1 MS 0429 W. C. Nickell, 5100

1 MS 0715 C. E. Olson, 6606

1 MS 0828 R. D. Skocypec, 9102

1 MS 0835 Carl Peterson, 9116

10 MS 0835 S. R. Tieszen, 9116

1 MS0835 $\quad$ R. W. Oliver, 9116

1 MS 0437 R. K. Thomas, 9118

3 MS 1135 J. L. Moya, 9735

1 MS 1135 B. Kampfe, 9761

1 MS 0492 P. E. D’Antonio, 12324

1 MS 0492 G. A. Sanders, 12332

1 MS 0405 D. D. Carlson, 12333

1 MS 0405 T. R. Jones, 12333

1 MS 9018 Central Technical Files, 8523-2 
5 MS 0899 Technical Library, 4414

1 MS 0619 Print Media, 12615

3 MS 0100 Document Processing, 7613-2

For DOE/OSTI 